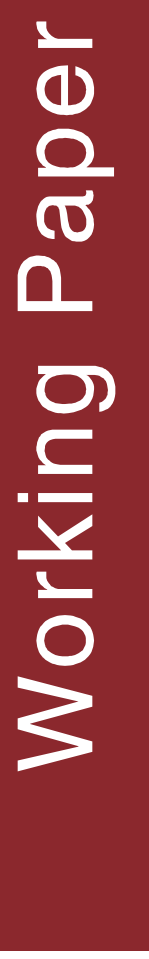

\title{
Landscape Dynamics Over Time and Space From Ecological Perspective
}

Sonya Dewi and Andree Ekadinata 



\section{Landscape Dynamics Over Time and Space From Ecological Perspective}

Sonya Dewi and Andree Ekadinata

Working Paper nr 103 


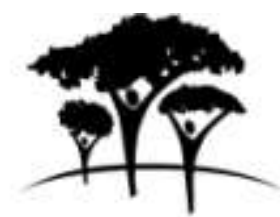

\section{World Agroforestry Centre}

TRANSFORMING LIVES AND LANDSCAPES

\section{Correct citation:}

Sonya Dewi and Andree Ekadinata. 2010. Landscape Dynamics Over Time and Space from Ecological Perspective. Working paper nr 103. World Agroforestry Centre. Bogor, Indonesia. 81p

Titles in the Working Paper Series aim to disseminate interim results on agroforestry research and practices and stimulate feedback from the scientific community. Other publication series from the World Agroforestry Centre include: Agroforestry Perspectives, Technical Manuals and Occasional Papers.

\section{Published by}

World Agroforestry Centre

ICRAF Southeast Asia Regional Office

PO Box 161, Bogor 16001, Indonesia

Tel: +622518625415

Fax: +62 2518625416

Email: icraf-indonesia@cgiar.org

http://www.worldagroforestrycentre.org/sea

(C) World Agroforestry Centre 2010

Working Paper nr 103

The views expressed in this publication are those of the author(s) and not necessarily those of the World Agroforestry Centre.

Articles appearing in this publication may be quoted or reproduced without charge, provided the source is acknowledged.

All images remain the sole property of their source and may not be used for any purpose without written permission of the source. 


\section{About the authors}

\section{Sonya Dewi}

Sonya Dewi is a Landscape Ecologist with formal backgrounds in soil science, computer science and theoretical ecology. She works extensively on broad tropical landscape issues from assessment of livelihood, environmental services, identification of opportunity and constraints of sustainable livelihoods and multifunctional landscapes to studies of spatial land use planning principles and practices. She also looks into some possible mechanism of rewards for environmental services, including in climate change mitigation through REDD+.

Contact: sdewi@cgiar.org

\section{Andree Ekadinata}

Andree Ekadinata is a Remote Sensing Specialist, primarily focuses on image processing and spatial analysis for natural resource management, including biodiversity assessments. He has extensive experiences in interpreting imageries across areas in Southeast Asia, Africa and Latin America, as well as across broad application and research questions within natural resource management areas, such as climate change mitigation, watershed management and spatial land use planning.

Contact: aekadinata@cgiar.org 


\section{Abstract}

Land use and land cover changes driven by multiple factors have tremendous impact on environmental services as well as livelihoods and economic development of people living in the landscapes and external to the landscapes. In particular for biodiversity, landscape configuration is at the very least as important as landscape composition by increasing fragmentation and reducing connectivity of habitat. Protected areas are necessary but not sufficient in maintaining biodiversity at the landscape level for several reasons: (i) management and enforcement are often weak, (ii) protected areas are often delineated in remote, rough terrain areas which does not represent various ecoregions with various species assemblages and endemism, (iii) the extent of protected areas sometimes are not large enough to allow minimum viable population such that in the long run species extinction might continue to happen, (iv) protected areas without buffer zones and corridors can easily be isolated areas rather than integral part of a landscape. Multifunctional landscapes that accommodate conservation and development need to be considered as an integrated, rather than segregation, systems; this will allow us to achieve the objective of maintaining biodiversity at the landscape level. Land use plan that aims to increase multifunctionality of landscapes should be informed by the current status of landscape composition and configuration, process of land use/cover changes in the past and future, areas that are vulnerable to changes in the future and options for intervention. The land use planning process should be conducted within a negotiation process among multiple stakeholders. This work provides some results to be used as a basis for negotiation, which are produced from the combination of tools from remote sensing, GIS and spatial analysis guided by ecological principles. The results provide data for further research as well as suggest follow-up research questions.

These analysis of five landscapes (Bungo in Indonesia, Viengkham in Laos, Manompana in Madagascar, Takamanda-Mone in Cameroon and East Usambara in Tanzania) using the same methodology and tool allows comparisons across sites. Deforestation rates and land use/cover changes across landscapes along with land use/cover changes are used to define the stage of forest transition; Takamanda-Mone, Viengkham, Manompana, East Usambara and Bungo is the ordered list from earliest to advanced stages. Spatial pattern of deforestation, depending on landscape topography, level of accessibilities and state of forest transition, either are concentrated in relatively flat areas in the landscape, follow encroachment pattern of primary forest block, along the transportation network, or expansion of existing settlement. Combining these spatial patterns of deforestation with changes in landscape configuration, especially at sub-landscape level (quantified by selected indices), we can identify vulnerable areas in the future such that options to reduce risks can be discussed and negotiated within land use planning processes.

\section{Keywords}

Landscape composition, configuration, matrix, connectivity, fragmentation, drivers of land use changes, multifunctional landscapes 


\section{Acknowledgements}

This work is funded by Swiss Development Cooperation (SDC) through the collaborative CIFOR-ICRAF Biodiversity platform. We would like to thank Meine van Noordwijk, JeanLaurent Pfund and John Watts for earlier ideas, discussions and feedback. 


\section{Contents}

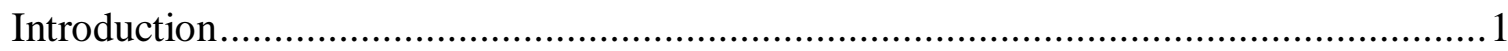

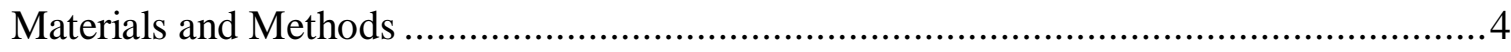

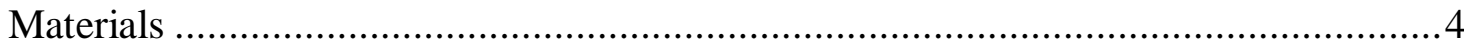

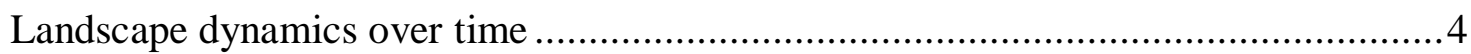

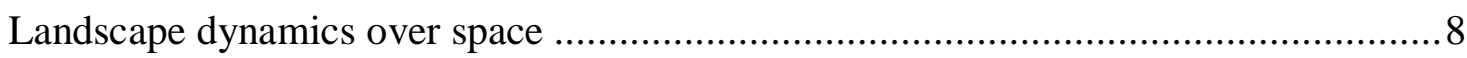

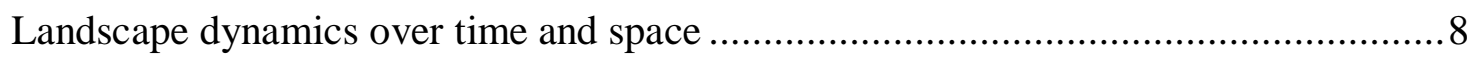

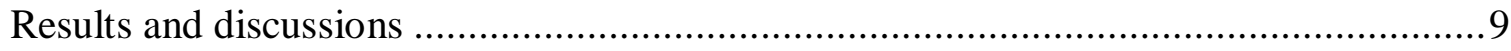

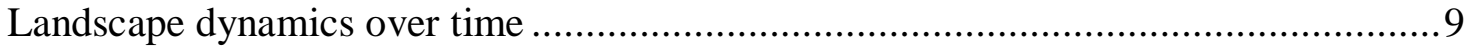

Forest Transition and spatial pattern of deforestation ............................................40

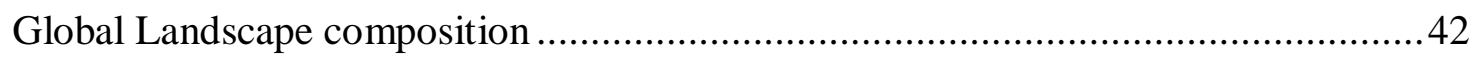

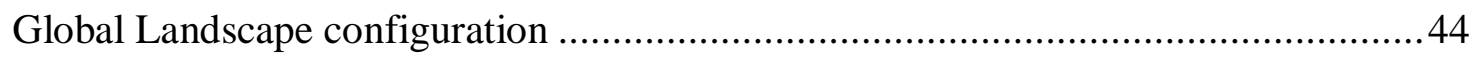

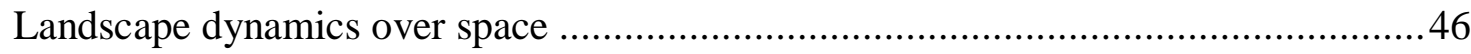

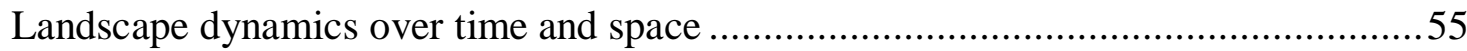

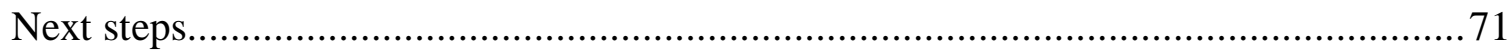

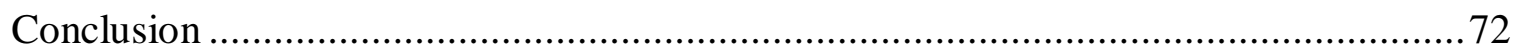

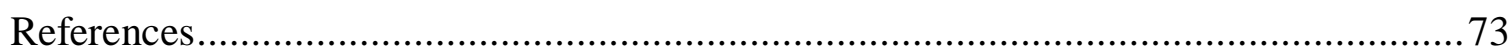




\section{Introduction}

Loss of habitat and fragmentation of habitat due to agricultural expansion are the primary causes of biodiversity loss across the planet (Sala et al., 2000, Tilman et al., 1994, Tilman et al., 2001, and Gardner et al., 2009). Fragmentation even leads to further biodiversity loss through time-delayed extinctions, or extinction debts, and co-extinctions (Krauss et al., 2010). Under extinction debt, loss of biodiversity is better explained by the history of land use/cover characteristics rather than the current ones (Kuusari et al., 2010). The very first large-scale evidence of extinction debts of vascular plants in fragmented European semi-natural grassland landscapes and co-extinction of specialized herbivory (Krauss et al., 2010) highlights to the importance to take act now in halting fragmentation and inducing connectivity to avoid greater loss of biodiversity in the distant future, beyond the immediate loss (Lindenmayer et al. 2008; Krauss, et al., 2010). Meta-analysis on impacts of fragmentation on biodiversity is scarce and one has to include spatial variability and spatial dimension, therefore integrating traditional statistical analysis with spatial analysis in drawing conclusions (Ewers et al., 2010). Due to lack of long term and large-scale biodiversity data of tropical landscapes (Collen et al., 2008), such comparable evidences of extinction debt and meta-analysis of fragmentation impacts on tree diversity cannot be conducted for tropical landscapes.

The potential roles of agroforestry with regards to biodiversity conservations are understood better recently, as refugia habitat of biodiversity, as matrix to connect nature reserves, to reduce pressure to natural ecosystem, to reducing risk of alien invasive species and by farmer planting to enrichment valuable species in multifunctional landscapes (Bhagwat et al., 2008, McNeely and Schroth, 2006, Swallow and Boffa, 2006, van Noordwijk, 2006). Review of literatures comparing richness and similarities between species of birds, insects, reptiles, mammals and plants in 69 agroforestry systems across 14 countries found that species richness in agroforestry system ranges from $39-61 \%$ of forest while similarities range from $25-69 \%$ (91\% of the cases show 39-61\% similarities) (Bhagwat et a11., 2008). Agroforestry system is also shown to maintain below ground biodiversity (Giller et al, 2005). Yet, most species shared between agorforest and forest is habitat generalists (Uezu, 2008, for birds in agroforest woodlots of Brazil; O'Connor, 2005, for birds in coffee agroforest of Indonesia; Rasnovi, 2005, for trees in rubber agrofrest of Indonesia). Distance to forest, configuration of landscape, age of agroforestry plots, intensity of management, canopy density of the agroforest determine the richness and similarities of biodiversity of an agroforest plot with natural forests. Agroforest could not and should not replace natural forest; its roles is optimum when is situated in the middle ground zone within the multifunctional landscape where trade-offs between conservation and development are necessary. The understanding of ecological processes underlines the importance of connectivity in designing conservation at the landscape level (Koh et al., 2009).

Biodiversity studies in a multifunctional landscape need to consider the dynamics of land cover and land uses over space in order to understand the changes in states, the threat and opportunities for interventions to maintain biodiversity. Composition and configuration of a landscape mosaicked by various land use and land cover, along with biophysical and 
ecological consideration, should be addressed in assessing/evaluating biodiversity in a (fragmented) landscape, both at global and local landscape level.

In most tropical landscapes, however, landscapes are also very dynamic temporally. The pattern and location of changes are rarely random. Drivers of land cover patterns and changes determine the extent, pattern and location of changes. Drivers can also change rapidly due to changes in infrastructure, policies, economies (local to global) and increasing extreme climatic events. Some changes are part of a long cycle within particular land-use systems and some are 'permanent'. For instance, shrub cover might be part of a shifting cultivation cycle while changes from forest to plantation are more permanent.

A landscape is a manifestation of direct, local livelihood driving factors, and indirect land use drivers. Land use and cover changes affect biodiversity indirectly through habitat changes (habitat loss and changes in micro- and global-climate) by changing landscape composition and connectivity by altering landscape configuration. In addition, livelihood activities might also affect biodiversity directly through extraction and management (hunting, harvesting and selective weeding).

Understanding the interaction between landscape dynamics over time and space is of immense importance since it will enable us to identify the location of (past and future) hotspots of threats to biodiversity in the landscape, drivers associated to those, and opportunities in addressing those including scenarios or options for intervention. Whilst many of the issues are location specific, the tropics share common governance and livelihoods issues and therefore cross-learning from different places will hopefully speed up awareness raising and the ability to respond to the urgent need of addressing biodiversity and livelihoods in integrative manner.

The complexities of interaction between livelihoods and ecological processes are not easily understood, while rapid changes on the ground continue to take place. A relatively quick approach to study the dynamics and interactions is therefore needed to address the issue. Data collection is expensive and time consuming. Remotely sensed data offer an extensive spatial and temporal coverage that are invaluable as proxies of some ecological factors and means of extrapolation. Map is a universal way to capture spatial variabilities and can be effective tools in communicating results to decision-makers as well as negotiating interventions to achieve common agenda among multiple stakeholders.

Further, spatial analysis can derive indices to quantify patterns of composition and configuration of patches in an image. Unfortunately, the theoretical understanding to make explicit links between patterns and ecological processes in interpreting the indices are seriously lacking. In addition, livelihoods are an inherent part of the system that are often missing or simplified in the analyses. Land use/cover changes are predominately resulted from livelihood and economic driven processes. These changes are detectable from remote sensing and some drivers can be made spatially explicit via geographical information systems. Whilst the elements of livelihood activities and strategies that affect biodiversity directly can only be studied through on-the-ground surveys, a quick discussion (participatory mapping) can help to formulate hypotheses about the intensity of uses. By using proxies such as distance to settlement, road etc. some "map-able" activities that directly affect biodiversity in correlation to land cover/use types can be inferred. Therefore even though the overall 
ecological processes affected by livelihoods and other economic drivers cannot be covered in high detail, an understanding at the coarse level, sufficient for landscape scale, can be derived.

Such a study will also be species-specific in terms of 'functional' landscape indices otherwise they will be quantifications of structural physical patterns only. In this study, we are focusing on tree species diversity. Traversability is inferred through dispersal agent, mode and range.

This report will address landscape dynamics over time and space with explicit links to the interface between livelihood and biodiversity in 5 study areas of the project: Bungo (Indonesia), Viengkham (Laos), Manompana (Madagascar), Takamanda-Mone (Cameroon) and East Usambara (Tanzania). General descriptions of sites are provided in the project documentation. The report is structured as follows:

- Landscape dynamics over time: quantification, pattern, location, drivers, global landscape composition and configuration (5 sites and comparison)

- Landscape dynamics over space: connectivity, hotspots of threat (local landscape composition and configuration) (5 sites and comparison)

- Landscape dynamics over time and space: changes in connectivity, hotspots of threats (changes in local landscape composition and configuration) (5 sites and comparison)

- Synthesis of comparison among the 5 sites

This interim report is written based on progress we achieve so far. There are still gaps in data and analysis to be filled. In the end of the report, we list some steps to be completed later during the project. Due to varying degrees of familiarity of the spatial analysis team to the reality on the ground in the 5 sites (only Bungo site was rigorously visited and studied by the spatial analysis team), the interpretation and discussion are not uniform in terms of details and accuracy. 


\section{Materials and Methods}

Within this report, the time reference is categorized into three time periods in order to simplify discussion per site and sites (Table 1). Land cover maps are derived from the satellite imagery interpretation using object-based image analysis under hierarchical classification. We used Definiens software for the remote sensing analysis.

Dynamics in land cover/use over time and space are captured both using area-based (nonspatially explicit) analysis and location-based (spatially explicit) analysis. Visualization and simple statistical analysis are used to describe the change patterns. Drivers over time and space are inferred from the understanding of the dominant processes of land use and land cover changes in the landscape and also from spatial analysis using several spatially-explicit proxies, like roads, rivers, settlements, concession boundaries, spatial plans and also patterns of past deforestation and changes.

Spatial dynamics with regards to biodiversity were quantified through local and global indices using FRAGSTAT software (McGarigal and Marks, 1995). Changes in the indices over time were used to infer the changes in spatial dynamics over time. Superimposition and visual interpretation were used to identify hotspots of threat and drivers associated to that.

Table 1. Periods of analysis based on satellite image availabilities.

\begin{tabular}{|c|l|c|r|r|r|}
\hline \multirow{2}{*}{ No } & \multirow{2}{*}{ Site } & \multirow{2}{*}{ \# Time series } & \multicolumn{2}{|c|}{ Time series } \\
\cline { 4 - 6 } & & $\begin{array}{c}\text { Period I (earlier than } \\
\text { 1990's) }\end{array}$ & $\begin{array}{c}\text { Period II (1990's- } \\
\text { 2000's) }\end{array}$ & $\begin{array}{c}\text { Period III (2000's - } \\
\text { 2007) }\end{array}$ \\
\hline 1 & Indonesia & 7 & 1973,1988 & 1993,1999 & $2002,2005,2007$ \\
\hline 2 & Laos & 2 & 1990 & & 2002,2007 \\
\hline 3 & Madagascar & 3 & 1986,1990 & & 2004,2005 \\
\hline 4 & Cameroon & 6 & 1992 & $2001,2002,2004,2005$ \\
\hline 5 & Tanzania & 4 & & & 2006,2007 \\
\hline
\end{tabular}

\section{Materials}

Multiple types of sensor and resolution of remote sensing data were used in this study. Most of the historical datasets were captured by Landsat sensors. The sensor resolutions range from 79m (Multipectral scanner/MSS) to 30m (Thematic Mapper/Enhanced Thematic MapperTM/ETM). Most recent imageries were captured by SPOT sensor. The resolution is $10 \mathrm{~m}$ for multispectral channel and $2.5 \mathrm{~m}$ for panchromatic channel. Table 2 showed the complete list of dataset used in this study.

\section{Landscape dynamics over time}

Landscape dynamics over time were assessed by conducting independent classification and land cover change analysis for each site. The main objective of this particular phase was to produce time series land cover maps covering the three time periods and gather information regarding the dynamics of the landscape. Using Landsat and SPOT imageries as primary datasets, the classification was conducted using object based-hierarchical classification approach using Denifiens software, while land cover change analysis was conducted using 
post-classification comparison approach with ArcGIS. Accuracy assessment should be the last steps taken to ensure the quality of information produced by image classification. However, at this stage due to the non-availability of groundtruthed data in most sites, the accuracy has not been calculated yet.

At this stage, we use level two of our classification hierarchy, which comprises the following land cover types:

- Forest: natural forest at various levels of quality;

- Tree-based cover: monoculture and agroforest (mixed, multistrata trees);

- Non-tree based cover: vegetation cover but not dominated by trees, e.g., cropland, imperata, shrubs (young natural re-growth);

- Non-vegetation cover: cleared land; and

- Settlement: cleared land with physical man-made buildings on top.

In this report, for land cover changes analysis, all dataset were re-sampled into 30x30m pixel size, despite of the variation in spatial resolution of Landsat and SPOT imageries. Change analysis are then conducted post-classification and resampling, i.e., by overlaying pairwise of land use/cover maps of different time periods and cross-tabulating the two for location-based change analysis or simply by quantifying the area of each land use/cover class in each time period and comparing those across different time period for area-based change analysis. These analyses capture the landscape composition and changes in landscape composition over time. The analysis of landscape configuration derives heavily from FRAGSTAT, both in theories and in technical aspects. Interested readers are recommended to consult FRAGSTAT background materials (McGarigal and Marks, 1995). For landscape configuration analysis, due to the extensive computing requirement, we resampled the maps to a 1 ha pixel size. 
Table 2. List of materials used for this interim report (additional images will be used in the near future, especially for Laos and Madagascar)

\begin{tabular}{|c|c|c|c|c|c|}
\hline No & Site name & Country & Time series & Sensor & Resolution \\
\hline \multirow[t]{7}{*}{1} & \multirow[t]{7}{*}{ Bungo } & \multirow[t]{7}{*}{ Indonesia } & 1973 & MSS & $79 m$ \\
\hline & & & 1988 & TM & $30 \mathrm{~m}$ \\
\hline & & & 1993 & TM & $30 m$ \\
\hline & & & 1999 & TM & $30 m$ \\
\hline & & & 2002 & ETM & $30 m$ \\
\hline & & & 2005 & ETM-SLC off & $30 m$ \\
\hline & & & 2006 & SPOT 5 & $10 \mathrm{~m} / 2.5 \mathrm{~m}$ \\
\hline \multirow[t]{2}{*}{2} & \multirow[t]{2}{*}{ Viengkham } & \multirow[t]{2}{*}{ Laos } & 2005 & ETM-SLC off & $30 m$ \\
\hline & & & 2007 & SPOT 5 & $10 \mathrm{~m} / 2.5 \mathrm{~m}$ \\
\hline \multirow[t]{3}{*}{3} & \multirow[t]{3}{*}{ Manompana } & \multirow[t]{3}{*}{ Madagascar } & 1990 & ETM & $30 \mathrm{~m}$ \\
\hline & & & 2005 & ETM-SLC off & $30 m$ \\
\hline & & & 2007 & SPOT 5 & $10 \mathrm{~m} / 2.5 \mathrm{~m}$ \\
\hline \multirow[t]{6}{*}{4} & \multirow[t]{6}{*}{ Takamanda Mone } & \multirow[t]{6}{*}{ Cameroon } & 1986 & TM & $30 m$ \\
\hline & & & 1990 & TM & $30 m$ \\
\hline & & & 2001 & ETM & $30 m$ \\
\hline & & & 2002 & ETM & $30 m$ \\
\hline & & & 2004 & SPOT 5 & $10 \mathrm{~m} / 2.5 \mathrm{~m}$ \\
\hline & & & 2005 & ETM-SLC off & $30 m$ \\
\hline \multirow[t]{4}{*}{5} & \multirow[t]{4}{*}{ East Usambara } & \multirow[t]{4}{*}{ Tanzania } & 1992 & TM & $30 \mathrm{~m}$ \\
\hline & & & 2000 & TM & $30 m$ \\
\hline & & & 2006 & ETM-SLC off & $30 \mathrm{~m}$ \\
\hline & & & 2007 & SPOT 5 & $10 \mathrm{~m} / 2.5 \mathrm{~m}$ \\
\hline
\end{tabular}

We use FRAGSTAT software to calculate some landscape and class indices for pattern quantification. We selected a few indices only among extensive number of indices made available by FRAGSTAT based on the uniqueness of information expressed by the indices since many indices highly correlate to each other and on the relevancies to ecological processes. In this interim report we will only present a few of the indices. We will cover both structural and functional indices and run the analysis both at the global and local (sublandscape level). Global level indices are calculated for the entire landscapes while the local level indices are calculated based on a specified window sizes.

Modified Simpson's Diversity and Evenness indices are used to capture landscape composition while Total core area, Aggregation Index and Connectivity Index measures landscape configuration, with Connectivity Index reflects the ecological functions of connecting one habitat to another from species' perspectives.

- Modified Simpson's Diversity Index measures the proportional abundance of each patch type. When the landscape contains only 1 patch (i.e., no diversity), the index is equal to 0. It increases as the number of different patch types increases and the proportional distribution of area among patch types becomes more equitable. 
- Modified Simpson's Evenness Index measures the proportional abundance of each patch divided by the total number of patch types. It is equal to 0 when $\mathrm{h}$ (i.e., no diversity) and equals 1 when distribution of area among patch types is perfectly even (i.e., proportional abundances are the same).

- Total Core area is the sum of the core areas of each patch, which is calculated, based on specified depth-of-edge distance(s) from the patch perimeters. Total Core area considers the reduction in the area by the encroachment from the edge at a specified depth; as patch shapes are more complicated and patch perimeters are longer, the differences between total area and total core area are larger.

- Aggregation Index measures the likeliness of patches of corresponding classes to be adjacent to each other.

- Connectivity Index measures the functional joining between all patches of the corresponding patch type based on defined similarity.

Further description of the indices can be found in the FRAGSTAT manual and user guides. These indices are calculated at the global (across the entire dataset) landscape; one landscape has one value of these indices attached to it under the same set of parameters. Changes in landscape over time and differences in patterns across landscapes of different places can be studied by comparing these values. Some of these indices are normalized such that they are not sensitive to sizes of landscapes to allow direct comparison of landscapes with varying extents..

We use the same parameters across landscapes of 5 study sites, as follows:

Edge depth:

\begin{tabular}{|l|l|l|l|l|}
\hline Land cover type & Forest & Tree-based & Non-tree-based & Non-vegetation \\
\hline Forest & 0 & 200 & 100 & 100 \\
\hline Tree-based & 0 & 0 & 200 & 100 \\
\hline Non-tree-based & 0 & 0 & 0 & 100 \\
\hline Non-vegetation & 0 & 0 & 0 & 0 \\
\hline
\end{tabular}

Similarity:

\begin{tabular}{|l|l|l|l|l|}
\hline Land cover type & Forest & Tree-based & Non-tree-based & Non-vegetation \\
\hline Forest & 1 & 0.8 & 0.2 & 0 \\
\hline Tree-based & 0.8 & 1 & 0.3 & 0 \\
\hline Non-tree-based & 0 & 0.3 & 1 & 0.1 \\
\hline Non-vegetation & 0.3 & 0 & 0.1 & 1 \\
\hline
\end{tabular}

Edge weight

\begin{tabular}{|l|l|l|l|l|}
\hline Land cover type & Forest & Tree-based & Non-tree-based & Non-vegetation \\
\hline Forest & 0 & 0.3 & 0.8 & 1 \\
\hline Tree-based & 0.3 & 0 & 0.5 & 0.8 \\
\hline Non-tree-based & 0.8 & 0.5 & 0 & 0.3 \\
\hline Non-vegetation & 1 & 0.8 & 0.3 & 0 \\
\hline
\end{tabular}


Edge depth parameter assumes that the encroachment to forest by tree-based is 200 meters while non-tree and non-vegetation are half of that of tree-based. Similarity parameter assumes that tree-based is $80 \%$ similar to forest, while non-tree is only $20 \%$. The edge weight assumes dissimilarity of tree-based and forest is $30 \%$ while non-tree is $80 \%$. These parameters are at this moment solely based on expert judgment and will be evaluated against field data later.

\section{Landscape dynamics over space}

The landscape indices above are derived with the assumption that only the overall patterns at the landscape level matter, while variations within a landscape can be neglected. However, for a large enough landscape and for small body sized species or species that only forage or disperse narrowly, local variations in sub-landscape level are at least as important and therefore quantifying patterns locally over a landscape space is crucial. The direct application might be the hotspot and threat location identification for land use planning.

We use a circular moving window of radius $1000 \mathrm{~m}$ to define a sub-landscape of such size and calculate several indices that reflect composition and configuration within the sublandscapes. These computations require extensive processing power especially for large landscape, high resolution maps and a large number of classes/land cover types. Re-sampling from the original resolution to a coarser resolution is needed for these computations due to hardware limitations. The parameters we use for calculating local composition and configuration indices are the same as those for global ones. The outputs are presented as a series of maps; each pixel represents the value of the indices of the sub-landscape, calculated within a circle of $1 \mathrm{~km}$ radius around it.

\section{Landscape dynamics over time and space}

In this report the comparison across time and space and among landscapes will only be presented through the series of maps. The output at this stage will be useful for the practical uses of focus group discussion and visioning and as the basis of further exploration using different sets of parameters. Further, these results will be analyzed and summarized under the what-if scenario and projections of land use/cover changes. 


\section{Results and discussions}

\section{Landscape dynamics over time}

This section describes the current land cover, temporal change, location change and drivers of each landscape, and then discusses them across landscapes. Description of global landscape composition and configuration of landscapes over time will also be presented.

\section{Indonesia (Bungo)}

Topography and current land cover

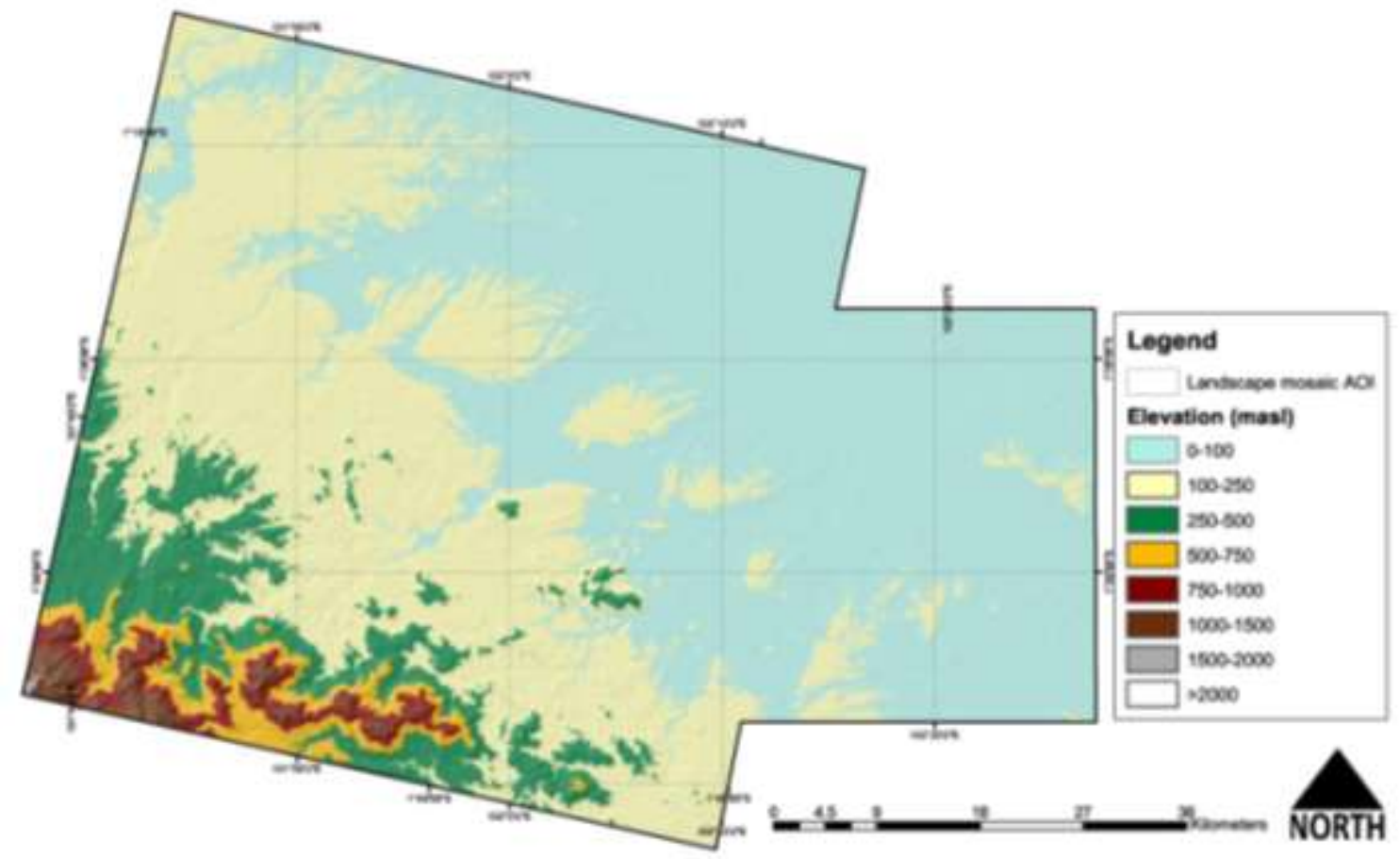

Figure 1. Elevation of Bungo site, ranges from 100 to 1700 meter above sea level

The landscape of Bungo is composed of lowland in the northeast and submontane ecosystem in the southwest with rough topography. Most of the submontane area is delineated as Protected Areas and currently this is the only large primary forest block left in the landscape. 


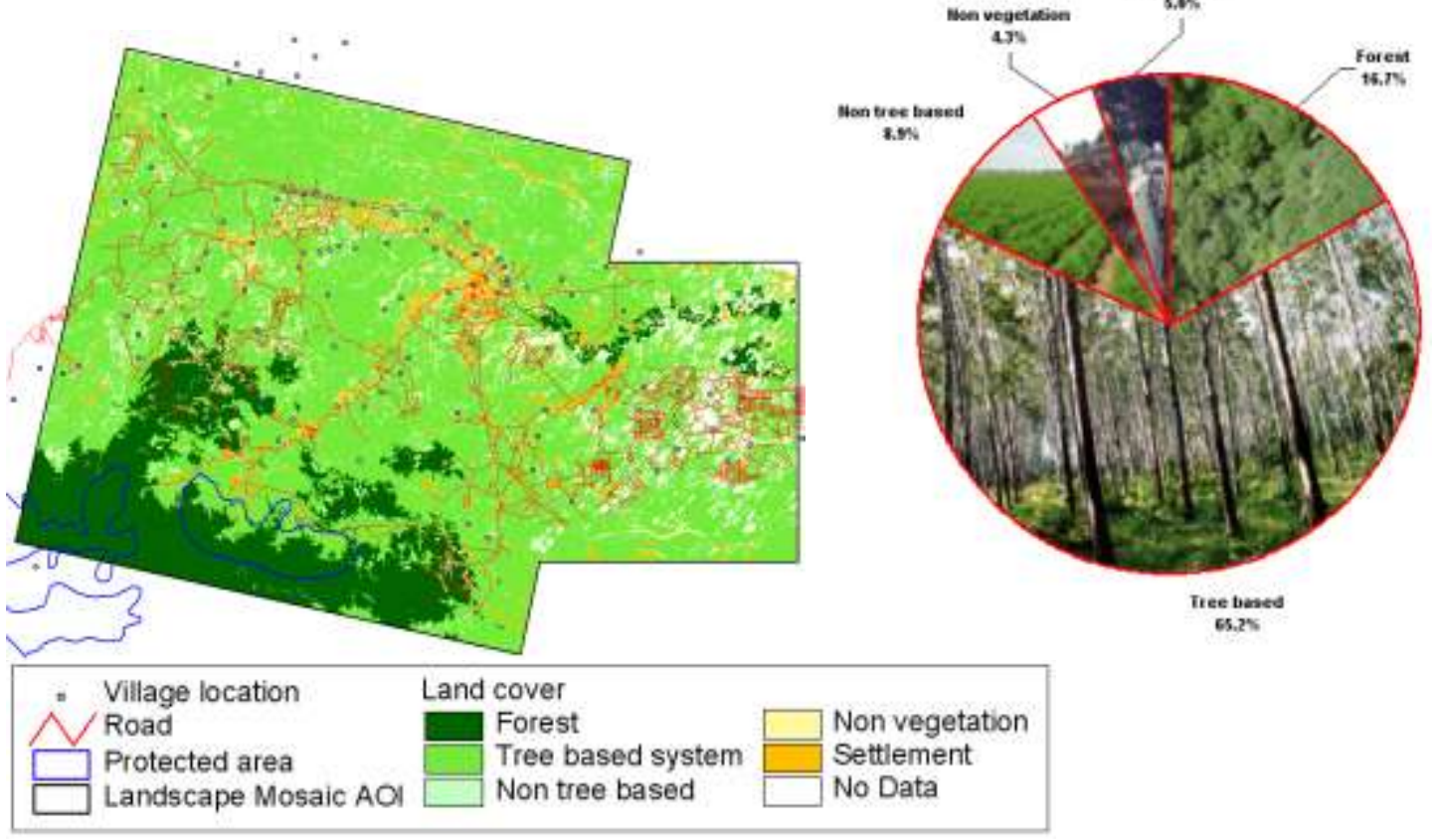

Figure 2 (a). Land cover map of Bungo site in 2007 (interpreted from SPOT 2007) (b). Landscape composition in 2007

In 2007, two thirds of Bungo landscape was dominated by tree-based land cover type; only $16 \%$ of the area is covered by natural forest. Most of the natural forests cover is exist as primary forest blocks of substantial sizes with complex shapes and only remains in higher altitude, surrounded by some small disconnected patches of primary, but degraded forest. Other even smaller forest patches still exist in the lower Batang Hari River as riparian forest. 


\section{Temporal Pattern}

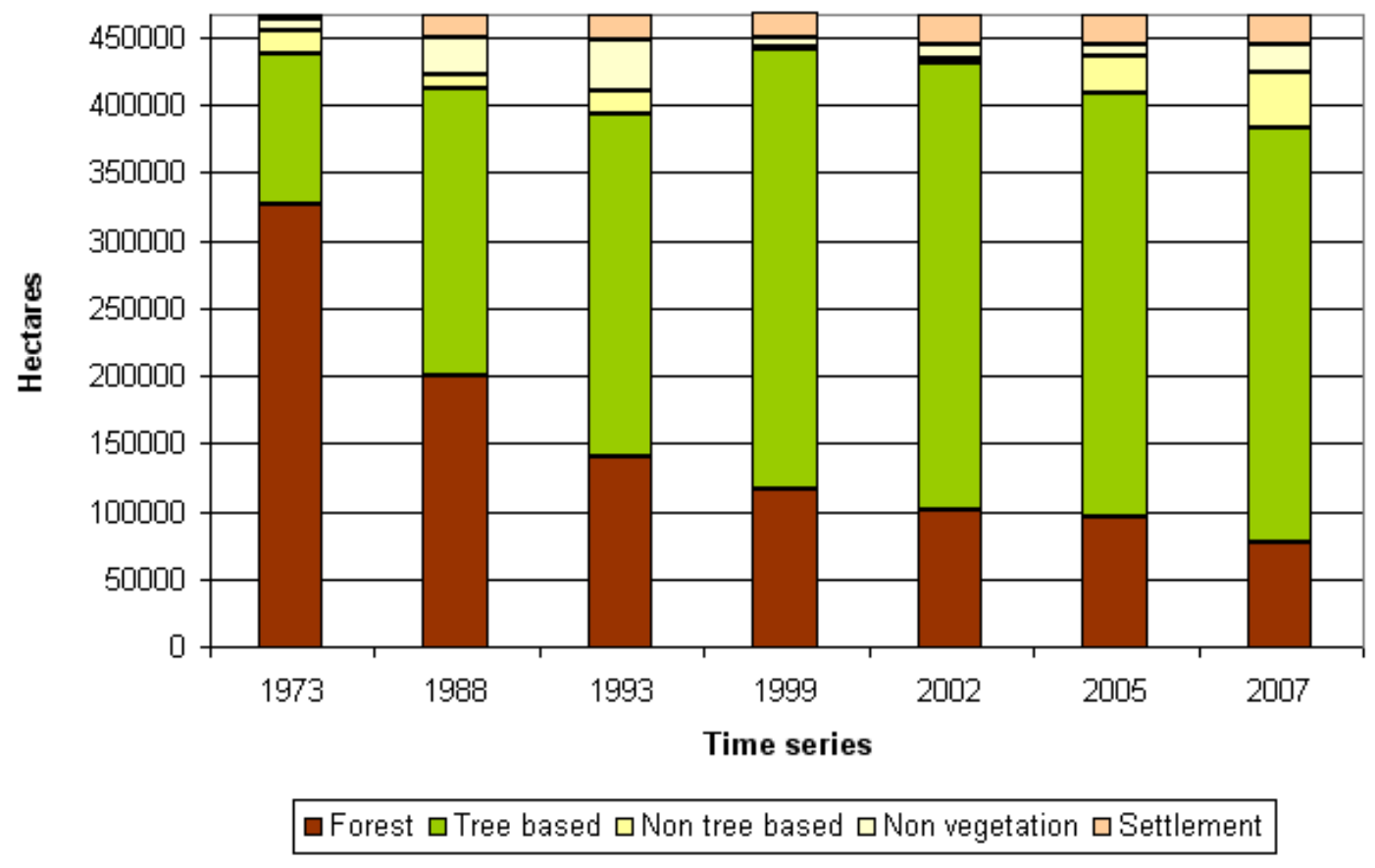

Figure 3. Time series of land cover composition of Bungo site.

Natural forest cover declined in period I, especially between 1973 to 1988, but tree-based land cover took over and became the dominant land cover since then (Figure 3). This treebased land cover continued to increase until 1999 (period II) when it stabilized. During period III, changes were within tree-based land cover class; a large proportion of agroforest (rubber multistrata) was converted to more intensively managed tree-based systems, such as rubber monoculture, oil palm and, very recently, to Acacia Mangium. In this case the image interpretation needs a finer classification scheme to differentiate further the types of the treebased systems, especially when our focus is on biodiversity. Until this interim report is written we have not yet finalized the image interpretation using the finest classification scheme. The finer classification process is scheduled to take place after the fieldwork is conducted in order to get more groundtruthed data. 


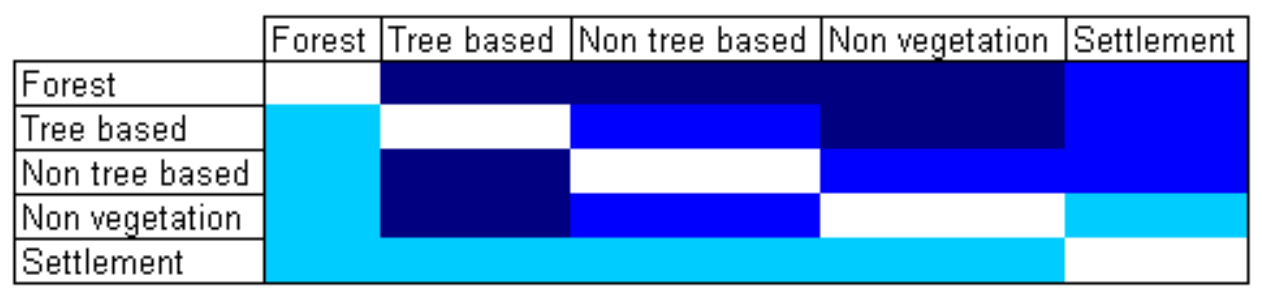

(a)

\begin{tabular}{|l|l|l|l|l|l|}
\cline { 4 - 5 } \multicolumn{1}{l|}{} & Forest & Tree based & Non tree based & Non vegetation & Settlement \\
\hline Forest & & & & \\
\hline Tree based & & & & \\
\cline { 1 - 1 } Non tree based & & & \\
\hline Non vegetation & & & \\
\cline { 1 - 1 } Settlement & & & \\
\hline
\end{tabular}

(b)

\begin{tabular}{|c|c|c|c|c|}
\hline & Forest & Tree based & Non tree based & Non vegetation \\
\hline \multicolumn{5}{|c|}{ Pow } \\
\hline Tree based & & & & \\
\hline Non tree based & & & & \\
\hline Non vegetation & & & & \\
\hline
\end{tabular}

(c)

Figure 4. Pattern of changes in 3 study period (a). Period I (1973-1993) (b). Period II (1993-2002) and (c). Period III (2002-2007). Darker colors indicate larger annual changes in proportion.

The pattern of changes during the three periods follows closely the forest transition theory. The earlier stage was dominated by loss of forest and biomass, in which most forests were converted to tree-based systems in period II (Figure 4). In Bungo, this period was also marked by increases in population and settlement area. There were new areas developed under the transmigration programs, both from surrounding areas and also from Java. The third period was marked with conversion of established tree-based systems to non-tree based systems and vegetation, which suggests either the transition to more intensified cropland and settlement or transition to more intensified tree-based systems, mostly monoculture rather than mixed tree, especially oil palm and rubber.

\section{Location of changes}

During the earliest period, deforestation occurred from the northern to the southern part of the district, and while this continues, the second period experiences further changes from the eastern side toward the western direction (Figure 5 and 6). The common characteristics have been that forest loss starts from lowland areas by timber harvesting that provides higher economic benefit, followed by clearing and conversion to either timber plantation, estate plantations, rubber agroforest, cropland or settlement. The most recent deforestation occurred in the edges of major primary forest block mostly found in higher altitudes only. 

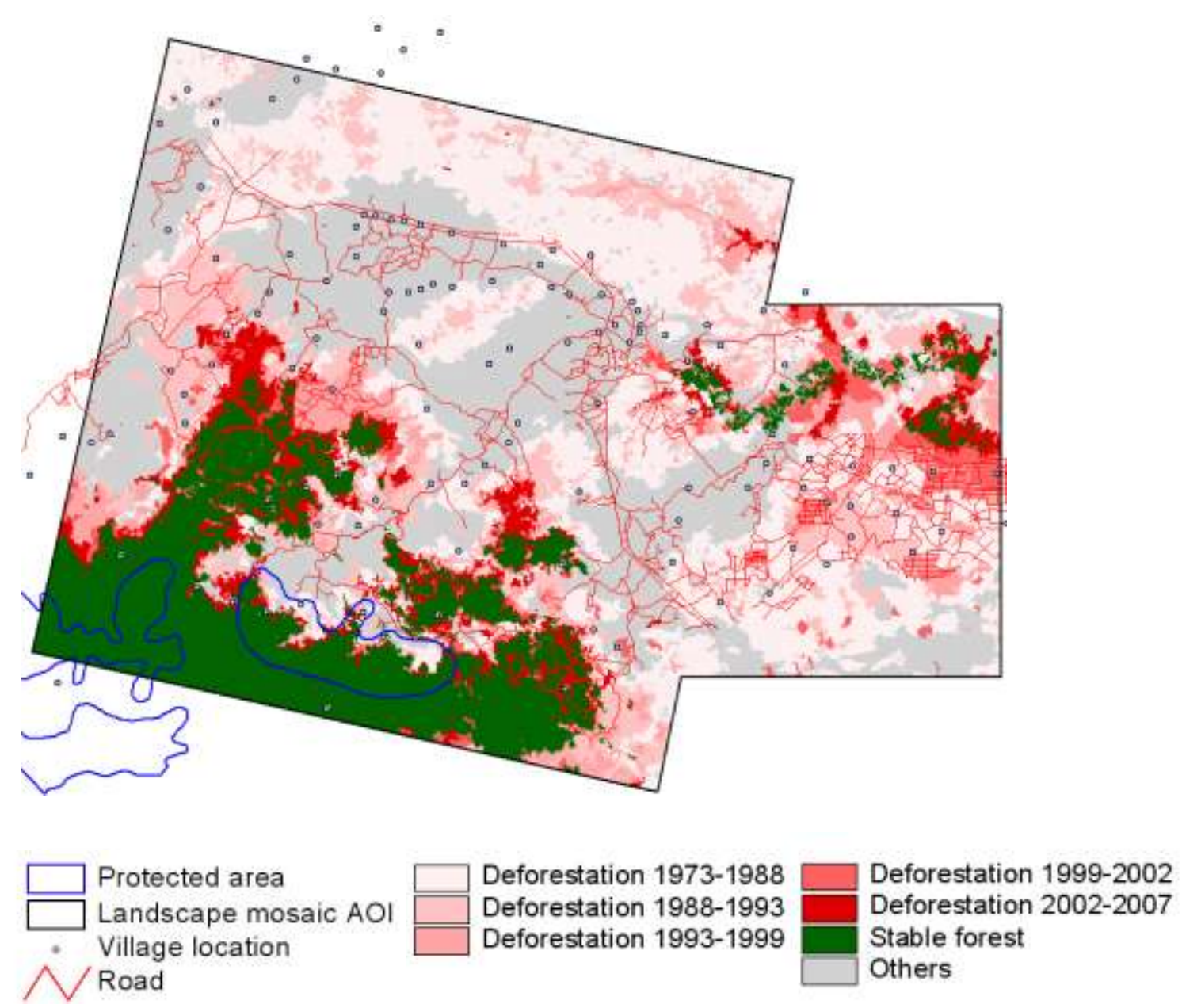

Figure 6. Location of deforestation in each time step in Bungo site.

\section{Drivers}

For Bungo site, where the Spatial Analysis team has been visiting repeatedly in the past and the where a long-term study has been conducted, the understanding of drivers of changes has been strong; several important agents of changes over time have been identified (Ekadinata and Vincent, 2008).

During the first period, where commercial timber was abundant, the land use/cover changes were dominated by logging activities under logging concessions. Under the regulations of the Forestry Department, only selective loggings are allowed, however heavily degraded forest were found in a considerable extents, followed by natural re-growth, cropland, imperata, mixed rubber plantation and conversion to timber plantations, and more recently by conversions to oil palm plantations in the second and third periods. 

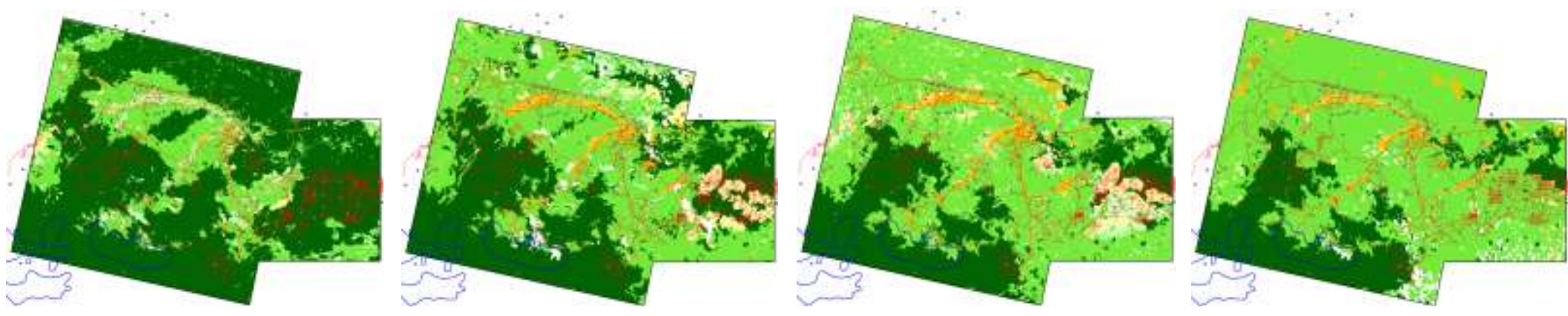

1973

1988

1993

1999
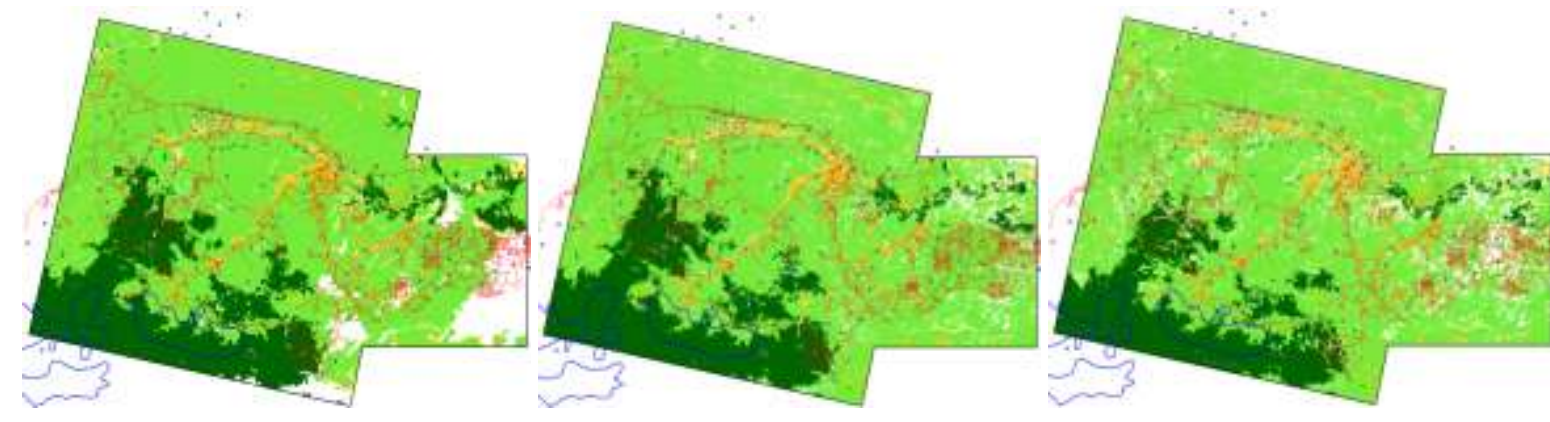

2002

2005

2007

$\begin{array}{lll}\begin{array}{ll}\text { Village location } \\ \text { Road }\end{array} & \text { Land cover } \\ \begin{array}{ll}\text { Protected area } \\ \text { Landscape Mosaic AOI }\end{array} & \text { Forest } \\ \square \text { Nree based system } & \text { Non tree based } & \text { Non vegetation } \\ \square & \text { No Data }\end{array}$

Figure 5. Time series of land cover map of Bungo site. 
As for the smallholder managed lands, during the first period dominant land uses were rice field, croplands under shifting cultivation systems, rubber agroforests and some rubber monoculture (intensive rubber). During the first period, there was not much interaction between farmers and the large-scale drivers in terms of land cover/use. In the second period, farmers started to convert their rubber agroforest to more intensively managed rubber gardens. Also some farmers started to plant oil palm a result of the interaction with larger scale agents.

The third period up to now is heavily dominated by conversion to oil palm and, to a lesser degree, timber plantations mostly for fiber, both under large-scale concessions and small-scale concessions under out-grower schemes. This latest trend is driven by global demand for oil palm and for rubber, and regional demand for raw materials for pulp and paper due to depletion of natural forest and improved law enforcement. Following the 'anarchy' period due to the euphoria of the enactment of decentralization law, which has not been resolved up to now, resulting in lack of clarity and uncertainty of land tenure, land grabbing by farmers is quite prevalent. Overall forest and landscape governance of Bungo could be found in Martini et al (2010).

The transmigration program, facilitated by the government, has been quite active. This involves people migrating from the surrounding area, known as local transmigration, and those from Java. Associated with this program is the establishment of cropland and tree-based systems from forest and shrubs.

Most recently, activities and permits for coal mining have been increasing sharply. This becomes a new driver of land use and land cover changes in the area. Despite of this, in Lubuk Beringin, one of the village within the Bungo landscape, has been awarded the Hutan Desa (Village Forest) permit, which is the first permit given throughout the country (Akiefnawati et al, 2010).

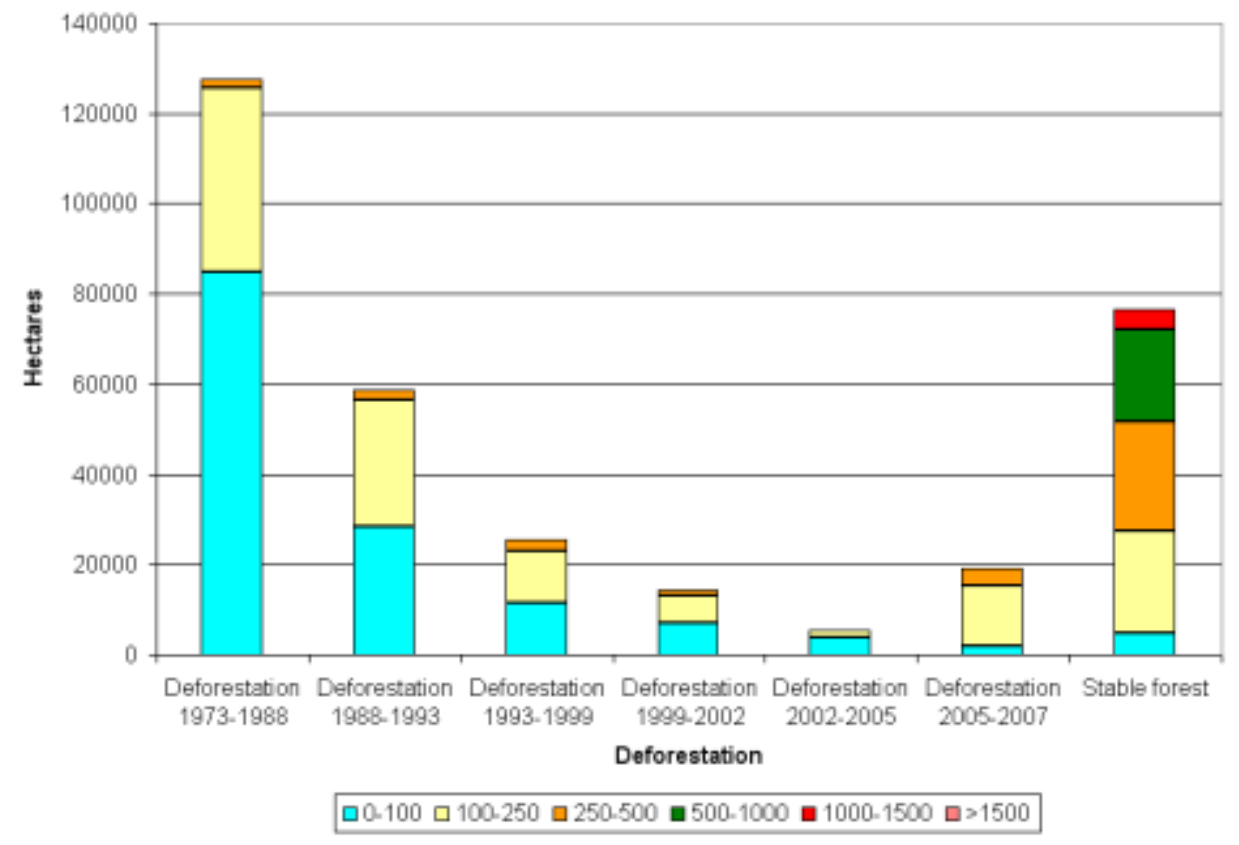

Figure 7. Forest loss (in hectares) in each time series by elevation class. 


\section{Access (River or road network)}

In the past, people depended on rivers for their transportation network, but lately the road network has been well established; most settlements in Bungo are connected to some larger townships by road. Bungo's location of deforestation correlates strongly with the existence of roads, like everywhere else in the tropics.

\section{Protected area}

Kerinci Seblat National Park covers the higher altitude areas in Bungo and is part of Bukit Barisan mountain range. Up to now the forest area of the national park in Bungo has been well conserved as part of the major block of primary forest remaining in the landscape. However, past trends show active encroachment from the forest edges and the buffer area of national park area are threatened by forest degradation, if not deforestation.

\section{Laos (Viengkham)}

\section{Topography and current land cover and description}

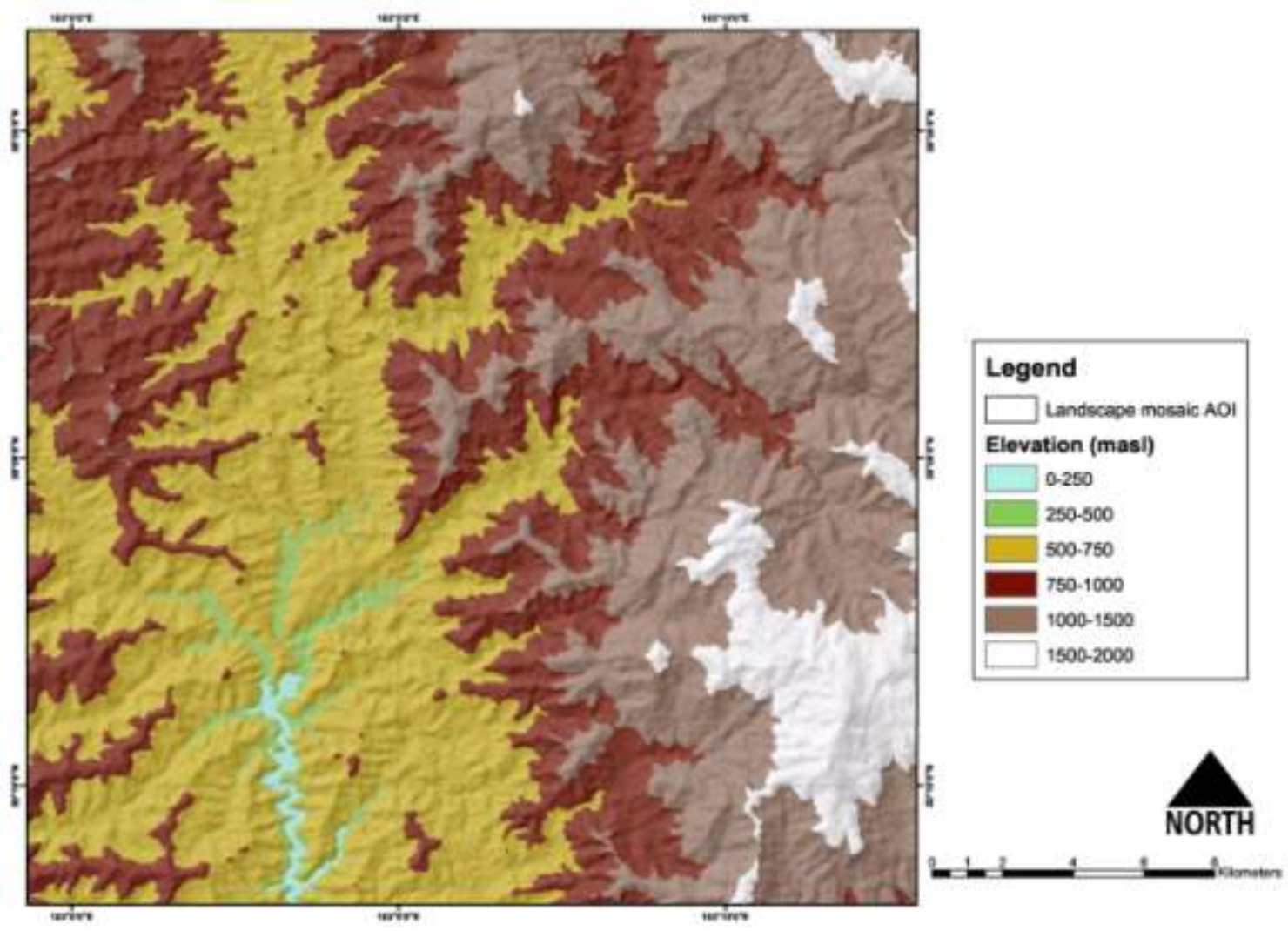

Figure 8. Elevation of Viengkham site, ranges from 400 to 2200 meter above sea level 
The landscape of Viengkham is dominated by montane ecosystem with rough topography, especially in the eastern half of the area and some area in the northwestern part (Figure 8). Among the five sites of the project, Laos is highest and roughest in terms of topography.
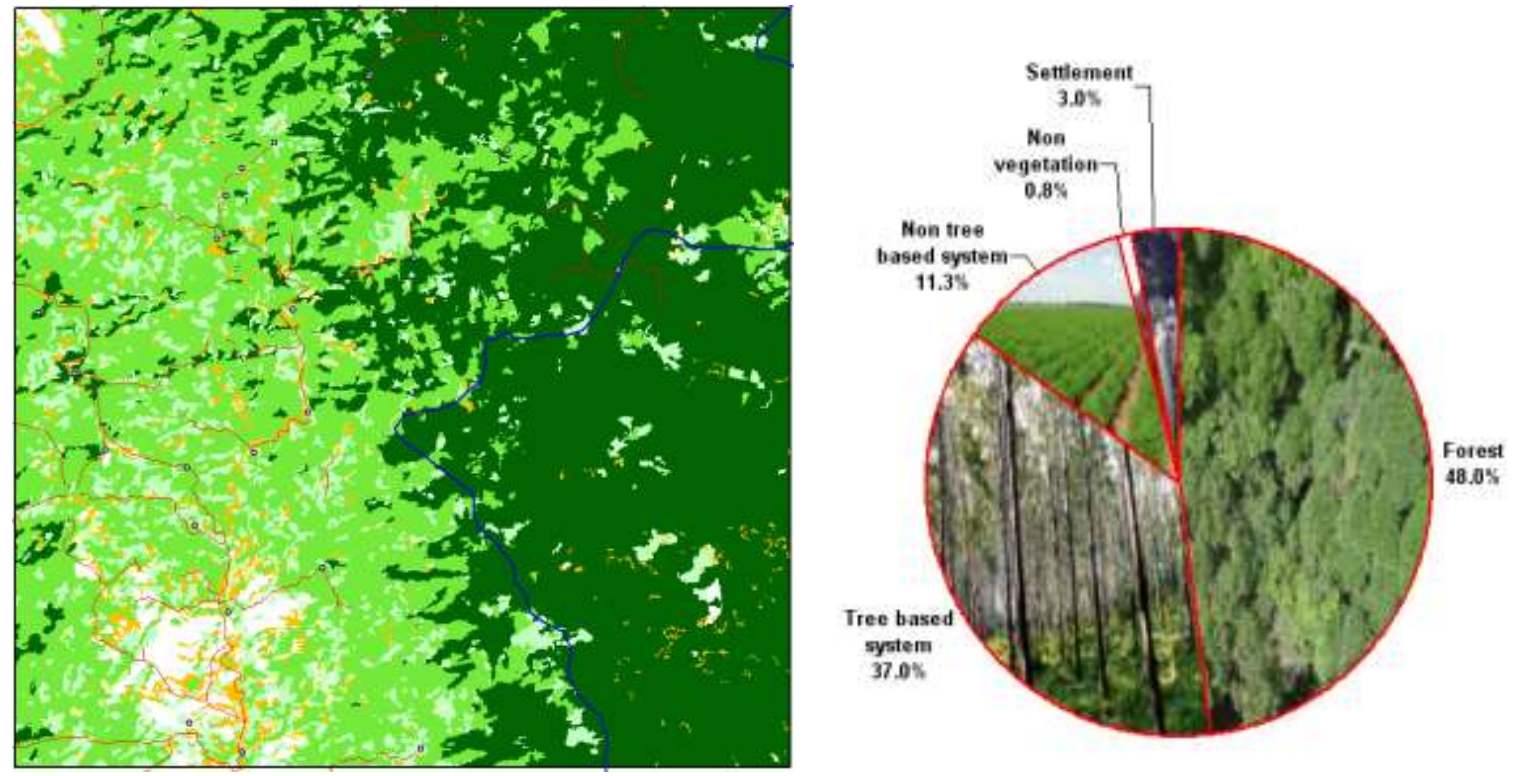

Figure 9 (a). Land cover map of Viengkham site in 2007 (interpreted from SPOT 2007) (b). Landscape composition in 2007

Almost half of the landscape area is covered by natural forest and 37\% of tree-based systems (Figure 9), which is most likely natural re-growth (fallow) that is partial to shifting cultivation systems. It seems that in the recent past this area was part of the opium production area but to what extent opium was grown before eradication programs were implemented (the last one was launched in 2004) in this area is yet to be learned. The road networks are limited and the pattern of forested-non-forested areas follow river networks very closely.

\section{Temporal Pattern}

From the very limited two time series of land cover maps (2002 to 2007) we have produced so far, during the past 5 years, we can see that the extent of forest cover changed a little while treebased land cover has increased dramatically replacing non-tree based cover (Figure 10 and 11). These changes perhaps are due to fallow period that allows natural regrowth to shrubs and woody trees. Seasonality might affect the spectral reflectance and the limited number of maps also constraints us to say more about the patterns. In the future this barrier will be addressed by looking for several other imageries that are relatively cloud free. 


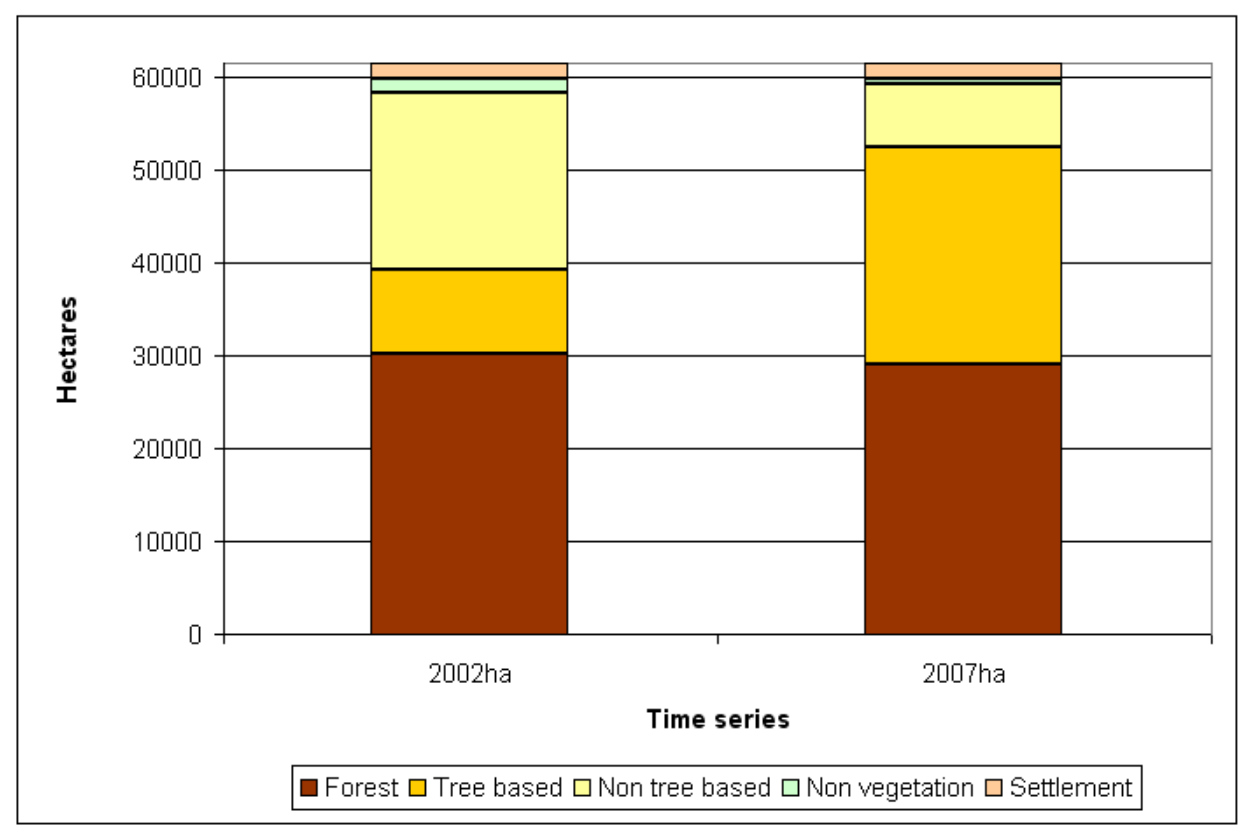

Figure 10. Time series of land cover composition of Viengkham site.

\begin{tabular}{|c|c|c|c|c|}
\hline \multirow{2}{*}{ Forest } & Forest & \begin{tabular}{|l|l|} 
Tree based & Non tree based
\end{tabular} & Non vegetation & Settlement \\
\hline & & & & \\
\hline Tree based & & & & \\
\hline Non tree based & & & & \\
\hline Non vegetation & & & & \\
\hline Settlement & & & & \\
\hline
\end{tabular}

Figure 11. Pattern of changes in Viengkham in Period III (2002 to 2007). Darker colors indicate large annual changes in proportion.

\section{Location of changes}

Almost in every part of the landscape where the altitude is relatively low (or outside the Protected Areas), the changes to tree-based land cover have been happening during the past 5 years (Figure 12). Some deforestation happened within the primary forest block area, rather than from the edges. These locations of deforestation are the enlargement or expansion of small patches of deforestation that occurred in the past in the core rather than the more common encroachment pattern from the edges. 


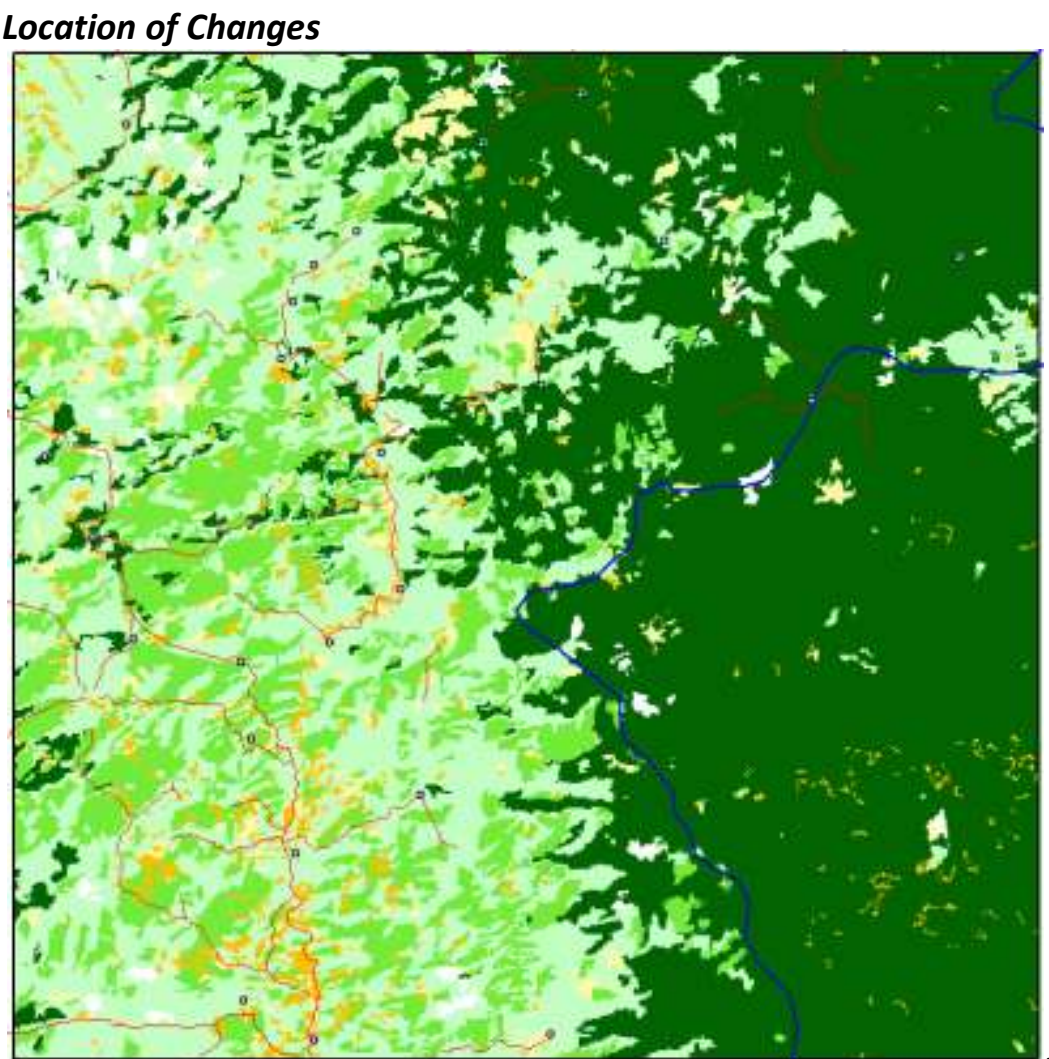

2002

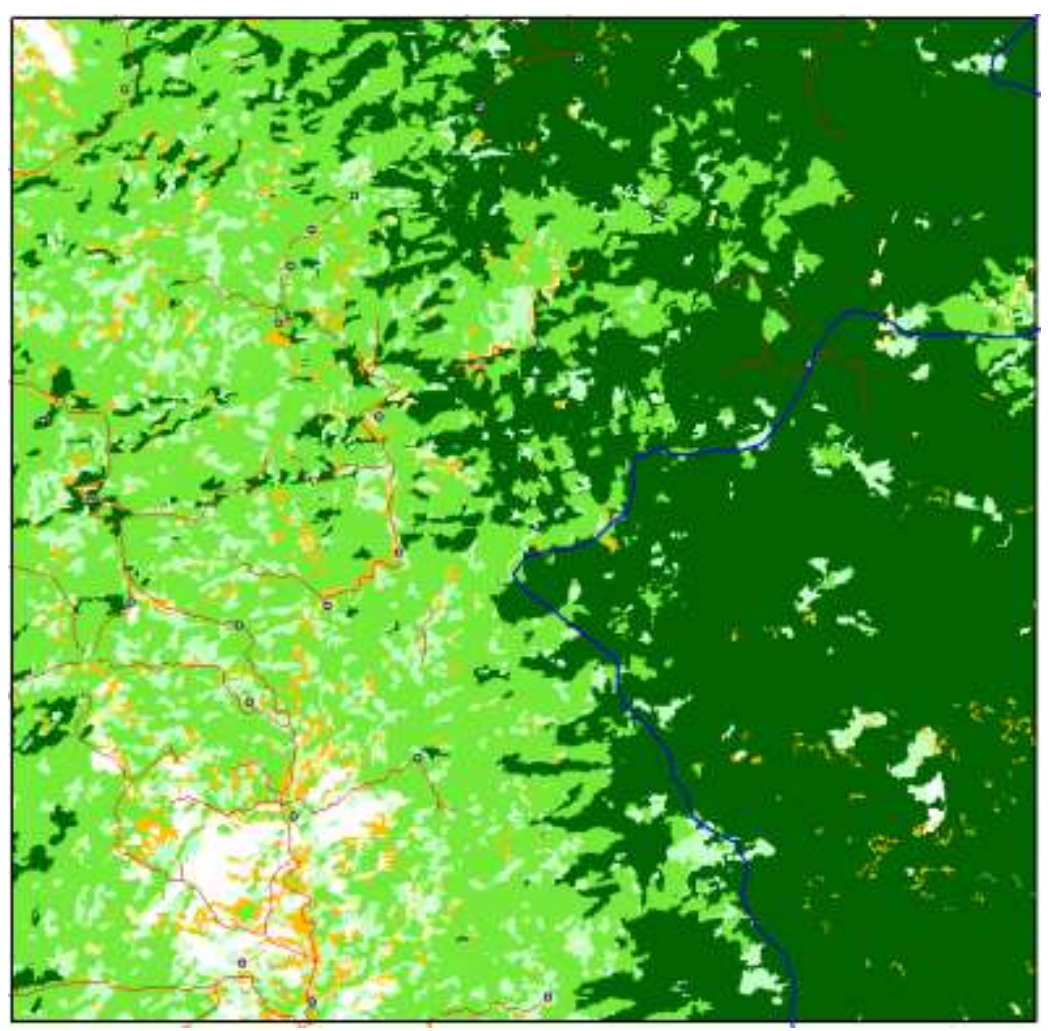

2007

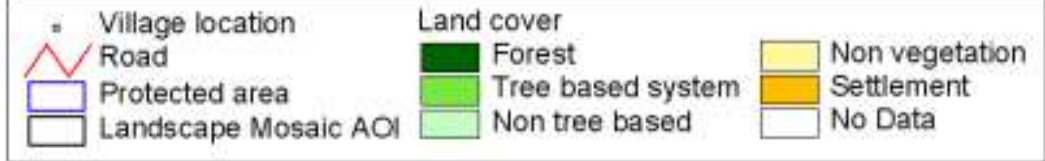

Figure 12. Time series of land cover map of Viengkham site. 


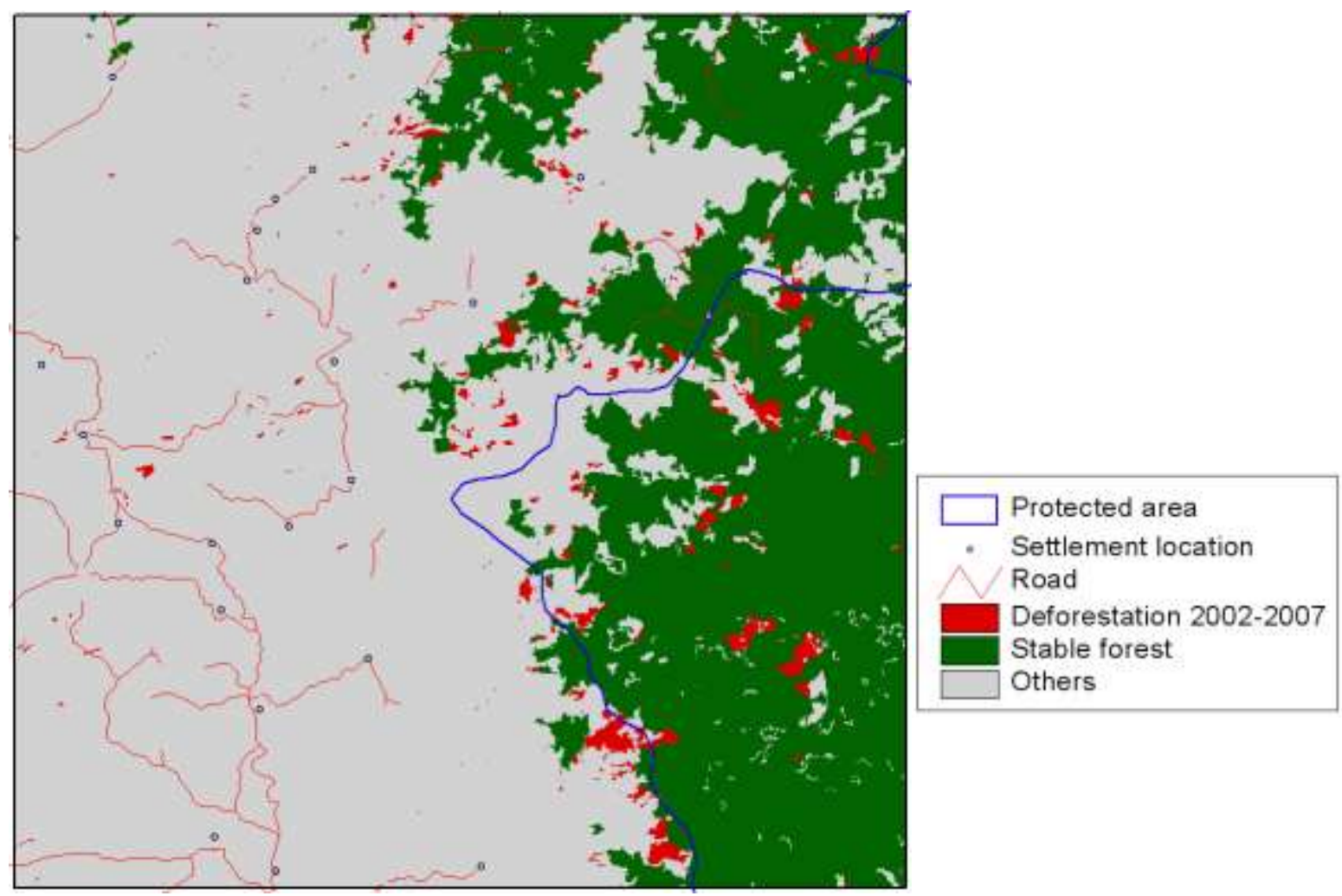

Figure 13. Location of deforestation in Viengkham site.

\section{Drivers}

\section{Agents}

Deforestation has been relevant in the protected area and dense forests have become scarce in agricultural landscapes with relatively high accessibilities and remains in less accessible areas. The typical landscapes consist of patches of different gradients of vegetation from degraded forest to grassland and are a consequence of human impact (slash and burn cultivation for upland rice, other farming systems, cash crop plantation, possibly effects of war, etc).

The main income sources are livestock (pigs, cattle, chicken etc.), followed by the collection of NTFPs (bamboos, grasses for broom, mushrooms). Teak cultivation is limited due to land tenure/land availability; technical limitation are also marked, e.g., in the case of eaglewood. Rubber planting is of the interest of local people but there are very few trials, mostly due to the rough terrain and market access. Population density of this landscape is very low, shifting cultivation is the most dominant land use system in the area. In 2004 the government enacted the policy to reduce the area of shifting cultivation by shortening the fallow period to three years only, as extensive shifting cultivation is believed to be the single most important reason of deforestation and degradation. 


\section{Topography}

Figure 14 shows that most forest loss happened in the lower altitude, however since we only have two time series we cannot compare pattern of forest loss with regard to topography during different periods. In the highest elevation area $(>1500 \mathrm{~m})$, forest loss is quite marked compare to the intermediate elevation class (1000 to $1500 \mathrm{~m}$ ), which perhaps are induced by new road development or other external drivers.

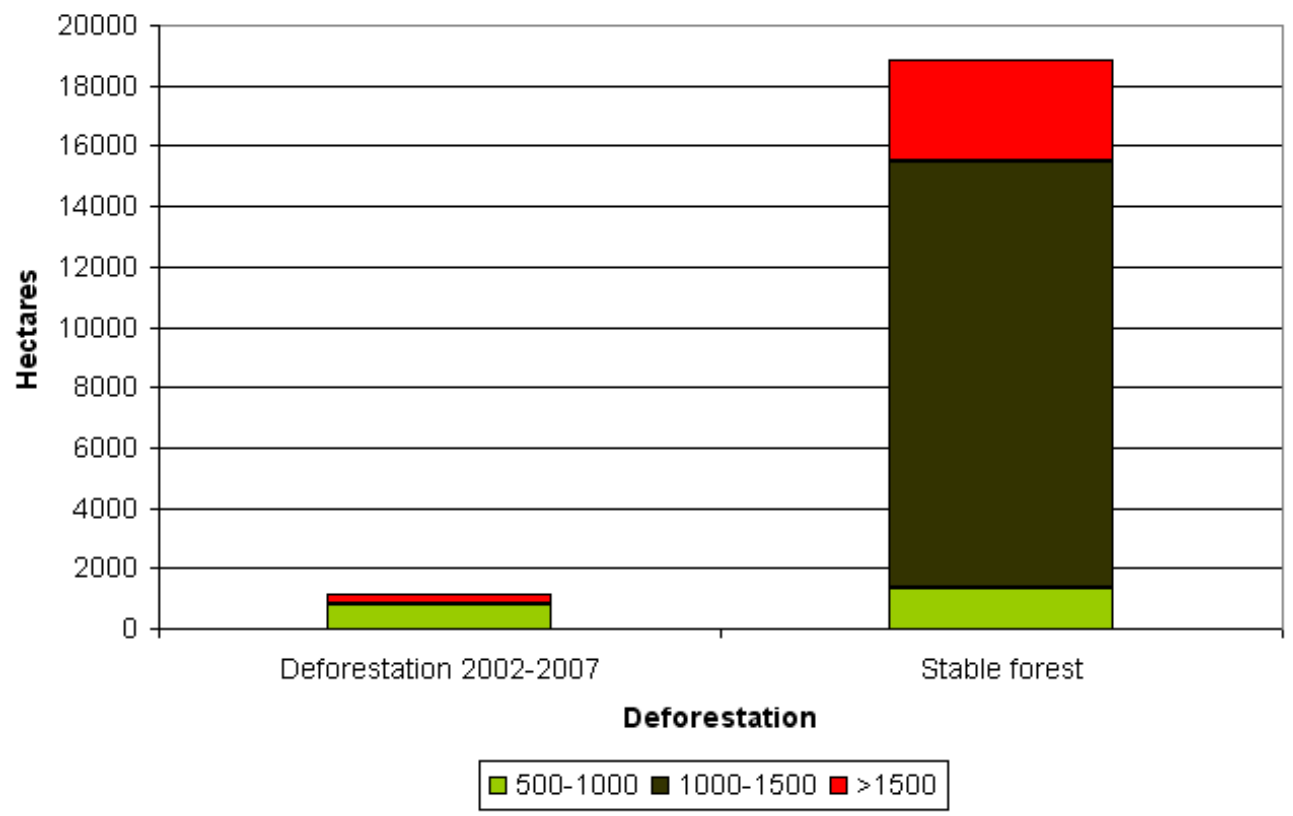

Figure 14. Forest loss (in hectares) by elevation class.

\section{Access}

Road access to the forests from Viengkham is limited, but some tracks are passable by motorbike during the dry season, otherwise farmers need to walk or build semi-permanent huts in the forested areas to extract NTFP or grow upland rice. Some major rivers are still functioning as transportation network but in most upland areas road is the main, but limited, transportation network.

\section{Protected area}

Phou Loei NBCA covers 150.000 ha (category VI according to WCMC); it was established in 1993 and is located in Phonxay and Viengkham Districts. It is a "managed resource protected area", where the conservation objective is sustainable use of its natural ecosystems. 


\section{Madagascar (Manompana) \\ Topography and current land cover and description:}

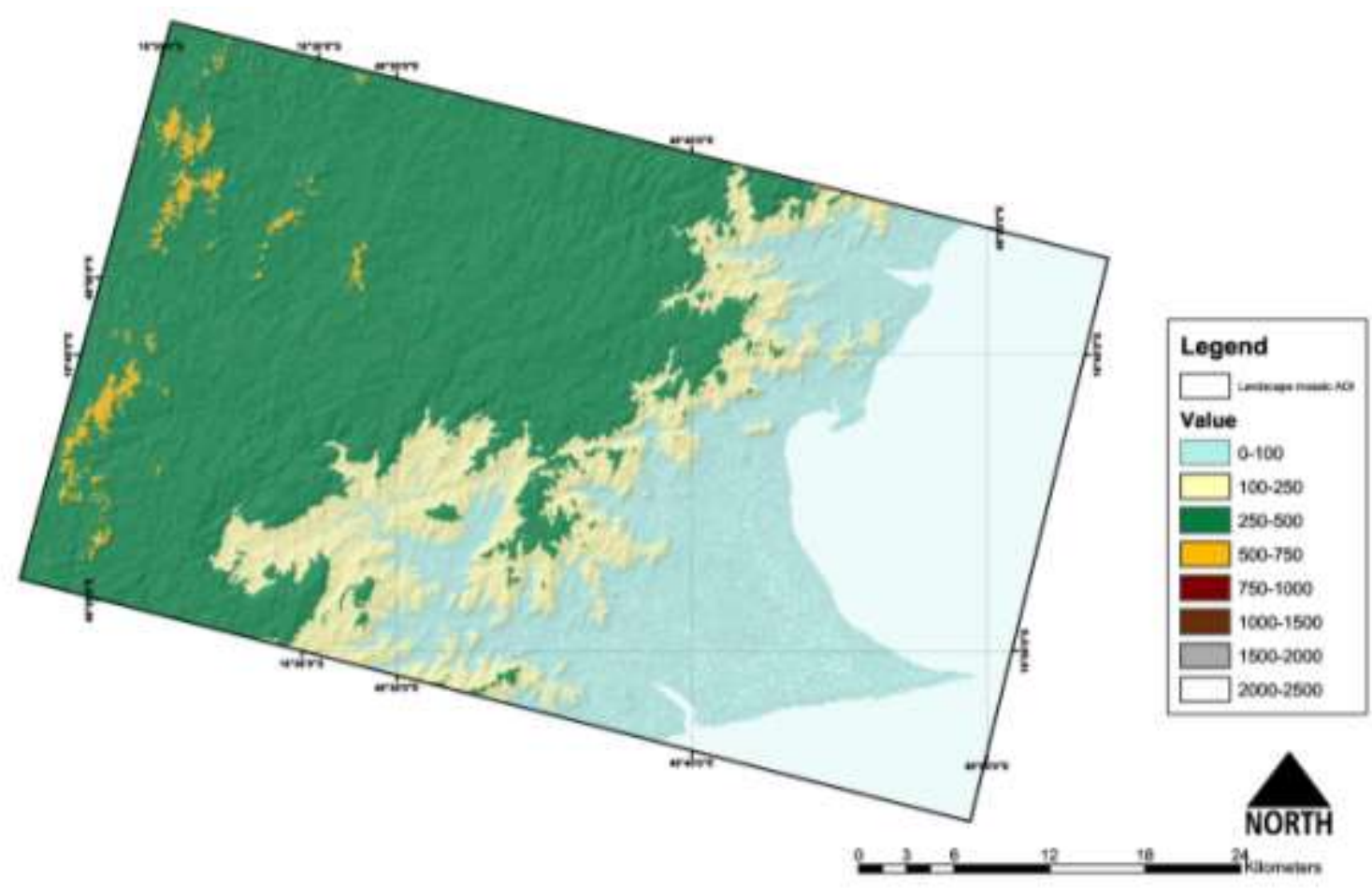

Figure 15. Elevation of Manompana site, ranges from 0 to 624 meter above sea level.

The landscape is dominated by a submontane ecosystem, with low to moderate topographic roughness, and the lowland area along the coastal zone (Figure 15). Within the landscape a little fragment of forest is found in the coastal area while most extents of forest cover are located in the hinterland. In 2005, the extent of forest cover was comparable to that of tree-based land cover and together they constitute two thirds of the landscape area (Figure 16). 


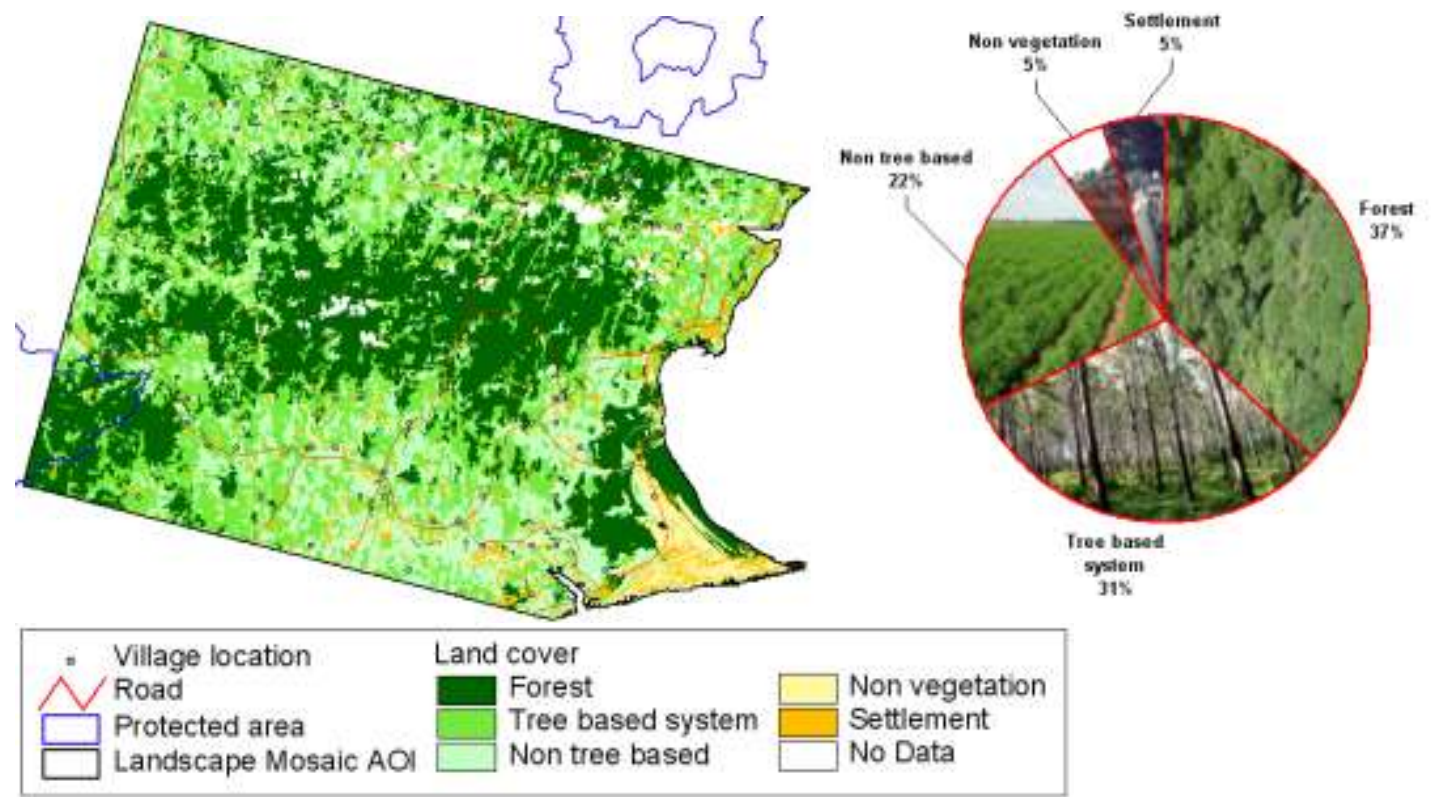

Figure 16 (a). Land cover map of Manompana site in 2005 (interpreted from SPOT 2005) (b). Landscape composition in 2005

\section{Temporal Pattern}

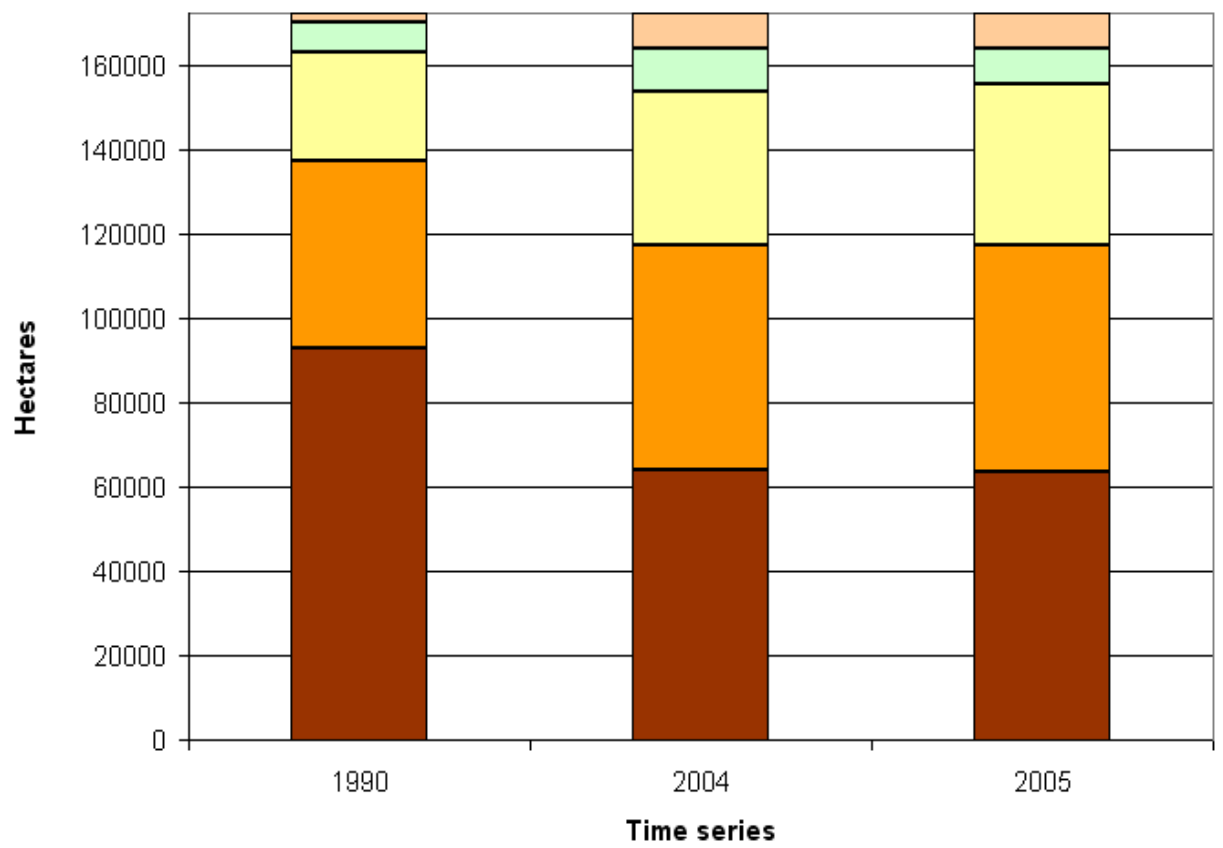

$\square$ Forest $\square$ Tree based system $\square$ Non tree based $\square$ Non vegetation $\square$ Settlement

Figure 17. Time series of land cover composition of Manompana site. 
A large extent of deforestation took place in period II and there has been little forest loss more recently (note that the observation period is only of one year). Both tree-based land cover and non-tree-based land cover increased as replacements to forest loss. It seems that while the extent of tree-based and non-tree based cover remain quite stable in the landscape (Figure 17), the location is changing (Figure 18) which indicates that shifting cultivation is actively taking place.

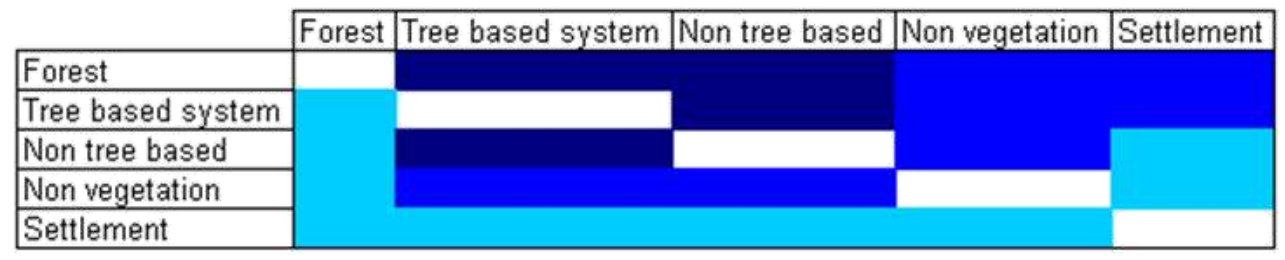

(a)

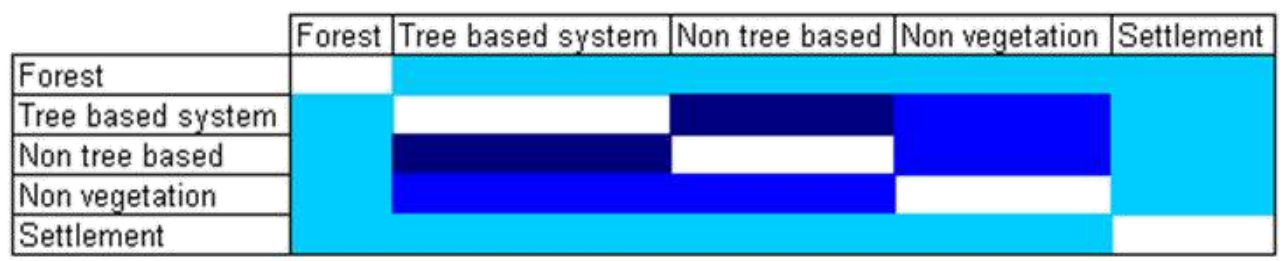

(b)

Figure 18. Pattern of changes in Manompana in Period II (1990 to 2004) (a) and Period III (2004 to 2005) (b). Darker colors indicate larger annual changes in proportion. 

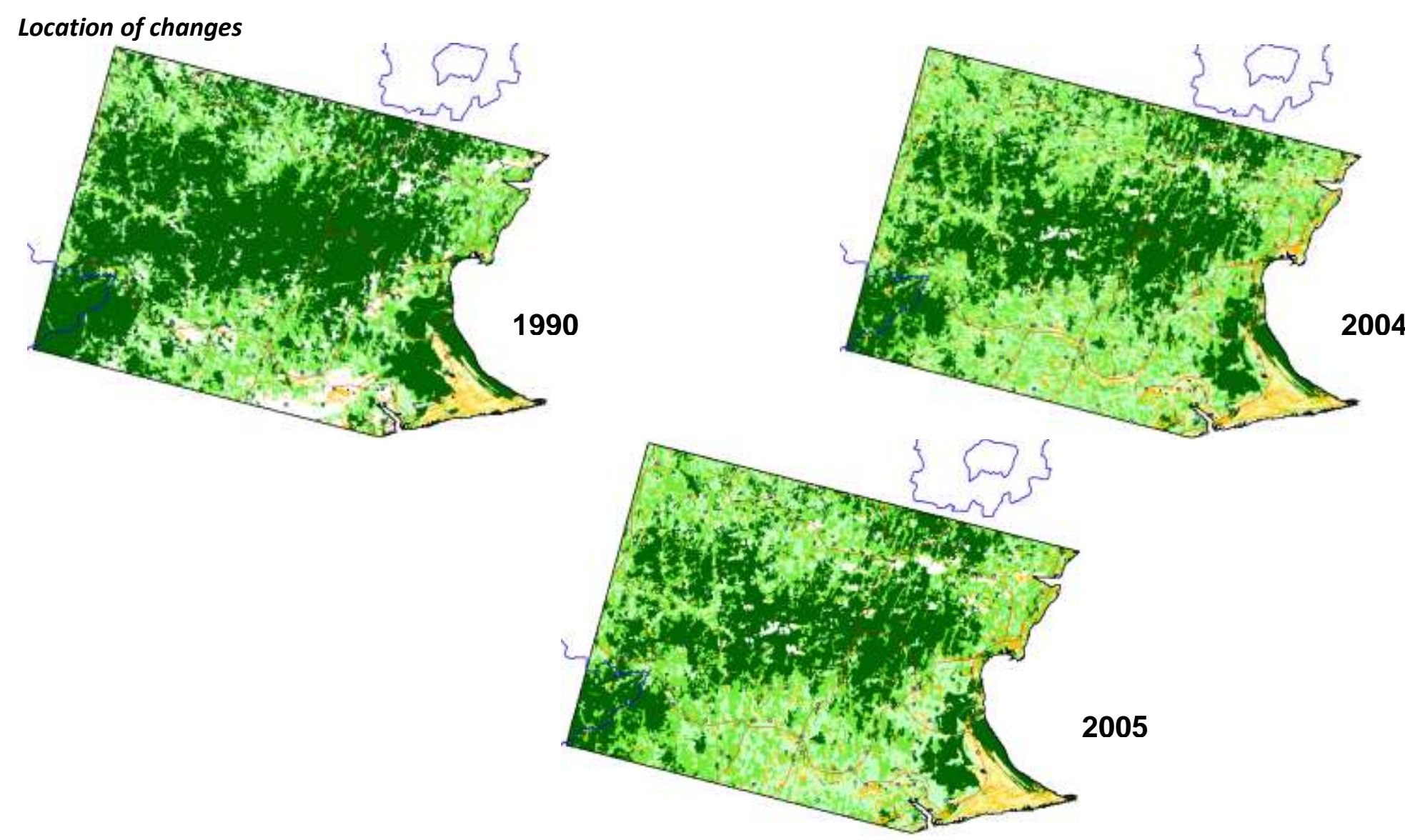

\begin{tabular}{|c|c|c|}
\hline Village & Land cover & \\
\hline$\checkmark$ Road & Forest & Non vegetation \\
\hline Protected area & Tree based system & $\begin{array}{l}\text { Settlement } \\
\text { No Data }\end{array}$ \\
\hline Landscape Mosaic AOI & & \\
\hline
\end{tabular}

Figure 19. Time series of land cover map of Manompana site. 


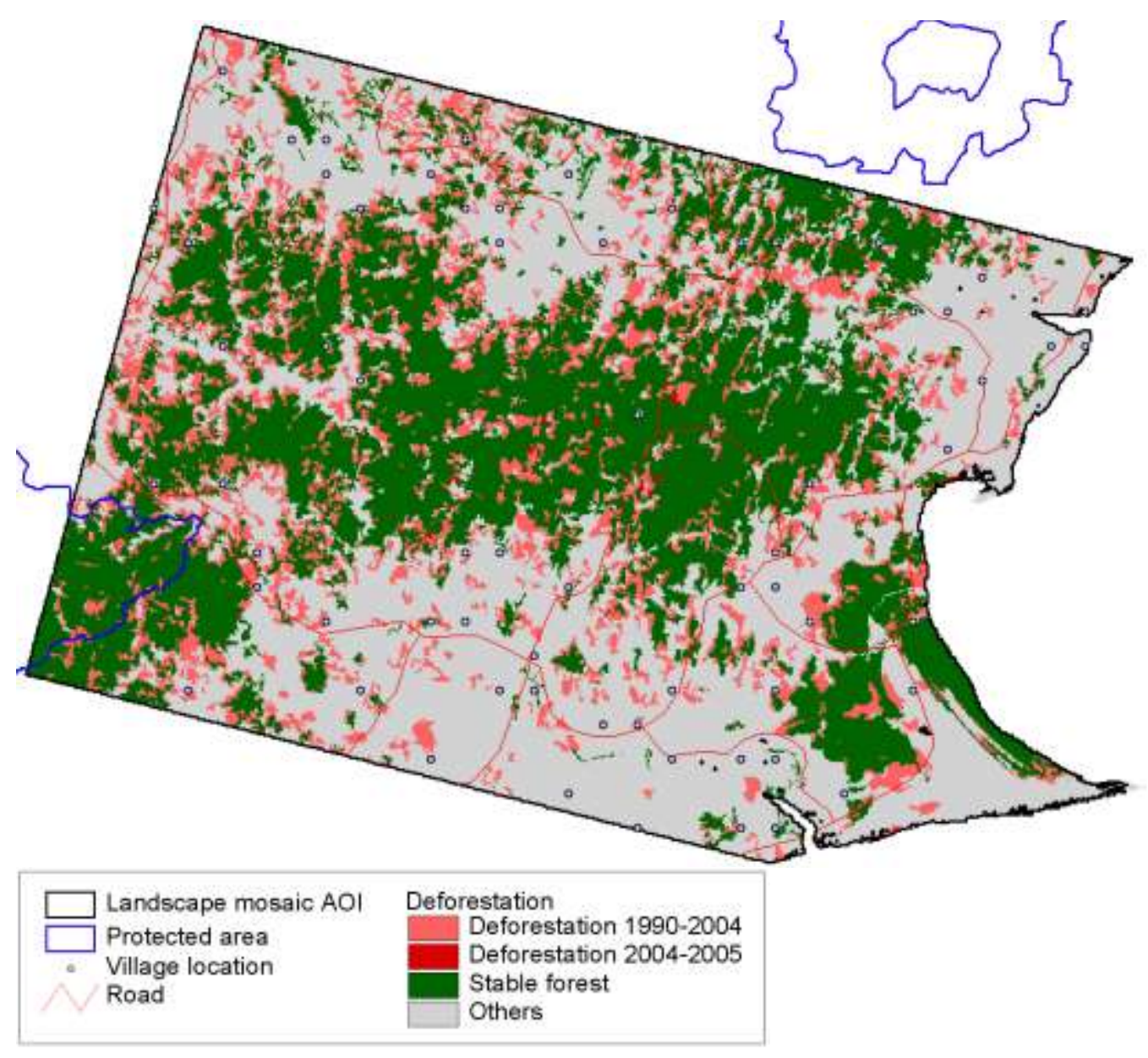

Figure 20. Location of deforestation in Manompana site.

Figure 19 and 20 shows that forest loss mostly happened as encroachment from the edges of primary forest blocks during 1990 to 2004 . However in the primary forest block in the centre of the landscape, some forest loss started from the middle of the block and then expanded from there.

\section{Drivers}

\section{Agents}

Inherent differences between coastal population and population of the hinterland are very important. The traditional hinterland economy is based on the production of upland rice for subsistence while coastal areas take advantage of better access to markets for cash crops (cloves, vanilla, coffee, etc.), fish and other sea products. Slash-and-burn practices for upland rice or cash crops is the dominant land use systems and believed to be the threat to the remaining forest. The national level estimation in 2003 suggested that $60 \%$ of the commercialized wood came from 
illegal logging. How this figure manifested within this particular landscape in Manompana is yet to be further explored.

Fallow system is a dominant land use systems in Manompana. Most deforestation is believed to be driven by this agricultural expansion. Around the village, home gardens of banana, papaya and other fruit trees are commonly managed in mixed agroforestry system while commodities like coffee, cloves and vanilla are planted as monoculture (Pfund et al., 2010).

\section{Topography}

Figure 21 shows that most of the forest loss in each of the elevation class is comparable to the existing forest, which suggest that there is no particular tendency that forest loss is associated with topography.

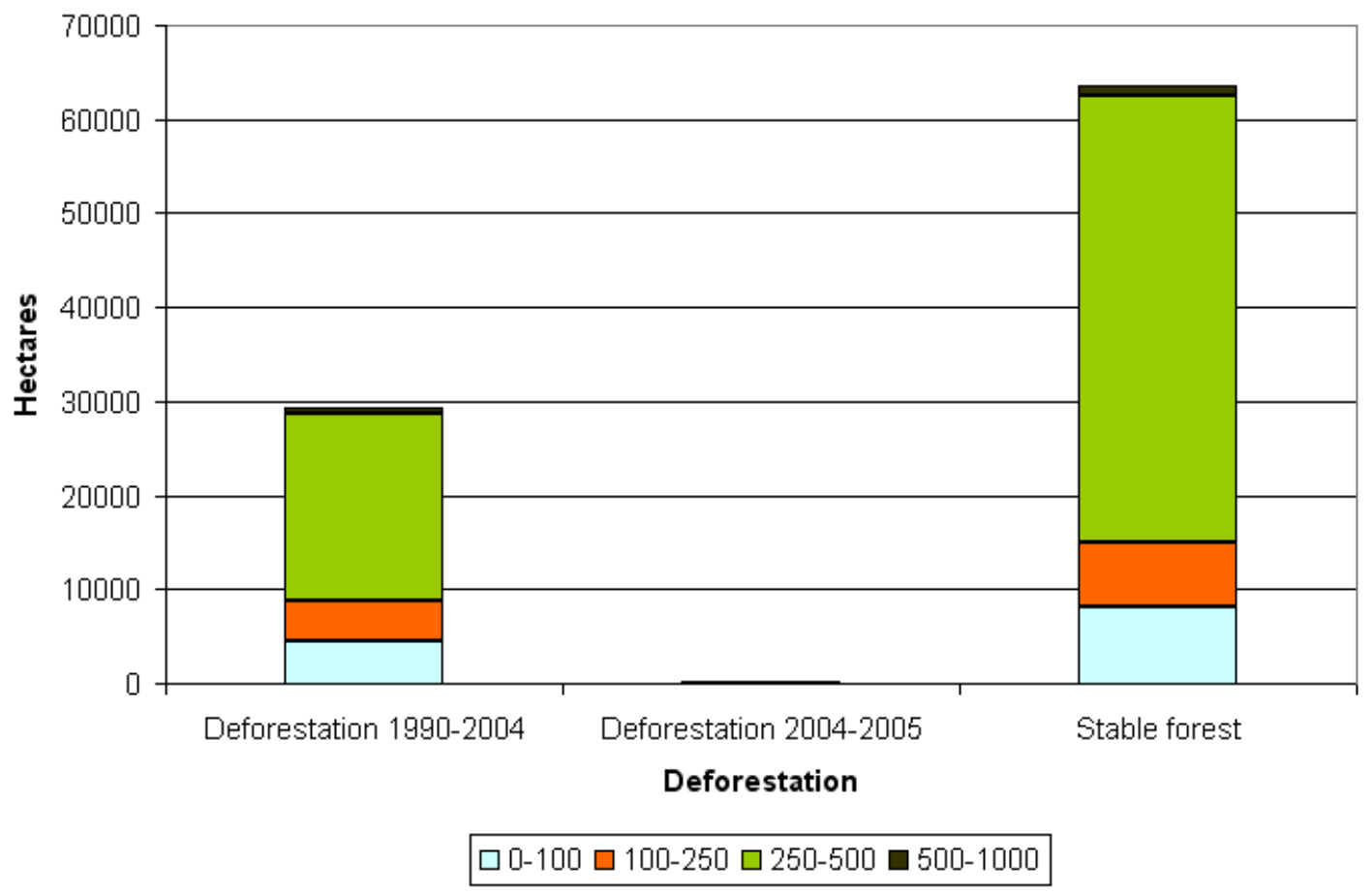

Figure 21. Forest loss (in hectares) in each period by elevation class.

\section{Access}

Even though road network is very limited, population seems to be well distributed in the landscape, including in the big forest blocks. Some river network has been functioning as transportation means but generally people use walking paths to travel from place to place. 
Cameroon (Takamanda Mone)

Topography and current land cover and description

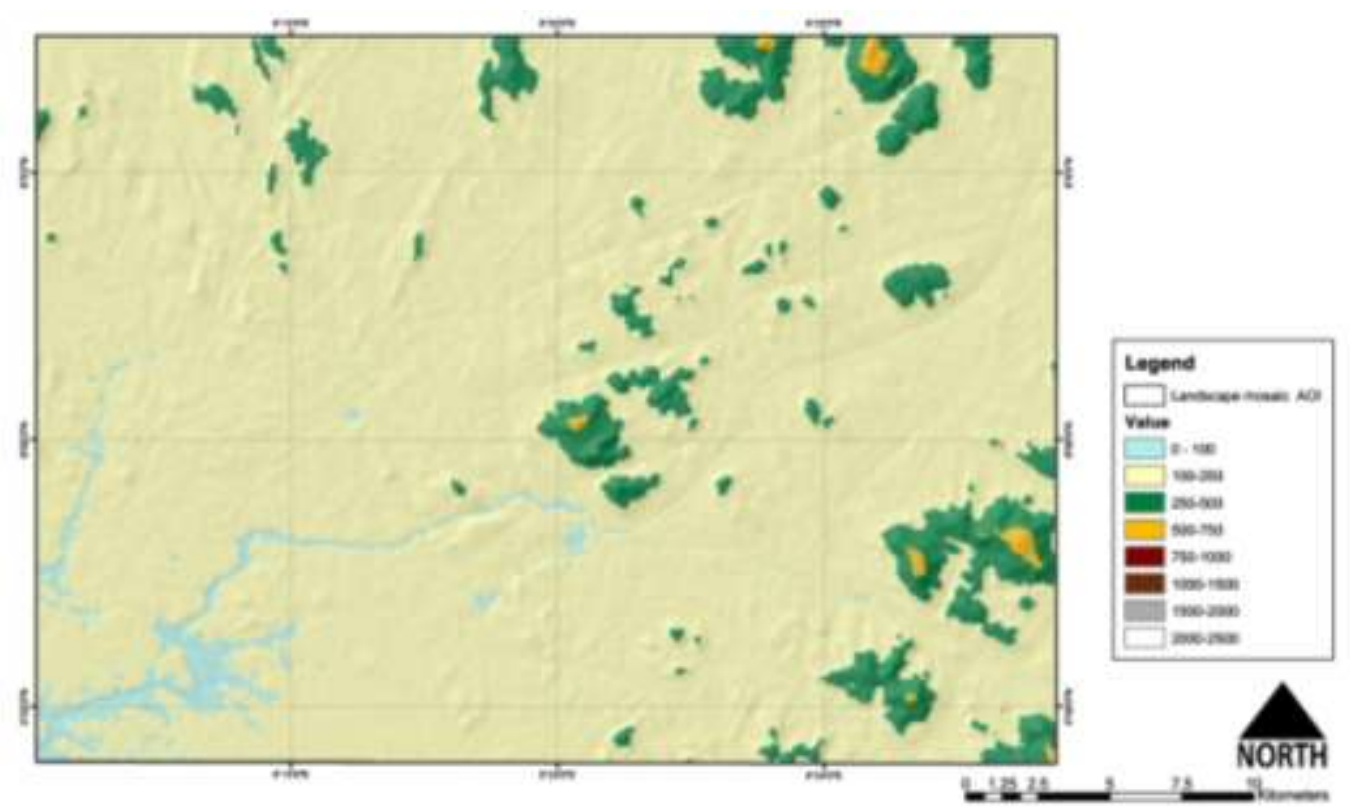

Figure 22. Elevation of Takamanda Mone site, ranges from 0 to 650 meter above sea level

The study site of Takamanda-Mone is quite flat and dominated mostly by lowland (Figure 22). Several islands of submontane and montane areas can be found in the landscape but the extents are small. River networks well cover the landscape.
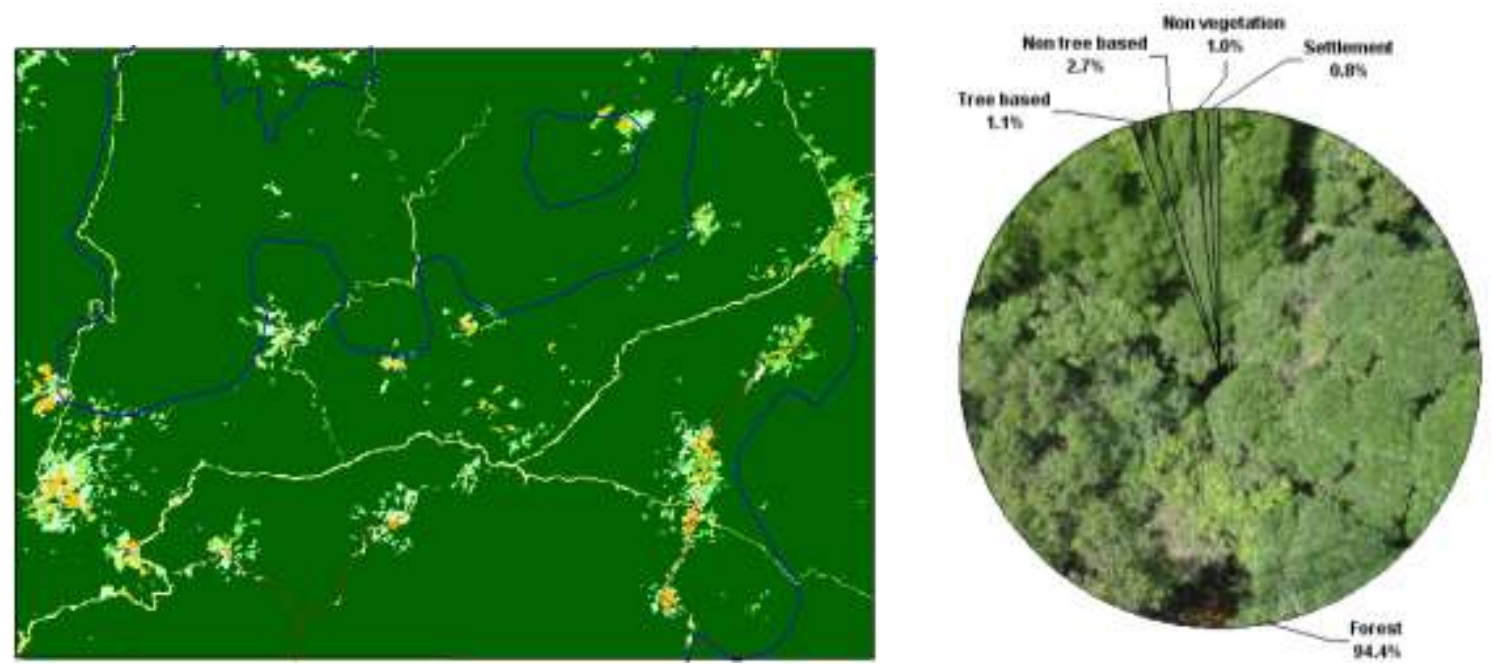

\begin{tabular}{|c|c|c|}
\hline Villag & Land cover & \\
\hline$\checkmark$ Road & Forest & Non vegetation \\
\hline Protected area & $\begin{array}{l}\text { Tree based system } \\
\text { Non tree based }\end{array}$ & $\begin{array}{l}\text { Settlement } \\
\text { No Data }\end{array}$ \\
\hline Landscape Mosaic AOI & & \\
\hline
\end{tabular}

Figure 22 (a). Land cover map of Takamanda Mone site in 2006 (interpreted from Landsat 2006) (b). Landscape composition in 2005 
In 2006, Takamanda Mone was highly dominated by forest (94.4\%), with some settlements found along the rivers and surrounded by some other land covers (Figure 22). Most of the areas are under protected status.

\section{Temporal Pattern}

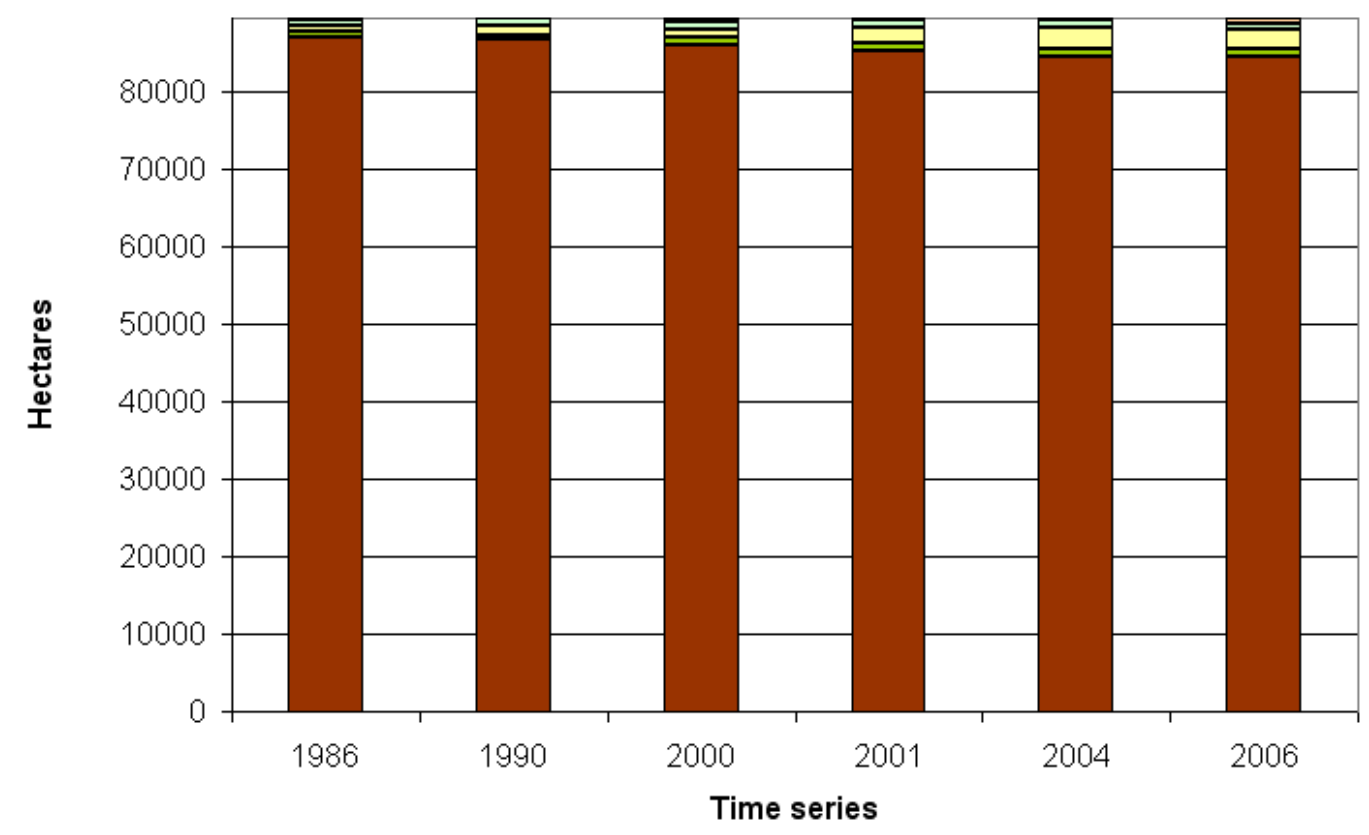

Forest $\square$ Tree based $\square$ Non tree based $\square$ Non vegetation $\square$ Settlement

Figure 23. Time series of land cover composition of Takamanda Mone site.

Within the time series, forest loss has been quite small in extent, compared to other sites. The increase of non-tree based cover is quite marked in the most recent years (Figure 23). Another pattern to note that has happened lately is the increase of area of settlement (Figure 24). This perhaps indicates either population increases (due to in-migration) or re-settlement. Interchanges from tree-based to non-tree based cover and vice versa is also high. 


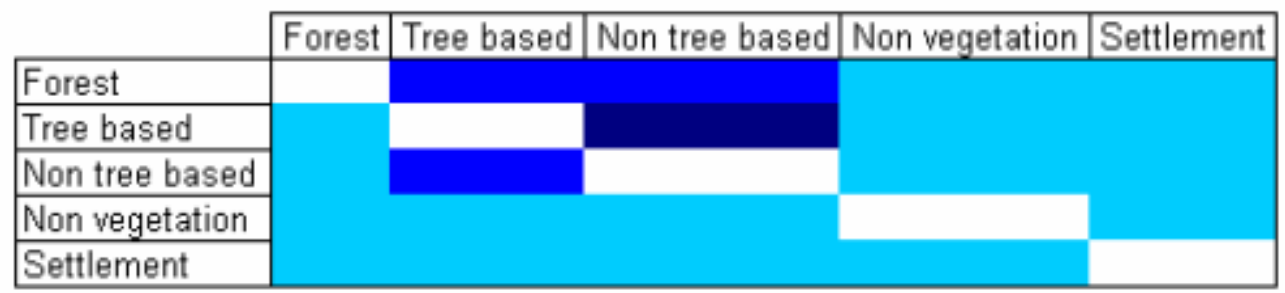

(a)

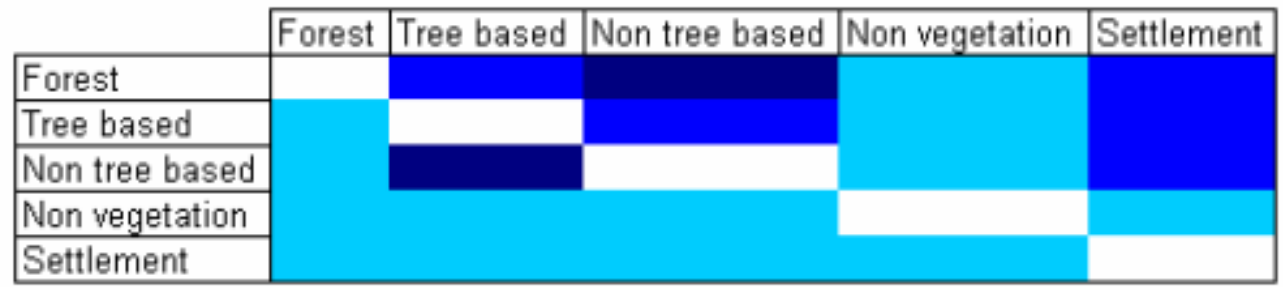

(b)

\begin{tabular}{|c|c|c|c|c|}
\hline \multirow{2}{*}{ Forest } & Forest & \begin{tabular}{|l|l} 
Tree based & Non tree based \\
\end{tabular} & Non vegetation & Settlement \\
\hline & & & & \\
\hline Tree based & & & & \\
\hline Non tree based & & & & \\
\hline Non vegetation & & & & \\
\hline Settlement & & & & \\
\hline
\end{tabular}

(c)

Figure 24. Pattern of changes in Takamanda Mone for 3 study periods (a). Period I (1986-1990) (b).Period II (1990-2000) and (c). Period III (2000-2005). Darker colors indicate larger annual changes in proportion. 


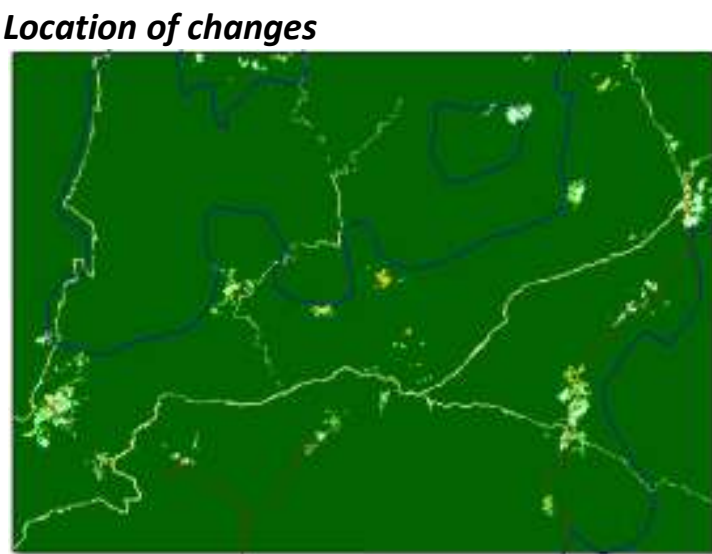

1986

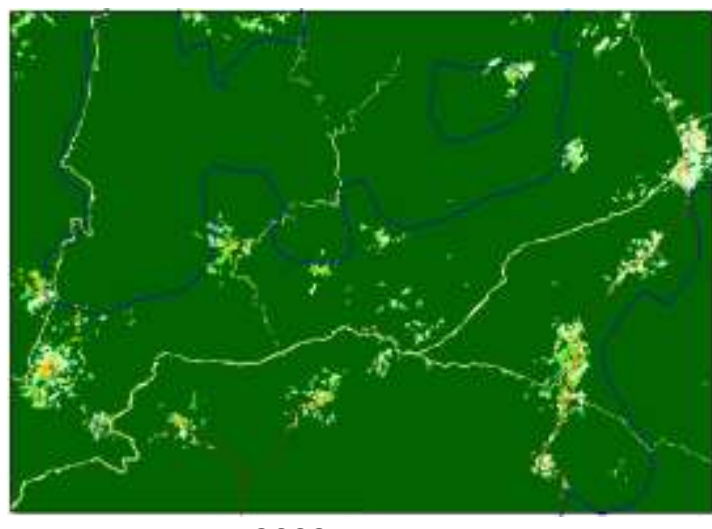

2002

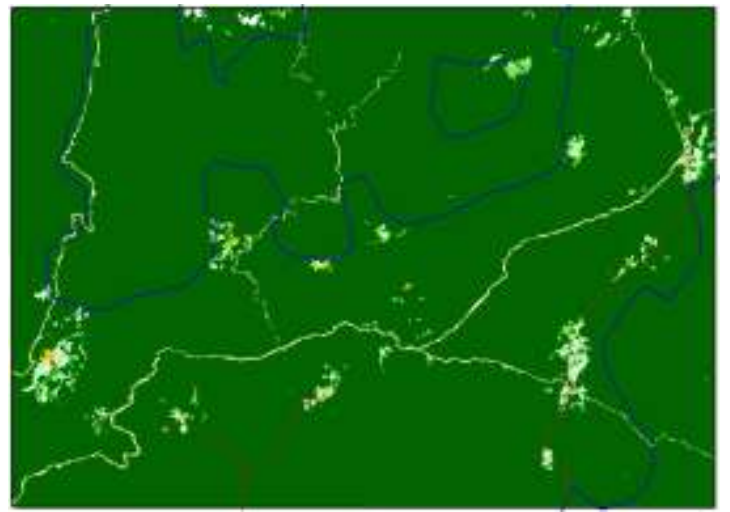

1990

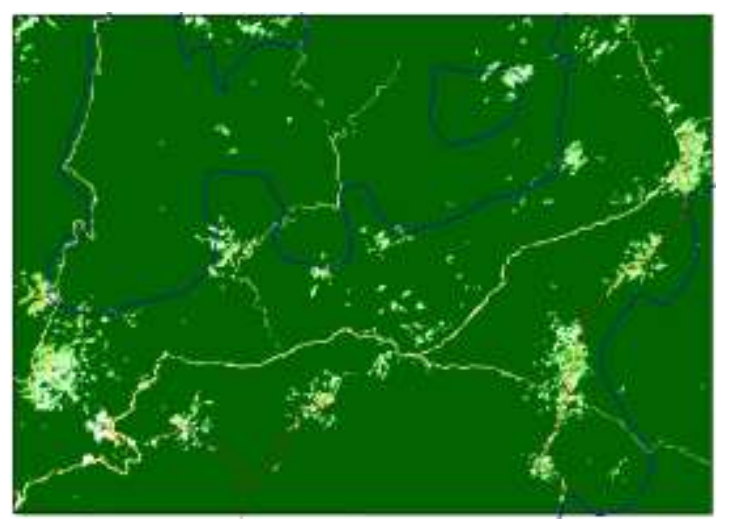

2004

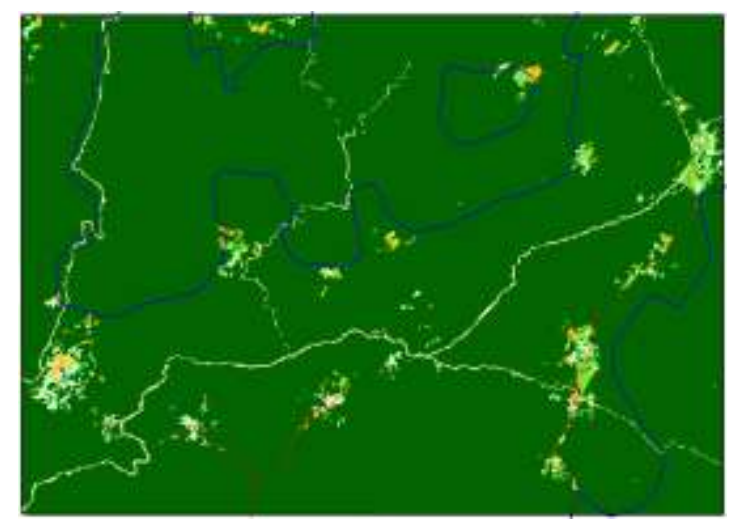

2001

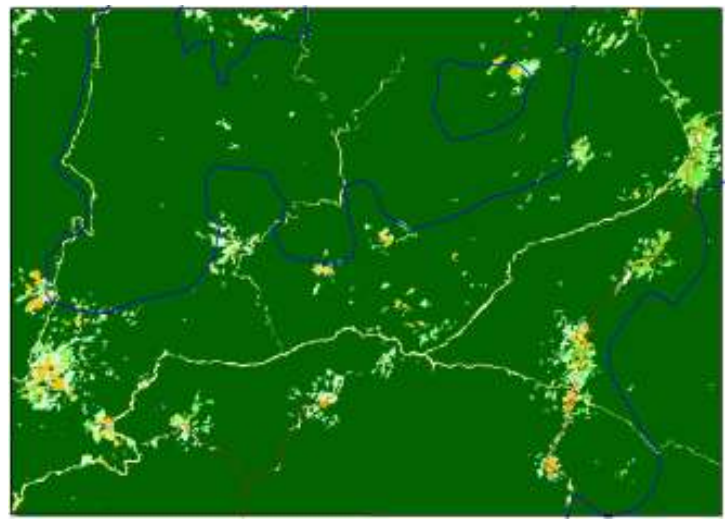

2005

\begin{tabular}{|c|c|c|}
\hline Village location & Land cover & \\
\hline & Forest & Non vegetation \\
\hline $\begin{array}{l}\text { Protected area } \\
\text { Landscape Mosaic AOI }\end{array}$ & Tree based system & Settlement \\
\hline Landscape Mosaic ACI & Thon tree Dased & \\
\hline
\end{tabular}

Figure 25. Time series of land cover map of Takamanda Mone site. 
Figure 25 shows that most of the deforestation patterns follow the river and road networks. Over time the settlements that started earlier expand further into the forest. This indicates that smallholder farmers are the dominant agent in the landscape.

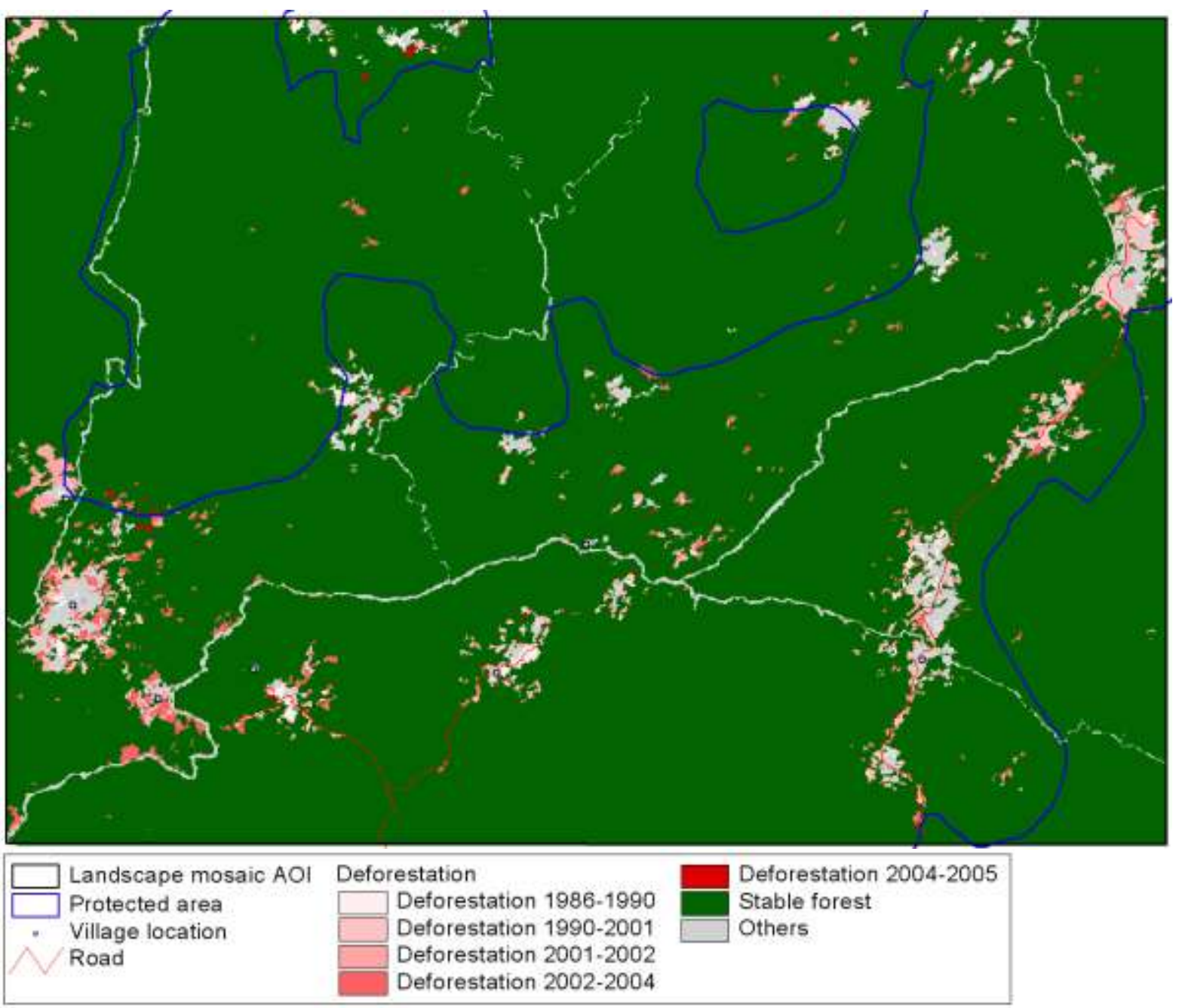

Figure 26. Location of deforestation in Takamanda Mone site. 


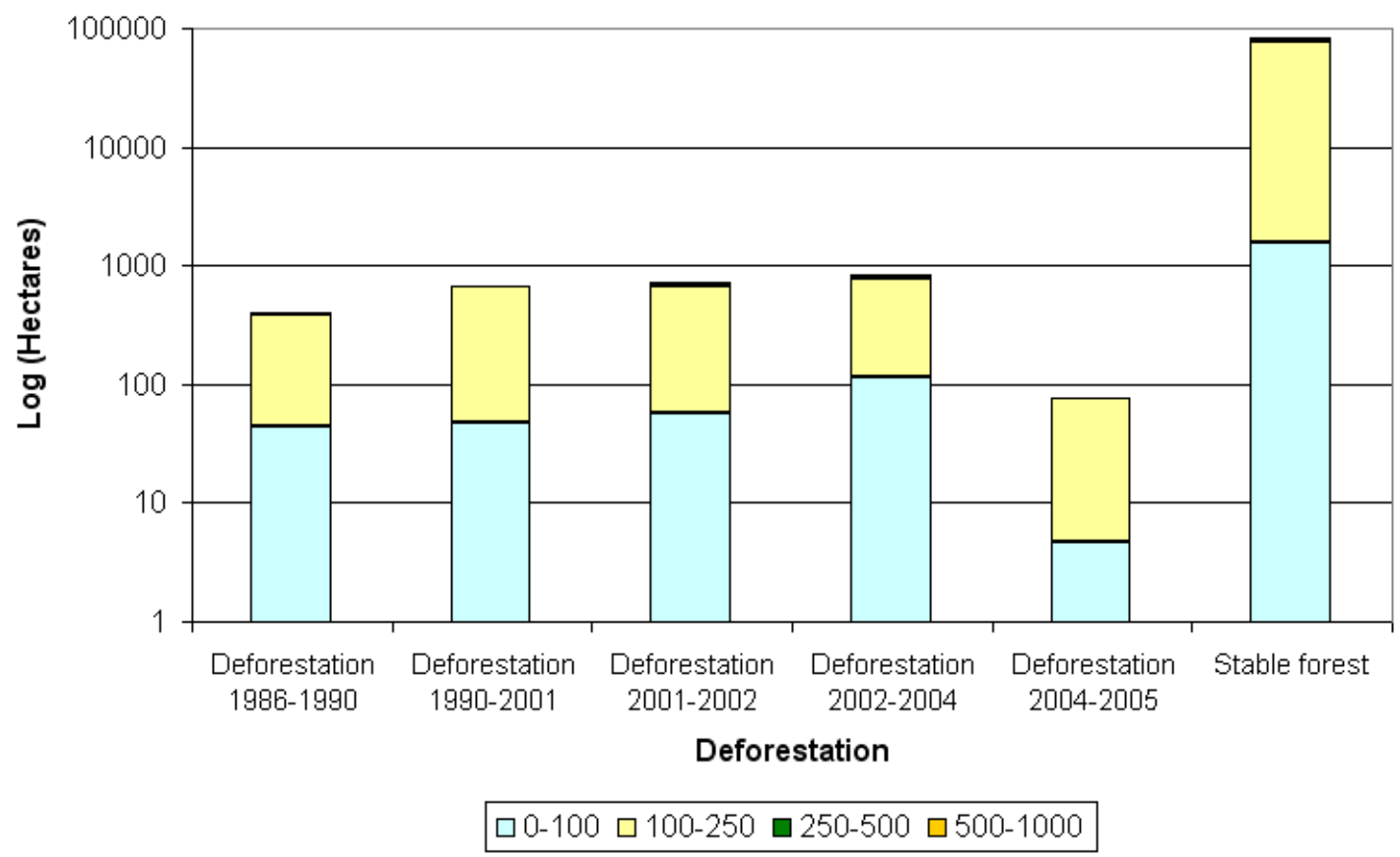

Figure 27. Forest loss over time by elevation class

Whilst the earlier period showed comparable forest loss in the lower and moderate elevation class in relation to the existing forest, the most recent forest loss revealed a new pattern: forest loss in elevations of 100-250 $\mathrm{m}$ is higher compared to those in the lower altitude (Figure 27). Population growth, either naturally or by resettlement, in tandem with new road construction can be the explanation of this pattern.

In this landscape, logging is active, but since forests are not differentiated in terms of density, i.e., between dense and degraded or logged-over forest, selected loggings are not detectable. Fallows are not identified as part of a cultivation cycle. Cultivation of cocoa, mixed with banana and plantains, along the road have increased recently due to market access. Small-scale oil palm plantations have been introduced and developed in the secondary forests as well tree plantings such as bush mango (Irvingia wombolo), bitter cola (Garcinia cola), and njansang (Ricinodendron heudelotii) which provide substantial income to farmers (Pfund et al, 2010). 


\section{Tanzania (East Usambara)}

\section{Topography and current land cover and description}

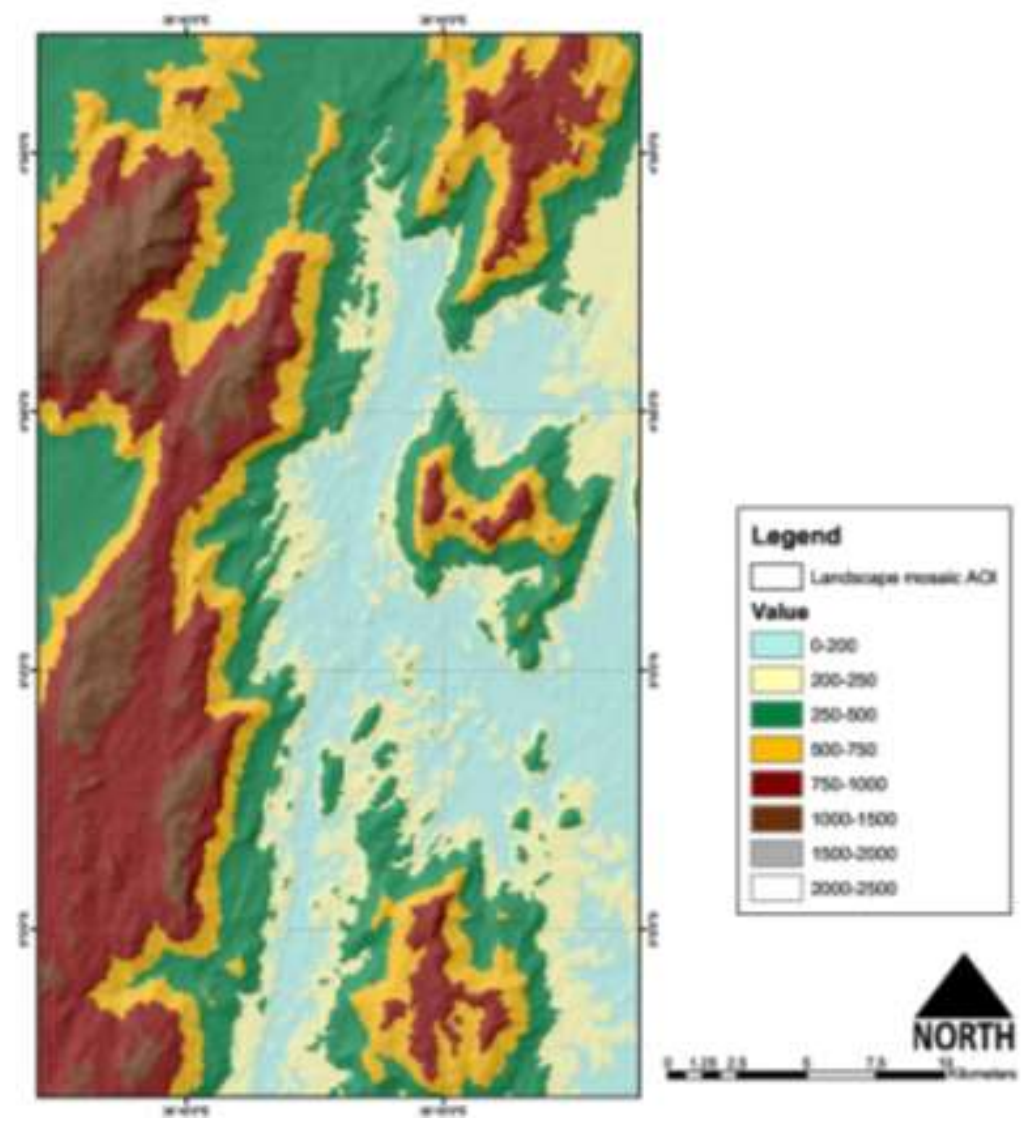

Figure 28. Elevation of East Usambara site, ranges from 100 -1500 meter above sea level

The landscape of East Usambara is the second highest and roughest in terms of topography among the five sites. In terms of topography, the landscape consists of one big island of montane ecosystems and 3 other smaller islands, 2 of them are disconnected from the biggest island (Figure 28).

In 2007, three quarters of the landscape was covered by forest and tree-based systems of comparable proportion. Compared to the other sites, forest cover in East Usambara landscapes is the most scattered and fragmented. The shape of forest patches is also complex with long edges compared to their areas. Forest patches are found mostly in montane and sub-montane, and to some lower extent in the lowland area. 

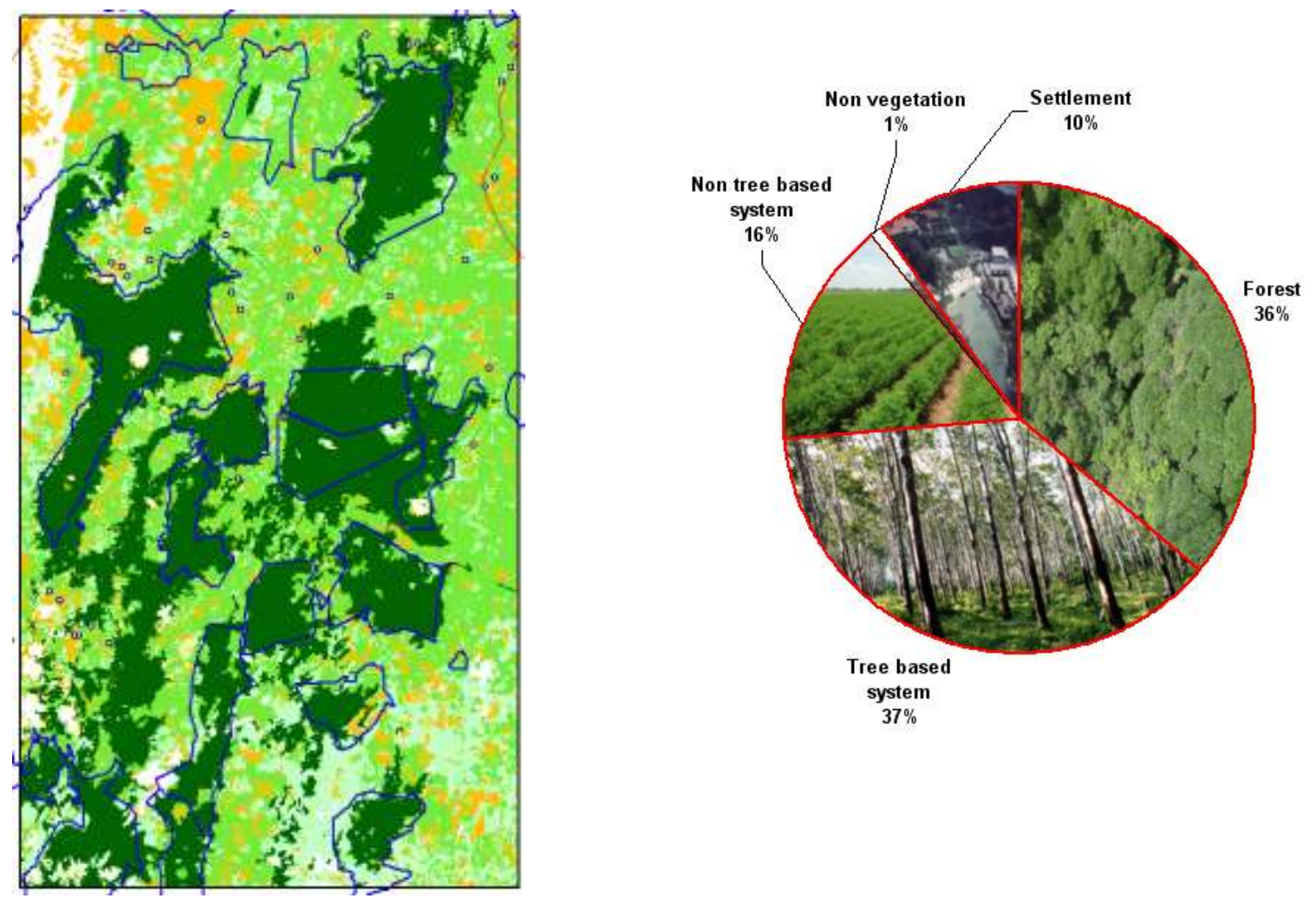

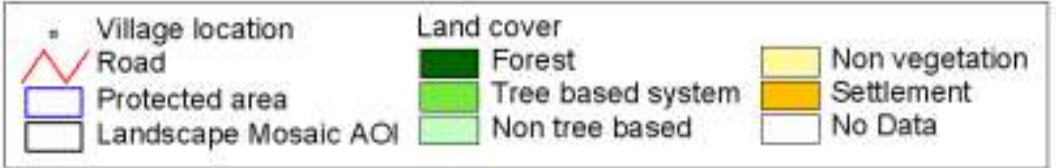

Figure 29 (a). Land cover map of East Usambara site in 2007 (interpreted from SPOT 2007) (b).Landscape composition in 2007

\section{Temporal Pattern}

Forest continues to decline over time. Proportion between tree-based and non-tree based cover interchanges over time, whilst settlement areas show steady increases in size. Most recently treebased cover dominates the landscape. 


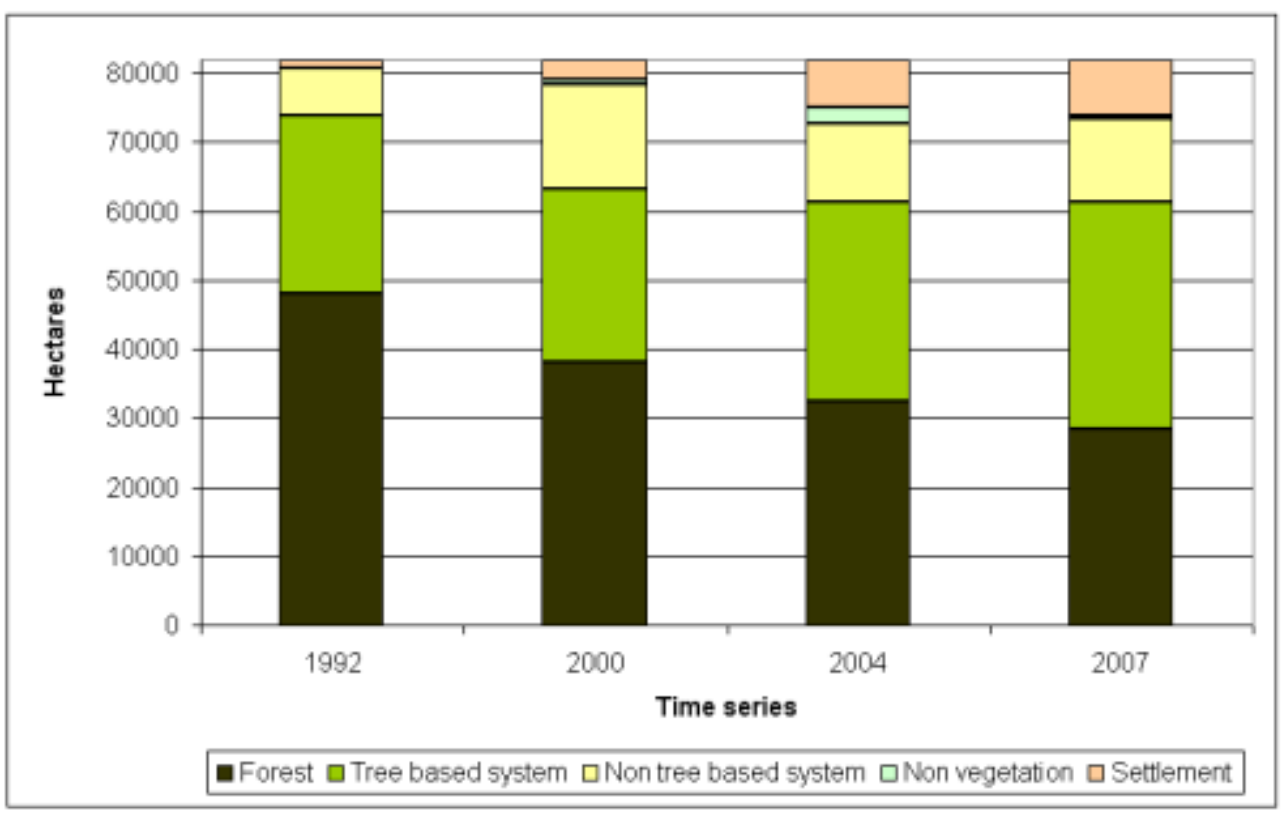

Figure 30. Time series of land cover composition of East Usambara site.

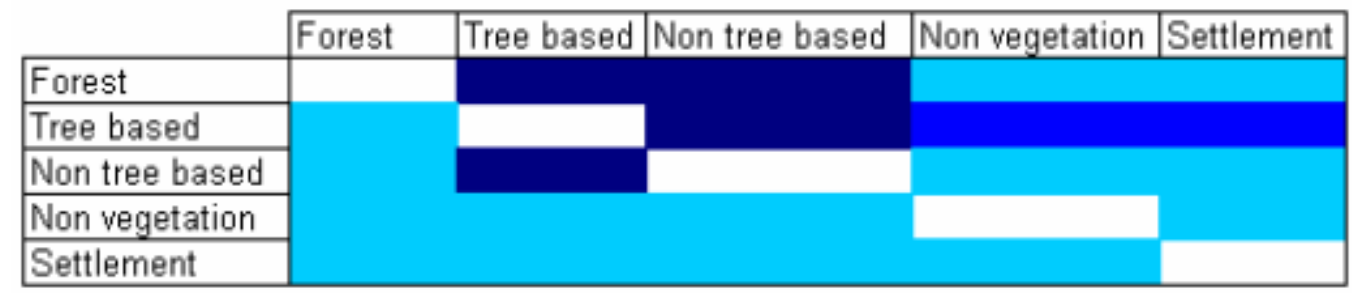

(a)

\begin{tabular}{|c|c|c|c|c|}
\hline & Forest & \begin{tabular}{|l|l|} 
Tree based & Non tree based \\
\end{tabular} & Non vegetation & Settlement \\
\hline Forest & & & & \\
\hline Tree based & & & & \\
\hline Non tree based & & & & \\
\hline Non vegetation & & & & \\
\hline Settlement & & & & \\
\hline
\end{tabular}

(b)

Figure 31. Pattern of changes in East Usambara for 2 study periods (a). Period II (1992-2000) (b). Period III (2000-2007). Darker colors indicate larger annual changes in proportion.

\section{Location of changes}

Figure 32 shows that forest fragmentation started in 1992 and increases over time; deforestation pattern over time is in the form of encroachment from the long edges of the forest core (Figure $33)$. 


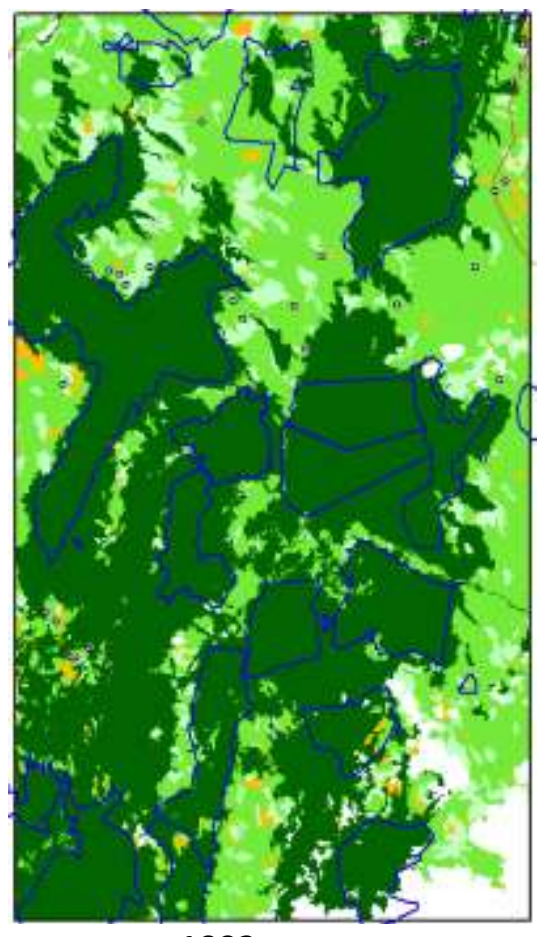

1992

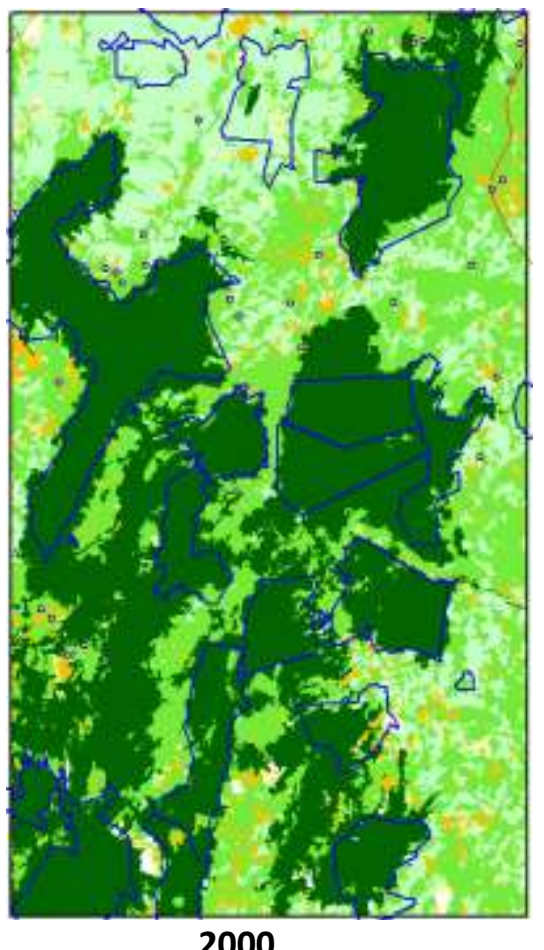

2000

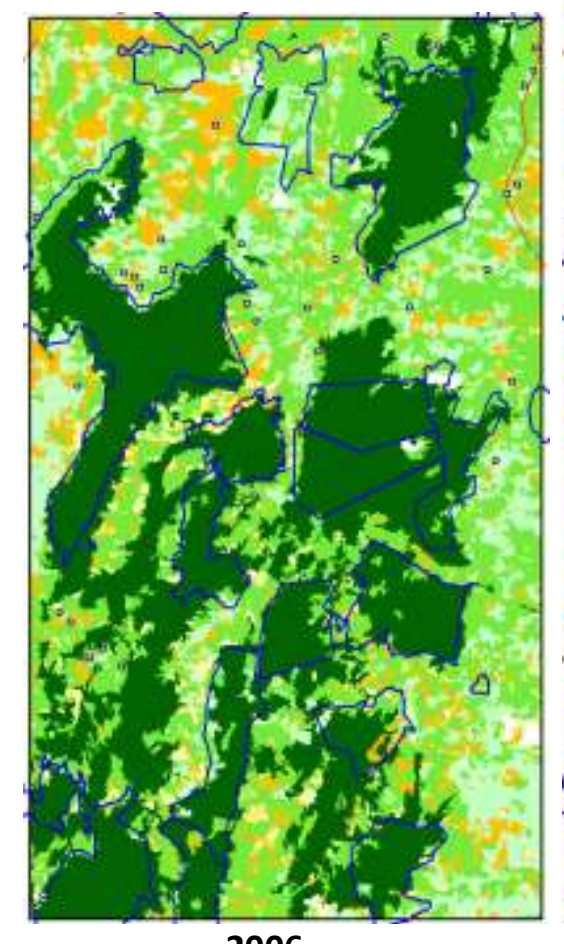

2006

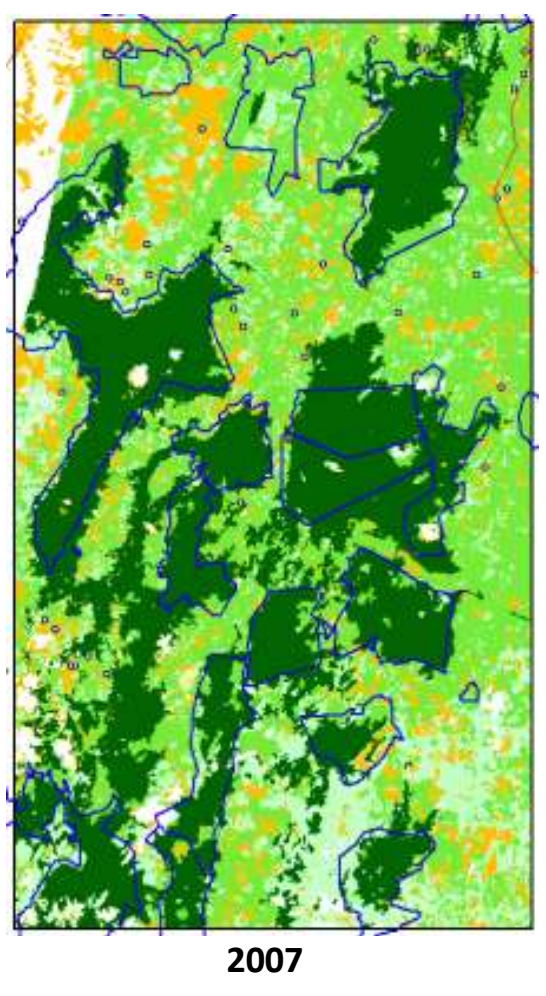

\begin{tabular}{|c|c|c|}
\hline \multirow{4}{*}{$\begin{array}{l}\text { Village location } \\
\text { Road } \\
\text { Protected area } \\
\text { Landscape Mosaic AOI }\end{array}$} & \multirow[b]{3}{*}{$\mathrm{m}$} & \multirow{4}{*}{$\begin{array}{l}\text { Non vegetation } \\
\text { Settlement } \\
\text { No Data }\end{array}$} \\
\hline & & \\
\hline & & \\
\hline & & \\
\hline
\end{tabular}

Figure 32. Time series of land cover map of East Usambara site. 


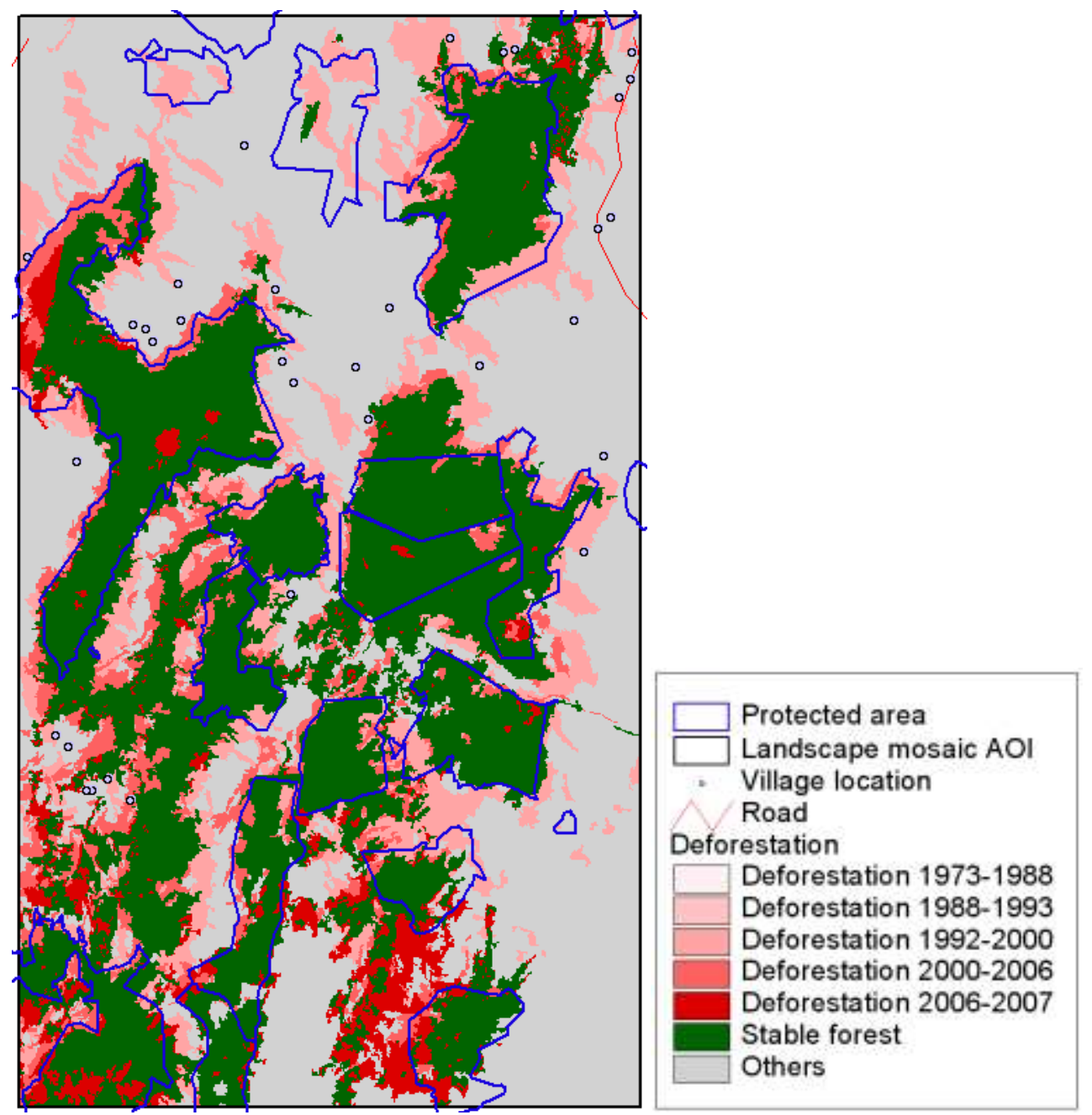

Figure 33. Location of deforestation in East Usambara site.

\section{Drivers}

\section{Agents}

Some remnant forest can be found on village land and available for conversion to farmland through village land allocation systems. The pattern of farmer managed land is dynamic: in both submontane and lowland forests, cash crops (mainly cardamom) are first cultivated under forest, followed by the gradual clearing of the agroforestry systems for more open cultivations of maize and beans, and finally cassava and sugar cane as land fertility is exhausted. Small-scale farming consists of rotational and continuous cultivation of food and cash crops, whereas commercial estate farming focuses on tea, sisal and cocoa. Tea plantations are perceived to be expanding in the highland areas. In a survey of 1995 , forests constituted about $50 \%$ of the total land use in the area compared to $43 \%$ agricultural land, but the ratio has been estimated to be changing rapidly as more forest is being cleared. 
During the past decades, other groups have migrated into the area, attracted by the favourable climatic conditions and job opportunities in the tea plantations. The population is rapidly growing at the annual rate of $2.2 \%$ (2001). The majority of the population belongs to the poor segment of smallholder farmers and tea estate workers.

Outside the protected areas forest loss continues rapidly for agricultural conversion due to increasing population pressure. People see the remaining forest as their future agricultural land and resist government efforts to gazette new protected areas to increase connectivity between remnant forest patches. Some advance has been made in the establishment of community managed Village Forest Reserves, since people are now increasingly dependent on the remaining forest in reserves for medicinal plants, fuel wood and building materials, as well as services such as a regular water supply. Fire is a major threat to forests both outside and inside the reserves due to burning of adjacent fields. Since 2004, a new threat to the forests and water reserves has emerged in the form of a considerable increase in small-scale mining. Also the impact of a growing industrial demand for firewood (tea curing) is becoming more significant, and new forest areas are cleared for fuel wood without a strategy for regeneration.

\section{Topography}

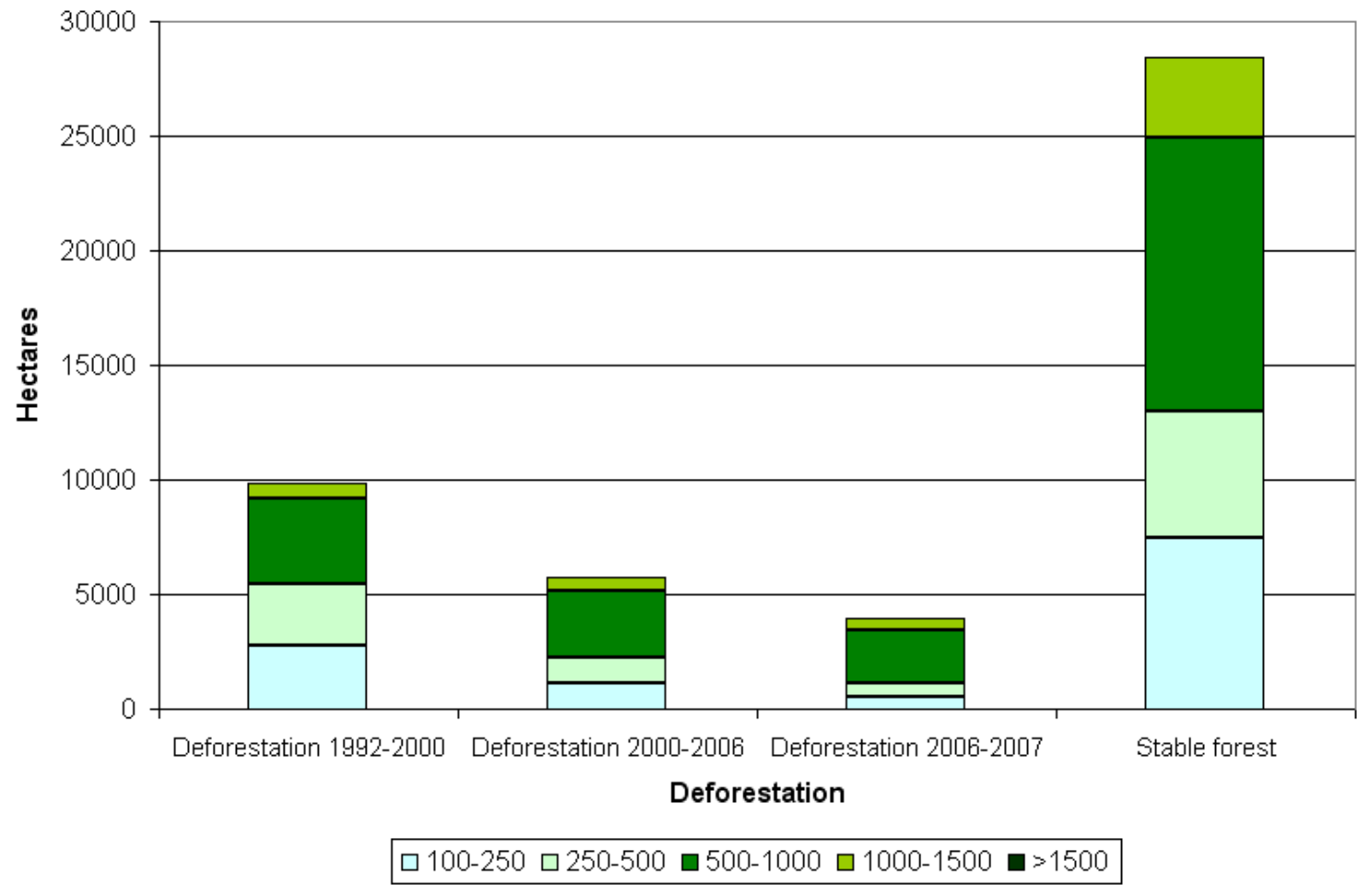

Figure 34. Forest loss over time by elevation class

Figure 34 shows that forest loss was quite well spread in terms of elevation in the earlier period and then growing more towards higher elevation of 500-1000 recently. 


\section{Protected area}

Protected forest area is about 33,000 ha or $75 \%$ of the total forest area (1995). Most of the remaining forests are found in the 18 Catchment Forest Reserves and the Amani Nature Reserve in the southern part of the East Usambaras which is the largest continuous forest area (8,300 ha) along with the Nilo Forest Reserve in the northern part of the East Usambara highlands.

\section{Forest Transition and spatial pattern of deforestation}

Forest transition theory was first coined by Mather (1992) to describe process of transitioning of forest at the country level, which starts from continuous declines of natural forest up to a certain point where 'forest' cover increases in different forms either due to demands for forest products, or to the abandonment of agricultural land of low intensification over other income generation, presumably non land-based activities. We use forest transition curve to capture varying stages of forest transition in the five landscapes based on the forest cover (Figure 35),, forest dynamics, forest fragmentation, the pattern of changes and the drivers, in order to help us compare and understand the dynamics, and to look for different options for interventions that are suitable for each sites.

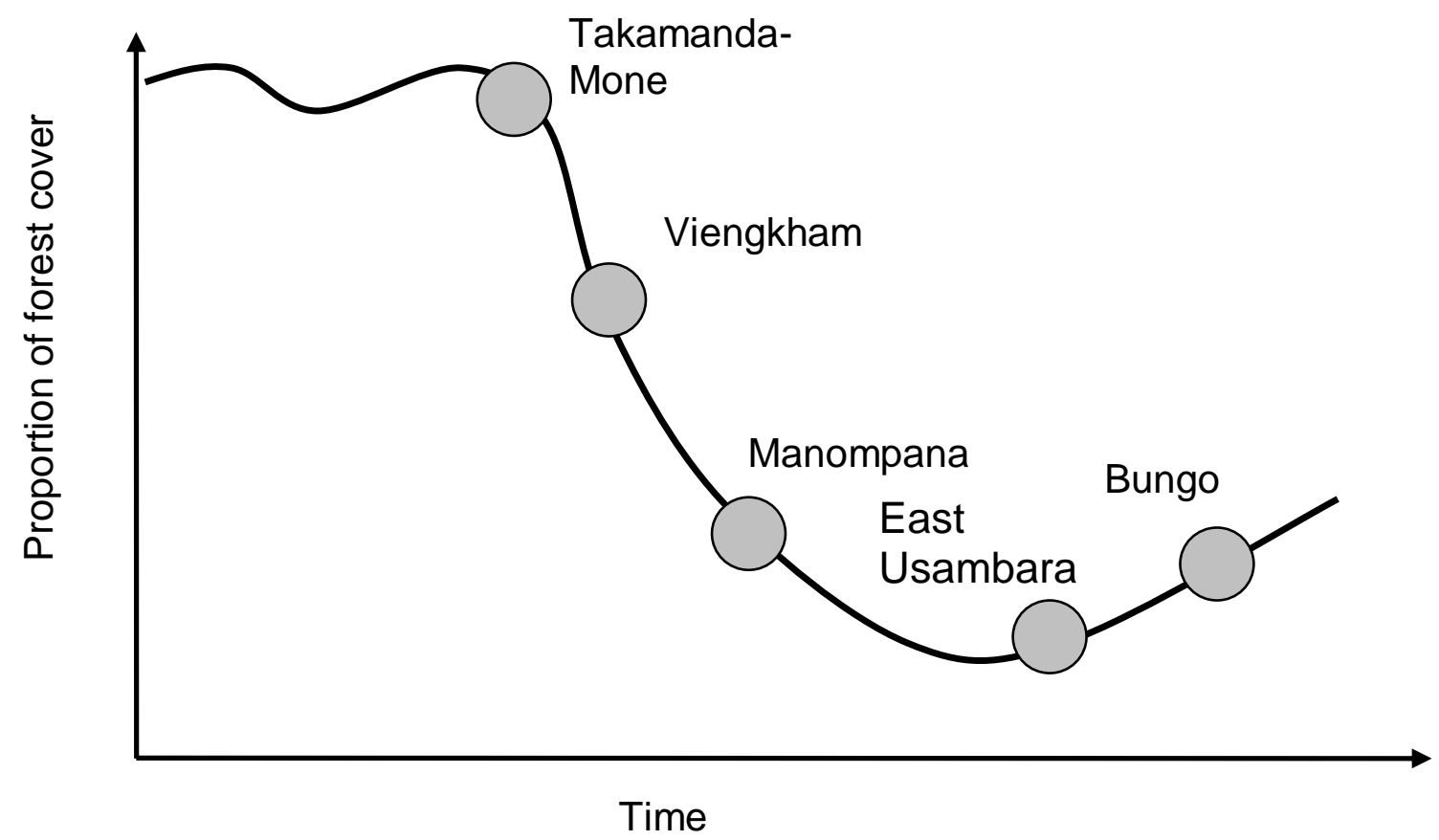

Figure 35. Forest transition stages of the five sites

Takamanda Mone landscape is at the earliest stage in the curve, quantified by its highest proportion of forest cover and lowest rate of forest loss. Population pressure perhaps started to increase lately but compared to other sites, the pressure is much lower. Forest in Viengkham landscape is perhaps protected by its rough topography even though lately there seems to be a 
new pattern of increasing deforestation at high altitudes inside the forest core. Manompana landscape has lost significant forest cover in the earlier period, resulting in a fragmented forest. More recently, the rate of deforestation has slowed down. However, the expansion of deforestation in the core area should be noted.

East Usambara currently has twice as much proportion of forest cover in the landscape compared to Bungo, but in absolute forest cover, Bungo is higher. In many aspects the two landscapes are comparable, especially in the existence of large scale operations in addition to smallholder farmers as land managers, and the interaction between the two agents. However, due to differences in topography and the dominating land use systems that replace forest, the two landscapes bifurcate along the forest transition path. In East Usambara, the roughness in terrain is more distributed compared to that in Bungo landscape. Natural forest in flat areas outside protected areas, which has higher probability to be converted, is higher in East Esambara, and therefore if the future land use/cover change follow the same trend as it was in the past, we could anticipate further reduction in forest cover in East Usambara compared to limited availability and accessibility of natural forest in Bungo landscape. Based on this, we position East Usambara and Bungo in similar level of $\mathrm{y}$-axis but different side of $\mathrm{x}$-axis with regards to the lowest possible forest cover level.

Spatial pattern of deforestation across the five landscapes can be summarized based on topography and accessibilities depending on the stage of forest transition:

- In landscapes with varying surface roughness, i.e., relatively flat in one part and rough in others, early deforestation take place in flat areas with high accessibilities and in the later stage in the edge of remnant primary forest blocks which partly is protected by law and topography (Bungo and East Usambara)

- In uniformly flat landscapes with low access, early deforestation predominantly happens along the river and road network and expands from there (Takamanda-Mone) and once forest is more fragmented, deforestation also happens in the form of encroachment of primary forest block as well as expansion of those along the transportation network (Manompana)

- When a landscape is almost uniformly rough in terrain with low accessibility, deforestation follow settlement placement in areas which is relatively flat locally and close to the river (Viengkham)

Each of the five landscapes has some protected areas delineated within it. If treated in segregated manner, the protected areas will be left as isolated small island(s) of submontane primary forest (see the case of Bungo and East Usambara). In this case, at the landscape level conservation of biodiversity will not be achieved for at least two reasons: (i) management and enforcement are often weak, (ii) protected areas are often delineated in remote, rough terrain areas which does not represent various ecoregions with various species assemblages and endemism (only $\alpha$-diversity is maintained but not $\beta$ - and $\gamma$-diversities), (iii) the extent of protected areas sometimes are not large enough to allow minimum viable population such that in the long run species extinction might continue to happen, (iv) protected areas without buffer zones and corridors can easily be isolated areas rather than integral part of a landscape. Multifunctional landscapes that accommodate conservation and development need to be considered as an integrated, rather than segregation, 
systems; this can answer the necessary-but-not-sufficient problem of protected areas. Land use plan that aims to increase multifunctionality of landscapes should be informed by the current status of landscape composition and configuration, process of land use/cover changes in the past and future, areas that are vulnerable to changes in the future and options for intervention. The land use planning process should be conducted within a negotiation process among multiple stakeholders.

\section{Global Landscape composition}

Two global landscape composition indices presented here are Modified Simpson's Diversity (MSDI) and Evenness Indices (MSEI). Please note that the Simpson's Indices here are used as measures of diversity of patches, and therefore habitat, rather than biodiversity measures (Figure 36 and 37).

Landscapes like Cameroon-Takamanda Mone which is highly dominated by forest in large contiguous patch show very low diversity and evenness indices. The other four landscapes show comparable diversity indices, but different temporal pathways. Whilst with deforestation and forest conversion, MSDI tends to increase in the Bungo landscape over time, there is period of drop in diversity index between 1999 and 2002 within which tree-based systems dominate the landscape. More recently, with some conversion of tree-based systems into more intensified cropland and others, diversity index increased again (Figure 36). Relative MSDI and MSEI in each site across time is consistent, however across landscape, Viengkham, Manompana and East Usambara landscapes show much higher MSEI than the other two, showing that composition of land use/cover classes are much more even in the three landscapes, while Takamanda landscape is highly dominated by forest and Bungo by tree and forest cover (Figure 37).

MSDI and MSEI in tandem with information on dominant land use/cover type can be used as a quick indication of landscape composition and forest transition stage. Low MSDI and MSEI with forest domination suggest early stage of forest transition (Takamanda-Mone), while high MSDI show broad portfolio of land use/land cover types. In the case of uniform number of land use/cover types under quite general classification scheme, comparison across sites is not very useful but across time within a landscape is quite useful. In the case of Bungo, where the stage of forest transition has reached the turning point from the lowest forest and tree cover fraction, it can be seen that MSDI increases with forest as the dominating land use/cover type until 1993, and MSDI decreases when tree cover took over as the dominating land use/cover type in 1999. MSEI shows similar pattern except that it is normalized by the number of land use/land cover types. Landscapes of Viengkham, Manompana and East Usambara show increasing and very high MSEI over time, indicating that apart from forest, the extents of other land use/cover types are very similar from each other, whilst those of Bungo are not. 


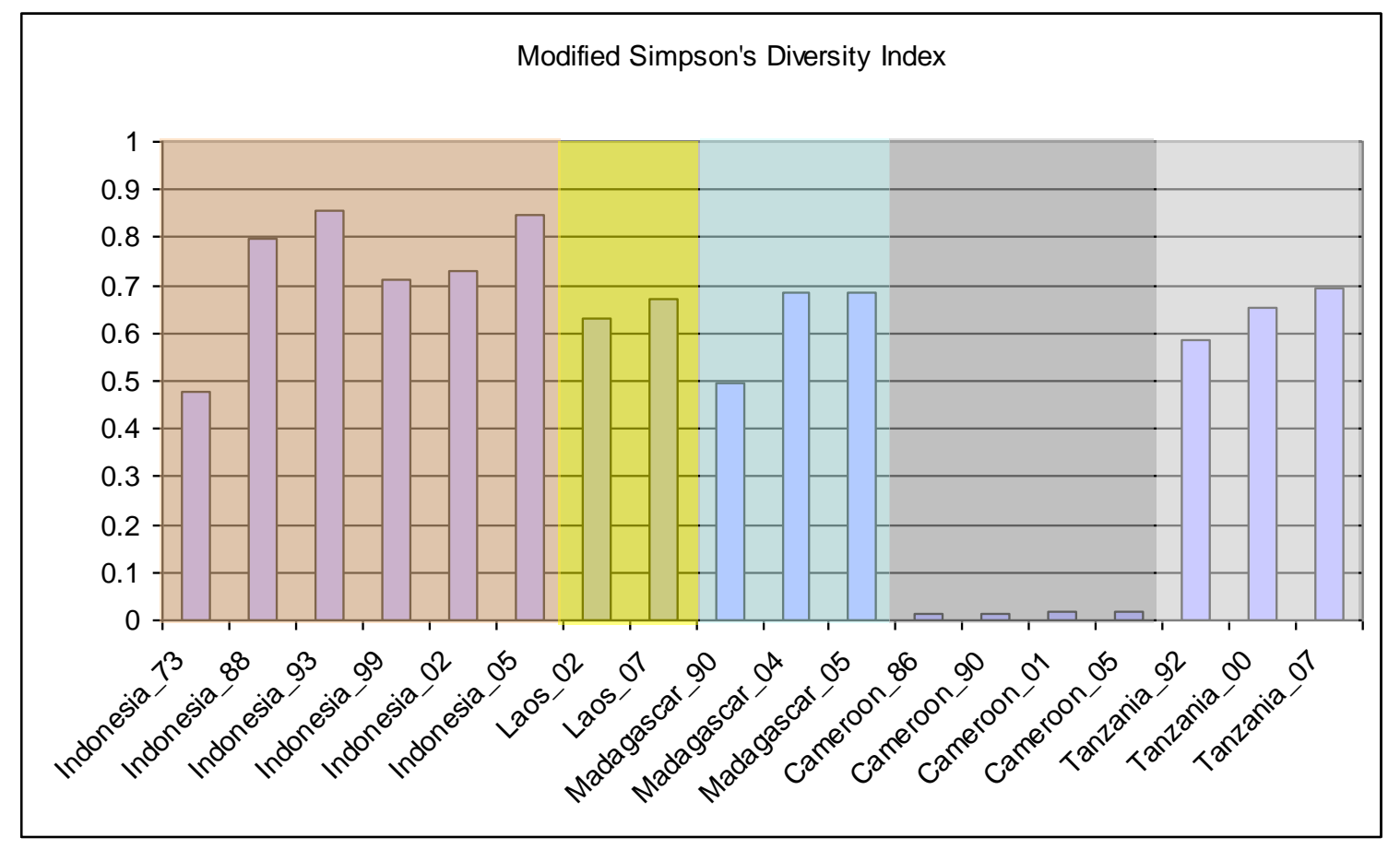

Figure 36. Modified Simpson's Diversity Index

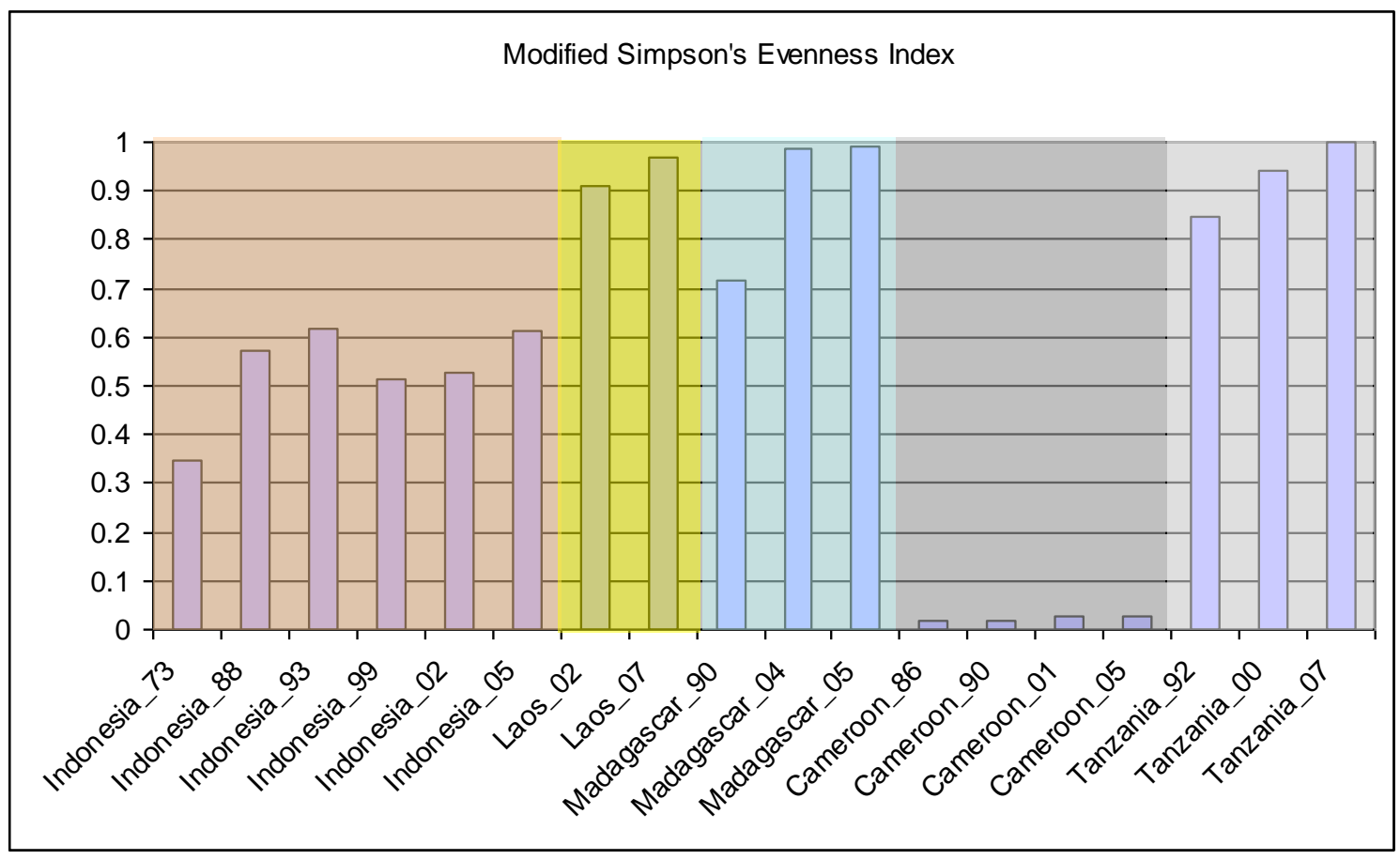

Figure 37. Modified Simpson's Evenness Index 


\section{Global Landscape configuration}

We selected three global landscape configuration indices to be presented and discussed here in regard to the relevance of our objectives and research questions. Total area of forest is relevant in terms of minimum habitat size of organisms, considering encroachment and invasion from the edge; Aggregation Index of forest is highly relevant since it shows how likely patches of forest are clumped together such that it reflects fragmentation of habitat, whilst Connectivity Index of forest captures the likelihood of other forest patches to be found in a specified radius of a particular forest patch, even if they are not contiguous. This allows the roles of matrix (nonhabitat) and the radius should highly be set specific to species based on dispersal ability. The two last indices are normalized such that comparison across landscapes can be done directly. Combination of the three indices should be able to capture some ecological processes that reflect biodiversity at the landscape level.

After a continuous sharp decline of Total core forest area (in hectares) over time in Bungo landscape, at present it is comparable to those of Takamanda-Mone. However in terms of proportion, Bungo total core area is much lower than Takamanda-Mone. While Bungo show the sharpest decline in total core area, Manompana and East Usambara show comparable rate, and Takamanda-Mone shows a much slower rate. Viengkham landscape shows increases in total core area, mostly due to increases of tree cover which reduces pressure of encroachment from the edge of forest block, even though forest cover does not increase in extent.

Aggregation index is highest in Takamanda-Mone, followed by Bungo landscapes, showing the clumpiness of forest in the landscape. Manompana and East Usambara landscapes experience sharp declines in Aggregation Index over time, showing the rapid rate of fragmentation of existing primary forest blocks. Viengkham landscape show relatively low connectivity index despite of high aggregation index showing that when not contiguous, forest patches located sparsely. These landscape level indices and changes over time can be an early indication of the types of species that might be endangered. Species which is general in habitat requirement is less sensitive to the reduction of total core area, while specialist is prone to extinction with sharp and fast decreases in total core area. Species with high ability to migrate is not sensitive to reduce in aggregation given that it does not happen very rapidly, but those without that ability is prone to extinction. Widely dispersed propagules will allow species to survive even when connectivity is available at a relatively large radius but those that do not disperse widely will be prone to extinction with lower connectivity. In East Usambara landscape, for example, specialist species will be threatened, as well as species that does not move across the landscape well, and species that does not disperse well. 


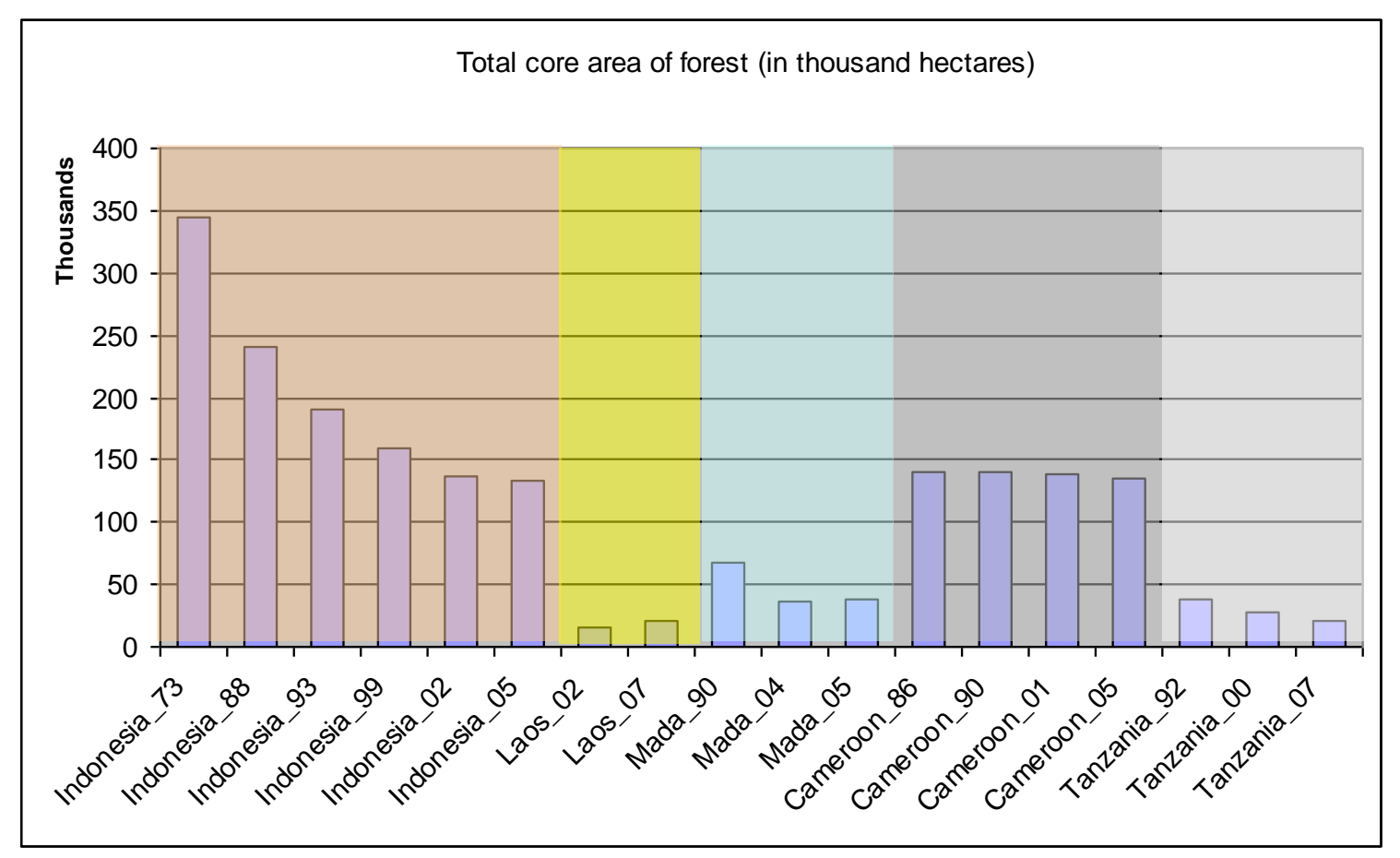

Figure 38. Total core area of forest in five sites over time

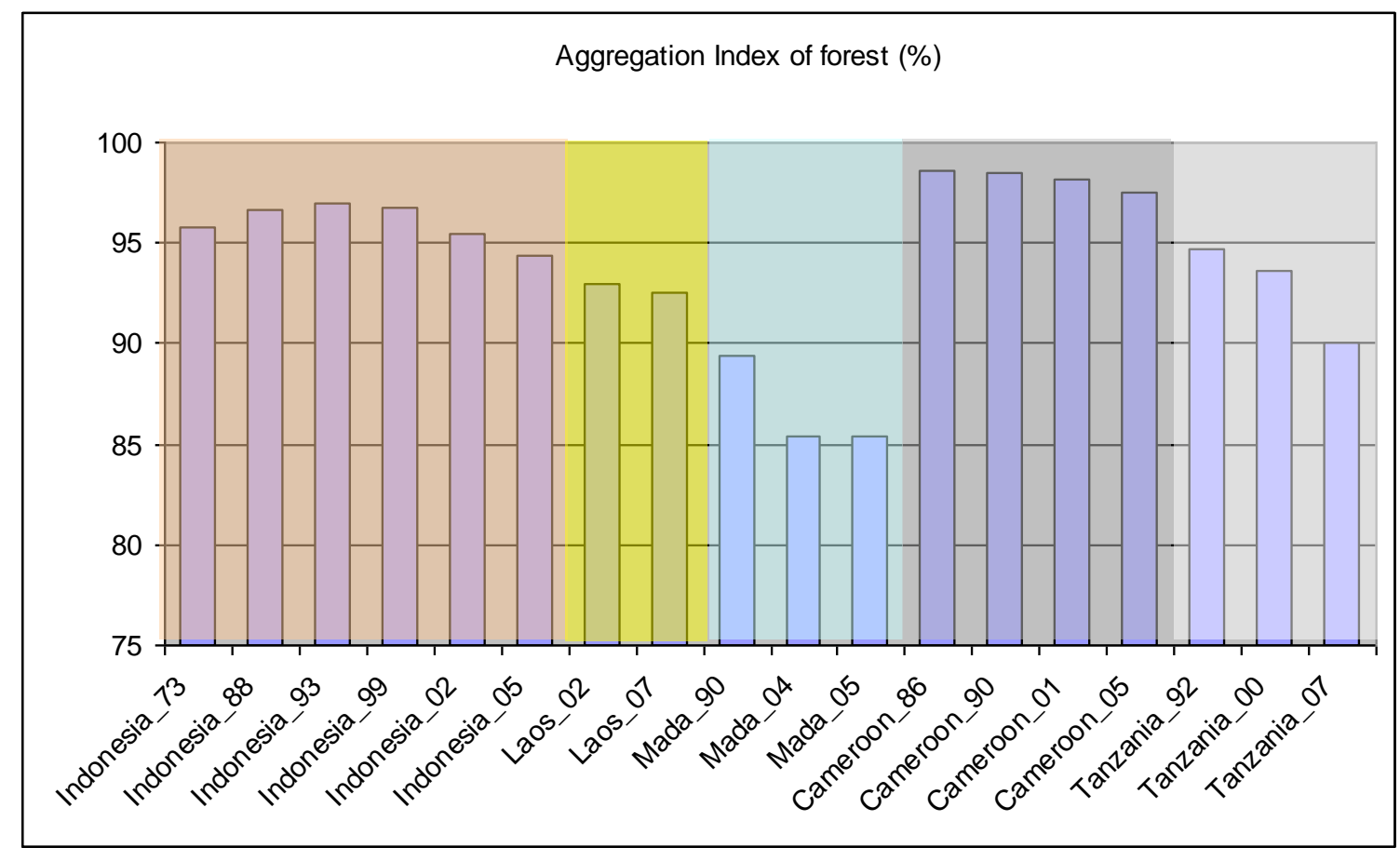

Figure 39. Aggregation index of forest in five sites over time 


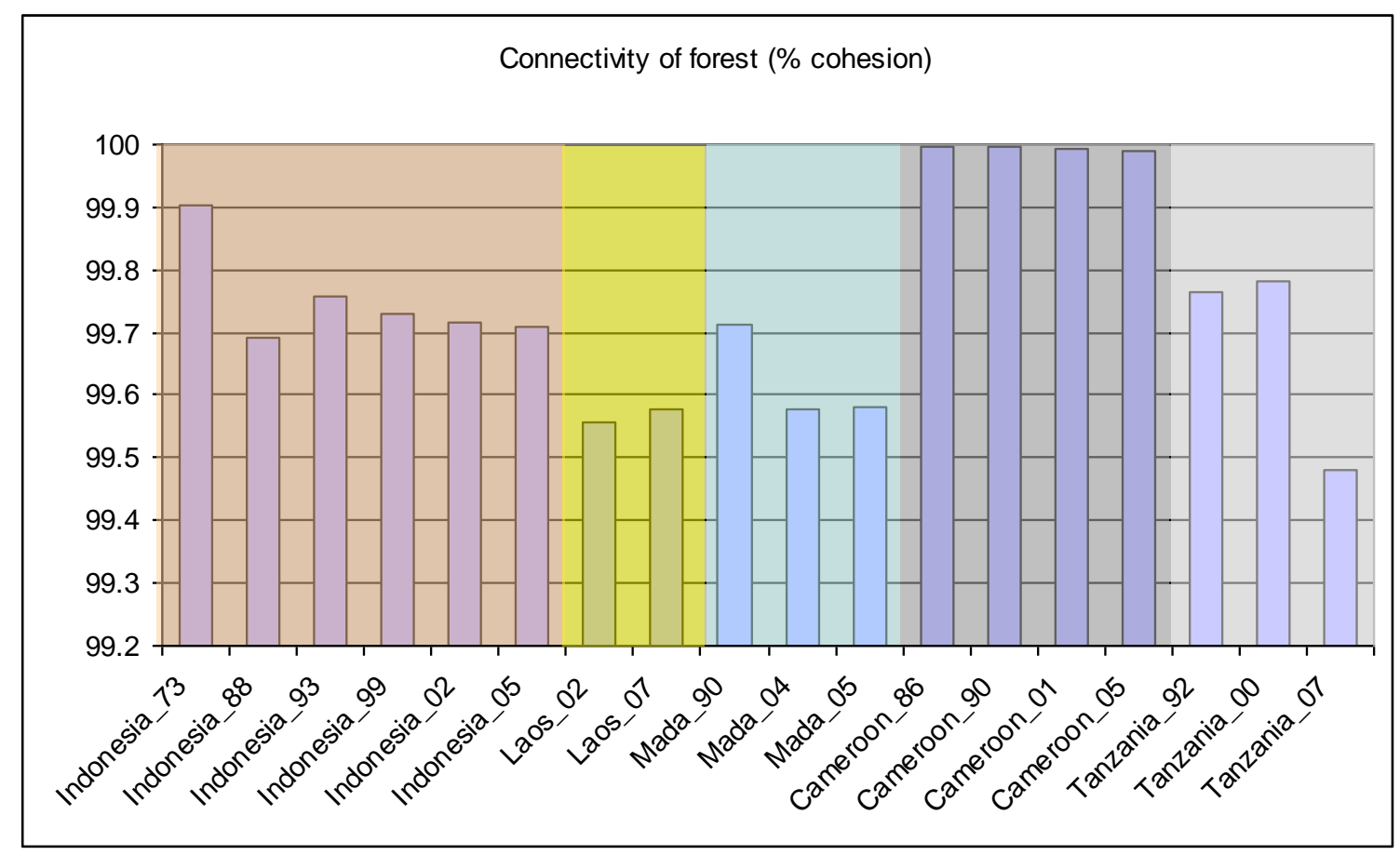

Figure 40. Aggregation index of forest in five sites over time

\section{Landscape dynamics over space}

This section will present visually the most current local (sub-landscape) configuration for each of the landscape. Each pixel represents the indices for the circular area of $1 \mathrm{~km}$ radius from it. Please note that while some aggregation index maps often look similar to connectivity maps, it is not always the case, especially when forest is surrounded by land cover dissimilar to forest, i.e., settlement, non-vegetation, non-tree based systems. When forest patches are often found in the surrounding of tree-based patches without being contiguous than connectivity is markedly different from aggregation, i.e., connectivity is much higher than aggregation.

This local (sub-landscape) analysis will be useful in terms of identifying the critical area where un-connectivity of two large blocks of forest is bound to happen and, therefore intervention could be endorsed. These visualizations should help in visioning, focus group discussion and communicating messages to public and policy makers, especially in the lights of land use planning to reconcile livelihoods options and biodiversity maintenance at local and landscape levels. Several guidelines, criteria and indicators can be negotiated among multiple stakeholders to reconcile local ecological knowledge, scientific perspectives and current policies and customary laws, such as:

1. High total core forest area should be under some measures of protection; otherwise if there are settlements close by, some awareness raising and contracts/agreements between government and the local people should be developed

2. Areas surrounding a large sized forest core area with high aggregation index should be tagged as priority areas for rehabilitation if located inside protected areas or conserved under some 
mechanism of Rewards for Environmental Services if located outside protected areas with some inhabitants or minimum management, e.g., under Village Forest contract. Highly aggregated forest outside total core forest areas and outside protected areas with no human presence should be delineated as protected areas

3. Areas surrounding a large sized forest core area with high connectivity index should be tagged as priority areas for rehabilitation if located inside protected areas or (re)-planted and managed under low intensification of land uses with trees of economic values, e.g., rubber agroforestry, if located outside protected areas with some local communities

4. Areas of none above but identified as critical in connecting pieces of primary forest blocks under potentially low costs or hotspots of endemic species or particular environmental services should be delineated as priority areas for agroforestry or other low intensified tree/forest under co-investment schemes between local communities and other stakeholders

Indicative areas of each above point for each landscape are shown in Figure 41-55. If there are specific concerns of endangered species, such maps can be used as tools to delineate specific habitat and threat such as measures of protection can be determined and negotiated upon.

\section{Indonesia (Bungo)}

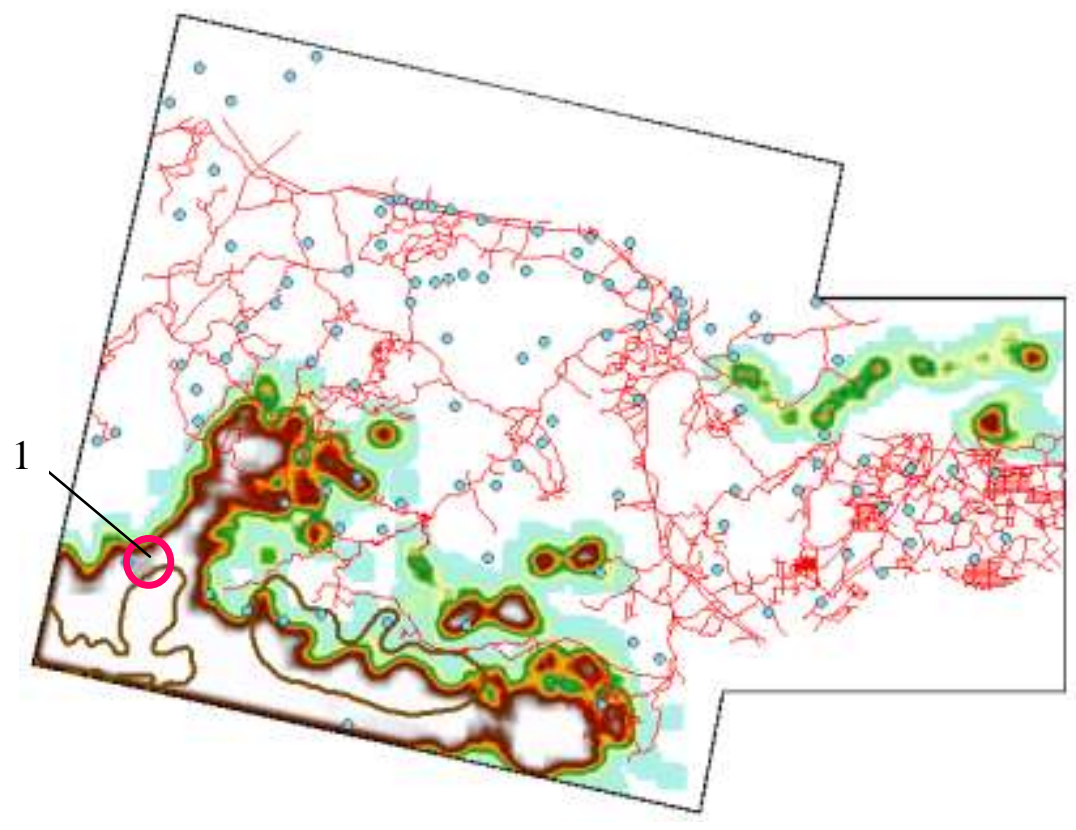

\section{Legend}

- Village iocation
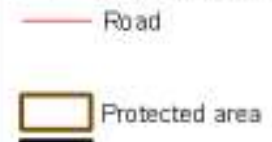

L Land scape mosaic AOI Value

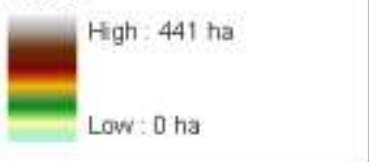

Figure 41. Current total core area of forest (0- 441 ha) of Bungo Indonesia 

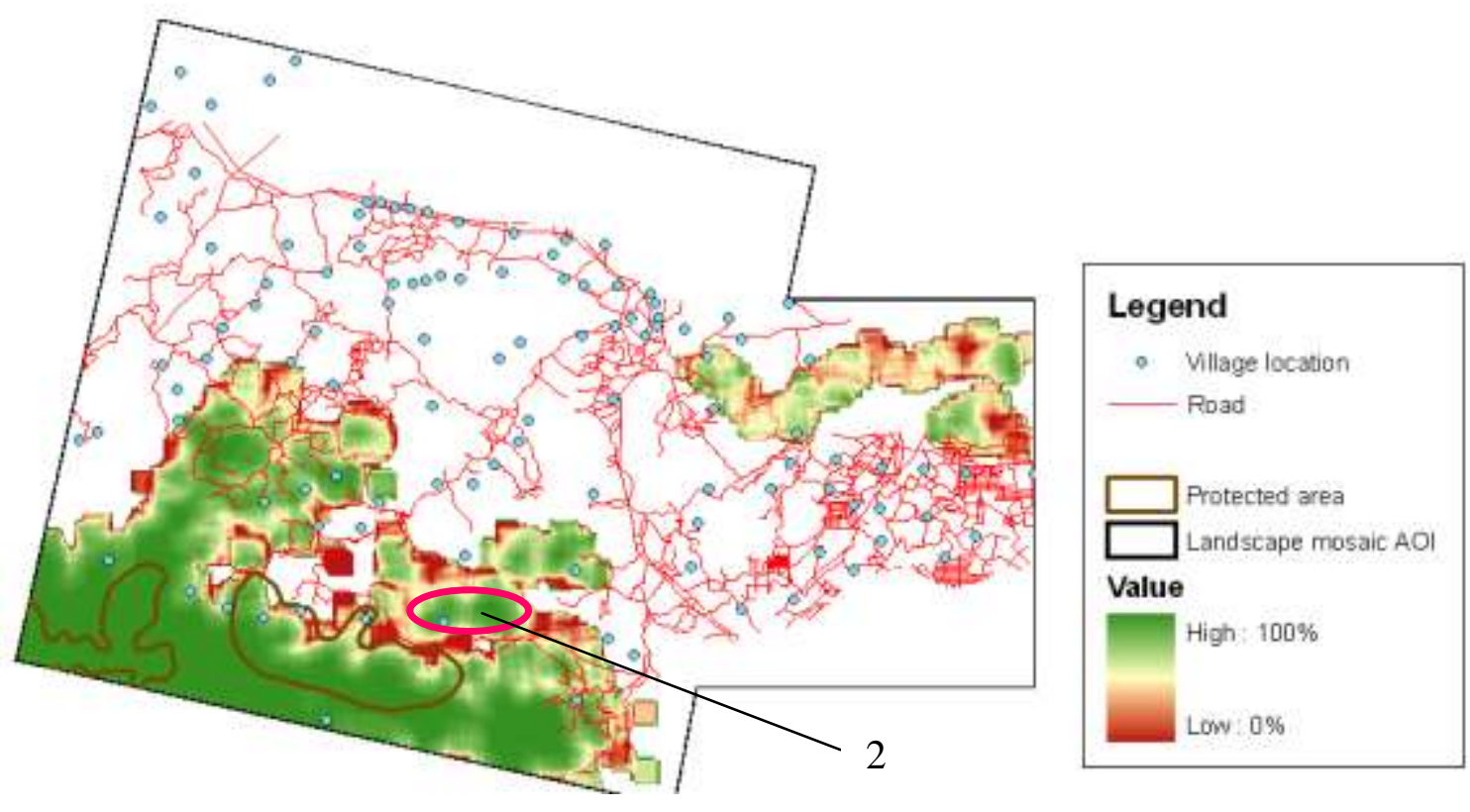

Figure 42. Current forest aggregation index (0- 100\%) of Bungo, Indonesia

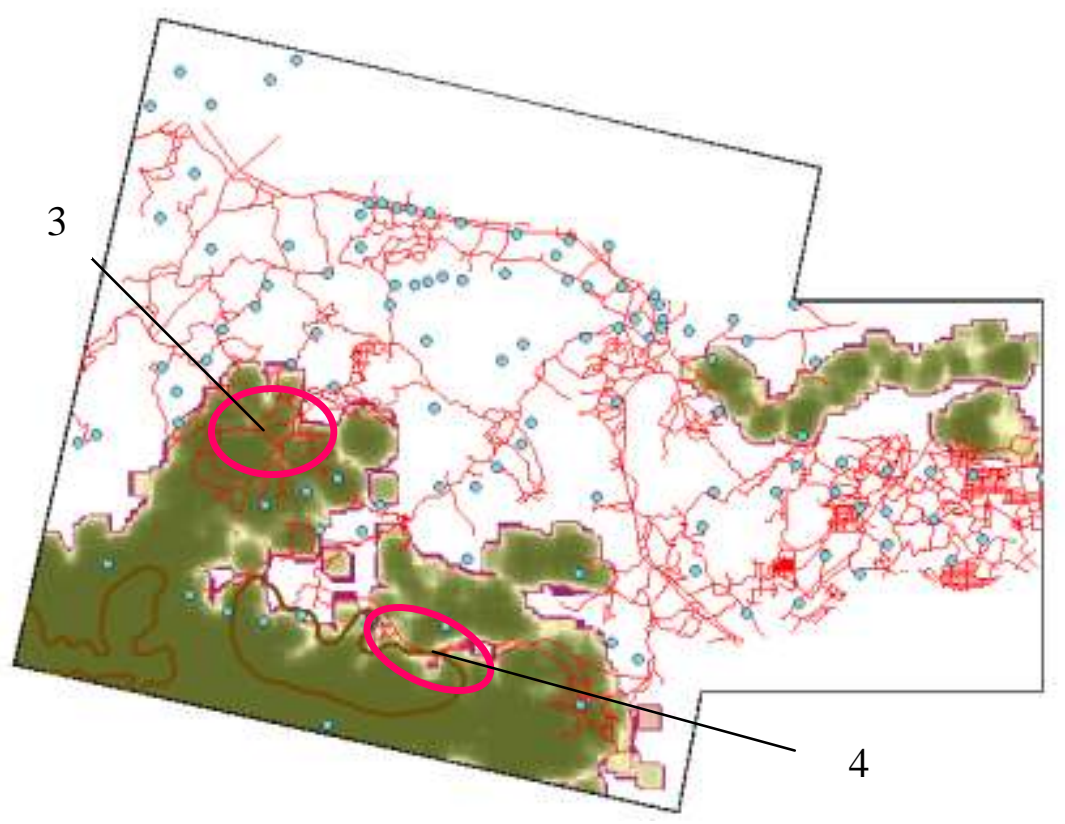

\section{Legend}

- Viliage location Road

Protected area

Landscape mosaic AOI

Figure 43. Current connectivity of forest (0-100\%) of Bungo, Indonesia 


\section{Laos (Viengkham)}

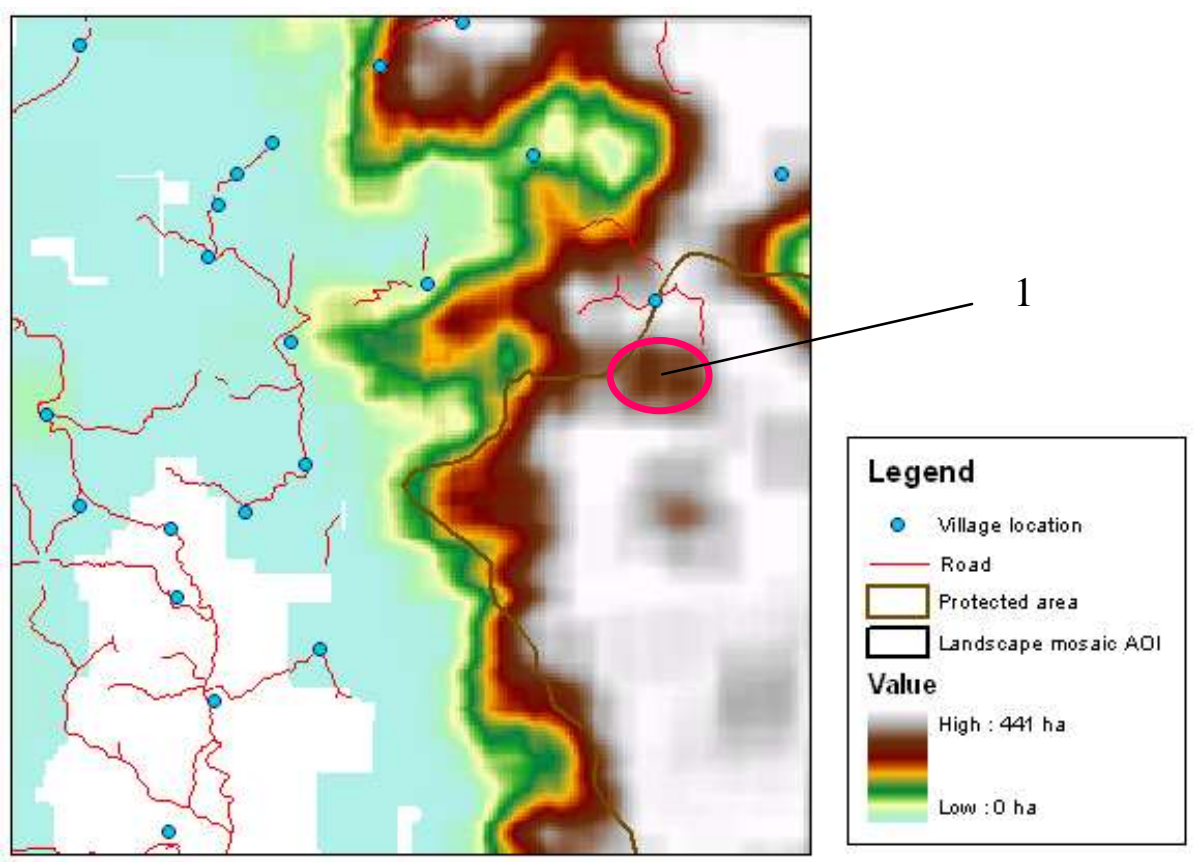

Figure 44. Current total core area of forest (0- 441 ha) of Viengkham, Laos

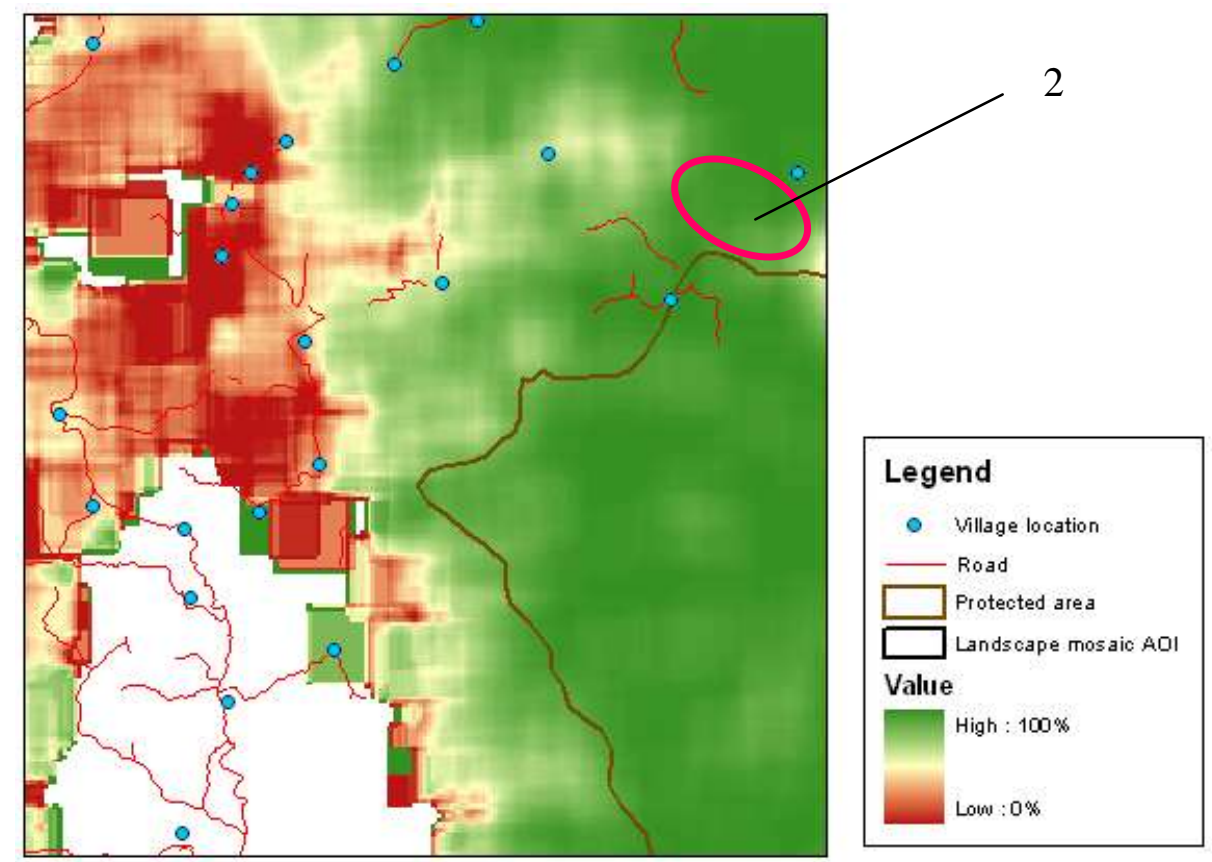

Figure 45. Current forest aggregation index (0-100\%) of Viengkham, Laos 


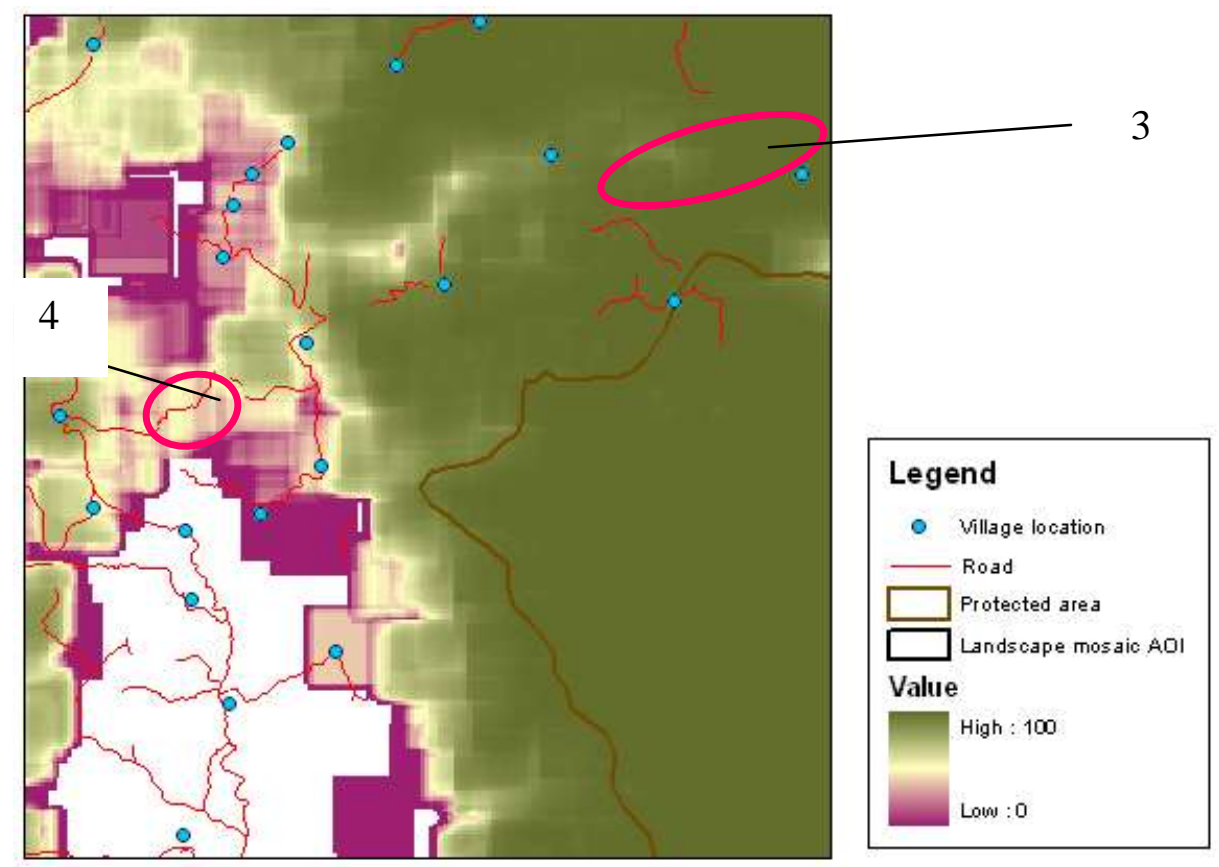

Figure 46. Current connectivity of forest (0-100) of Viengkham, Laos

\section{Madagascar (Manompana)}

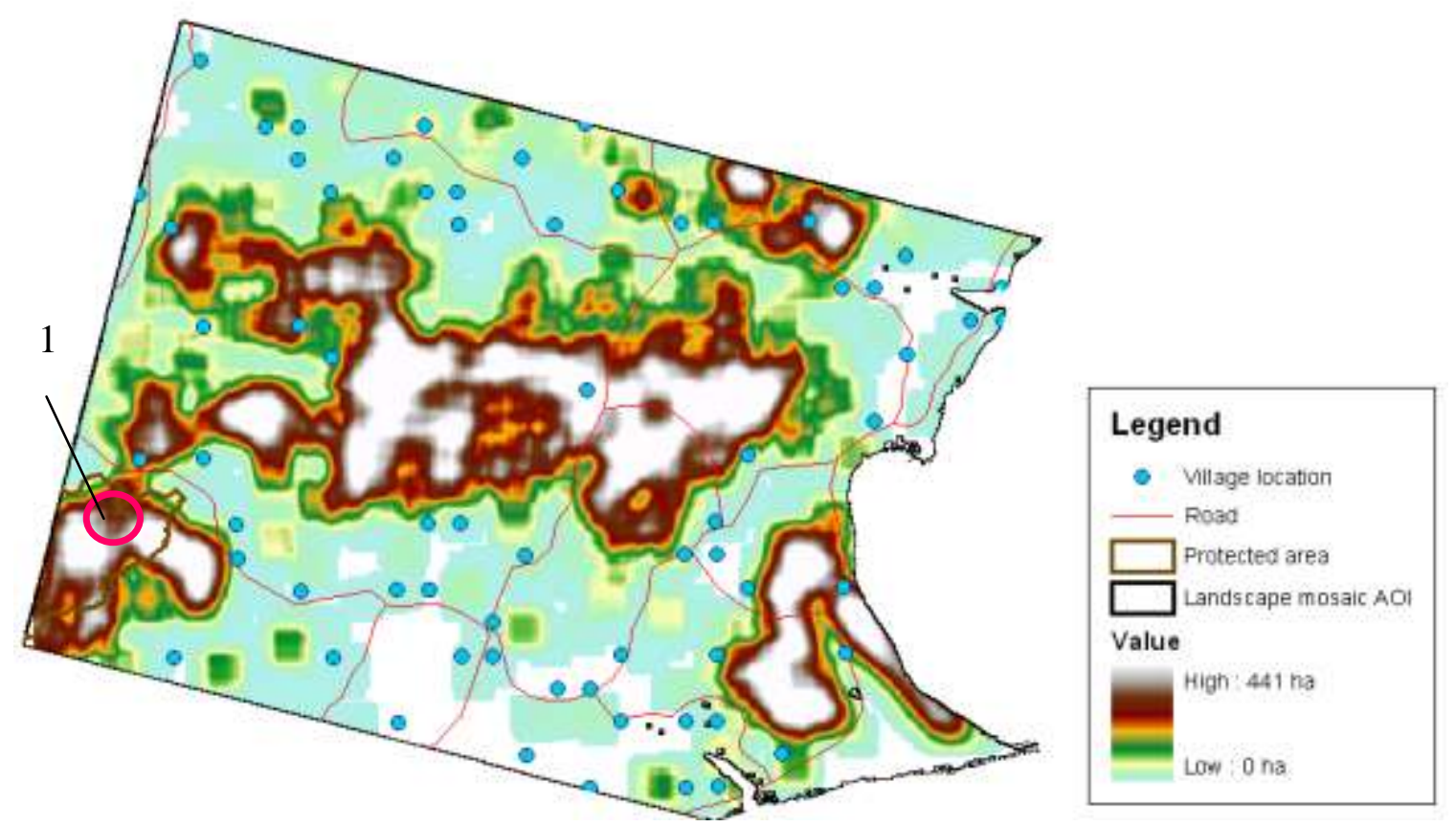

Figure 47. Current total core area of forest ( 0 - 441 ha) of Manompana, Madagascar 


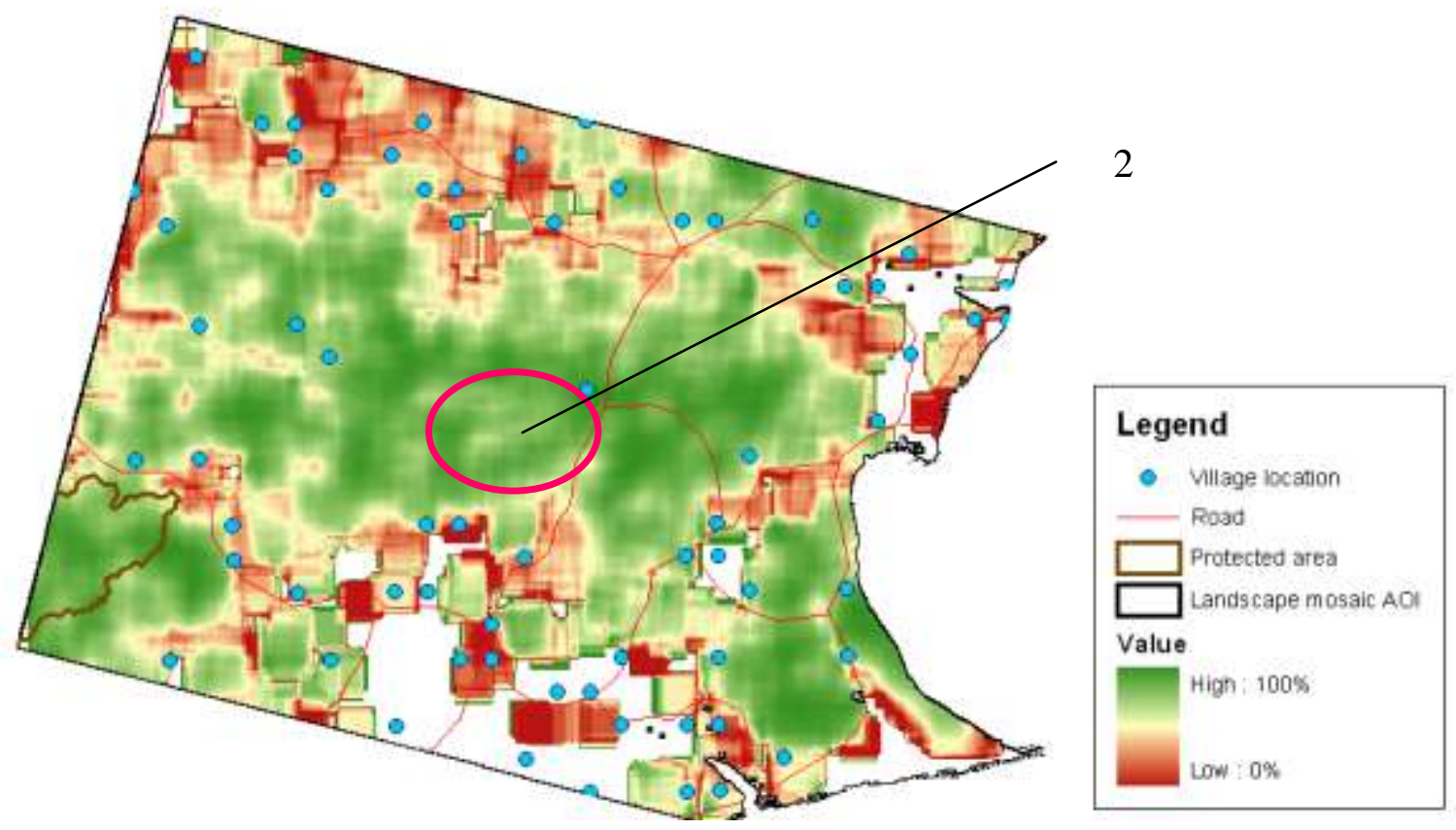

Figure 48. Current forest aggregation index (0-100\%) of Manompana, Madagascar
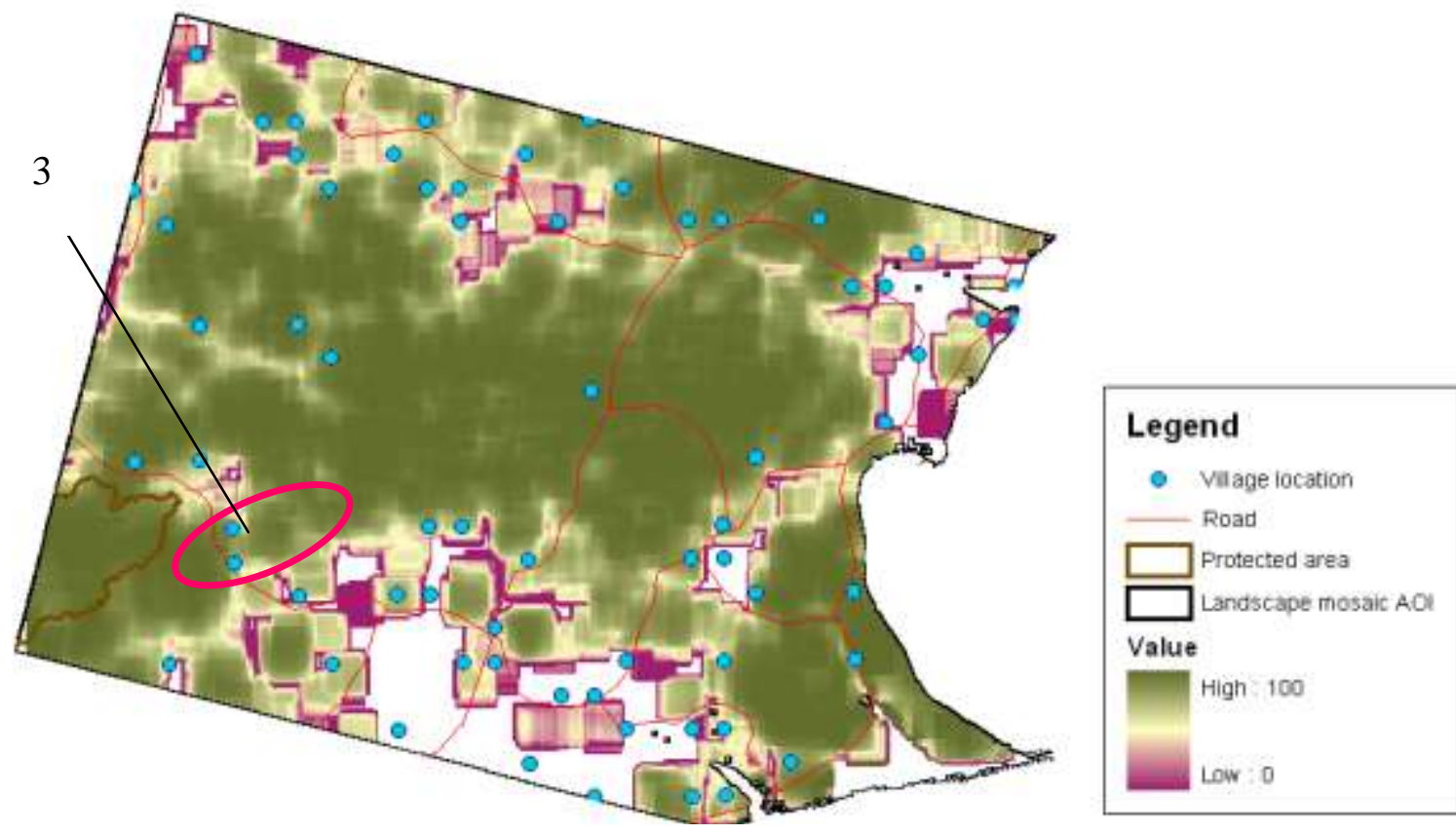

Figure 49. Current connectivity of forest (0- 100) of Manompana, Madagascar 


\section{Cameroon (Takamanda Mone)}

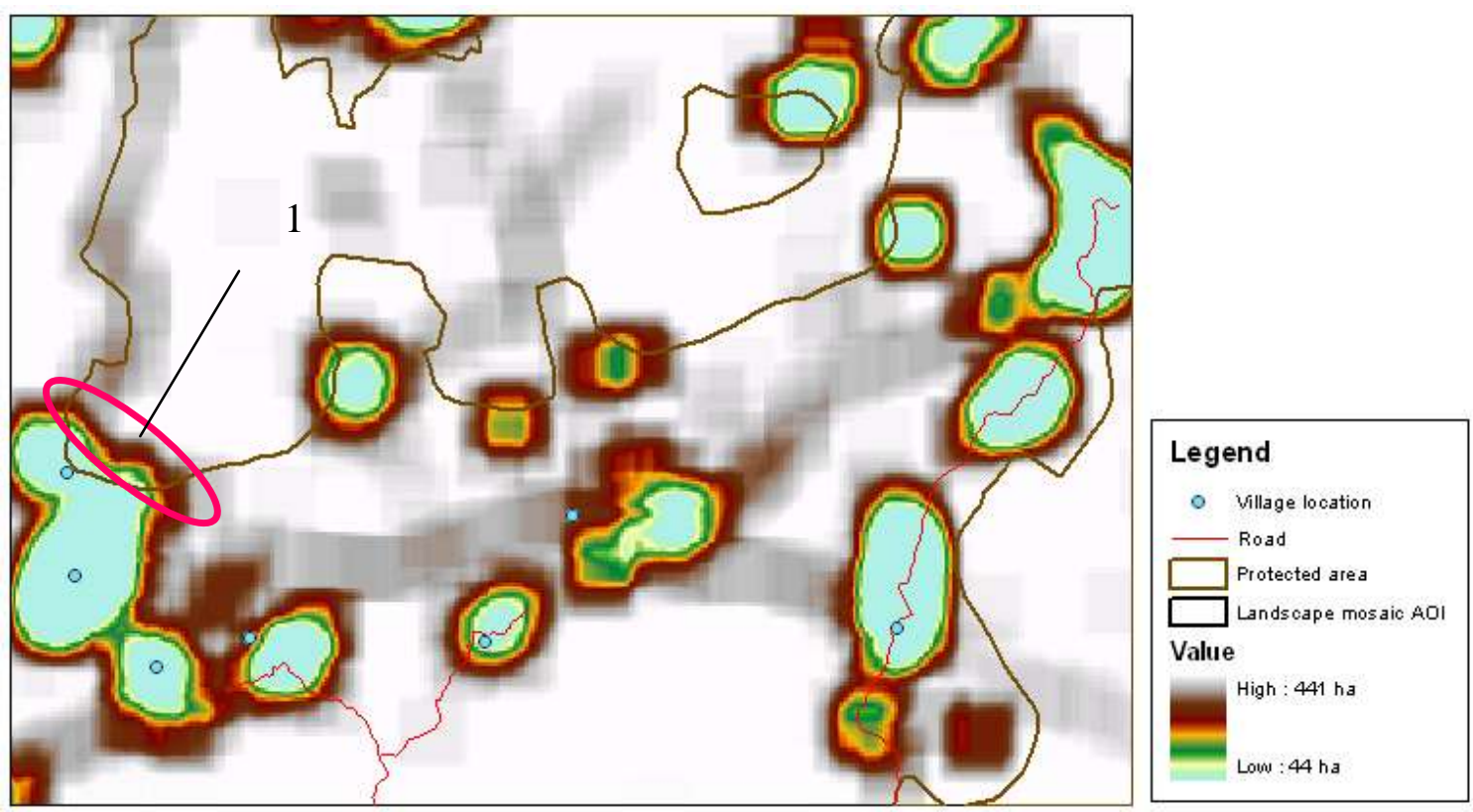

Figure 50. Current total core area of forest ( $0-441$ ha) of Takamanda Mone, Cameroon
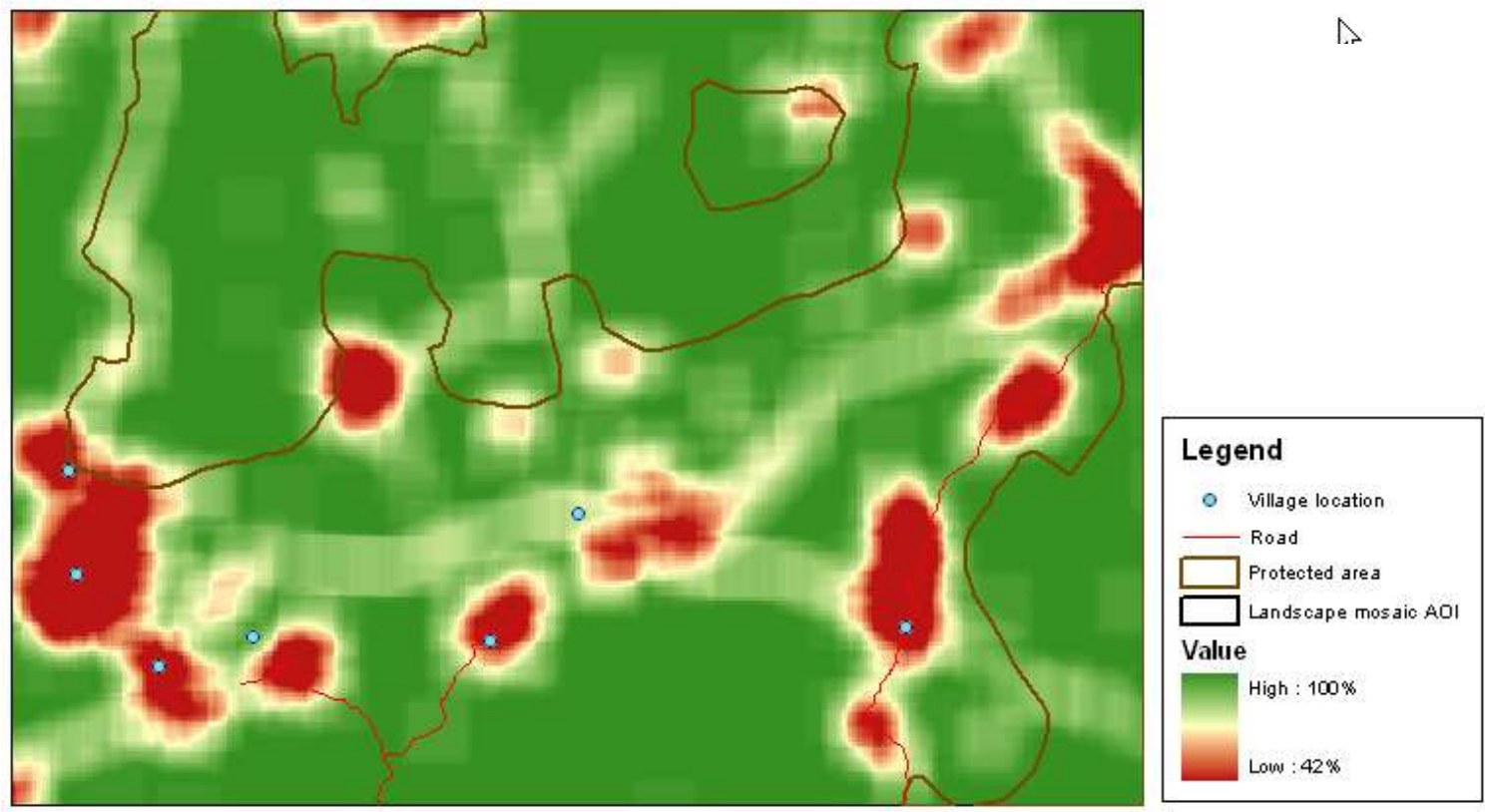

Figure 51. Current forest aggregation index (0-100\%) of Takomanda Mone, Cameroon 


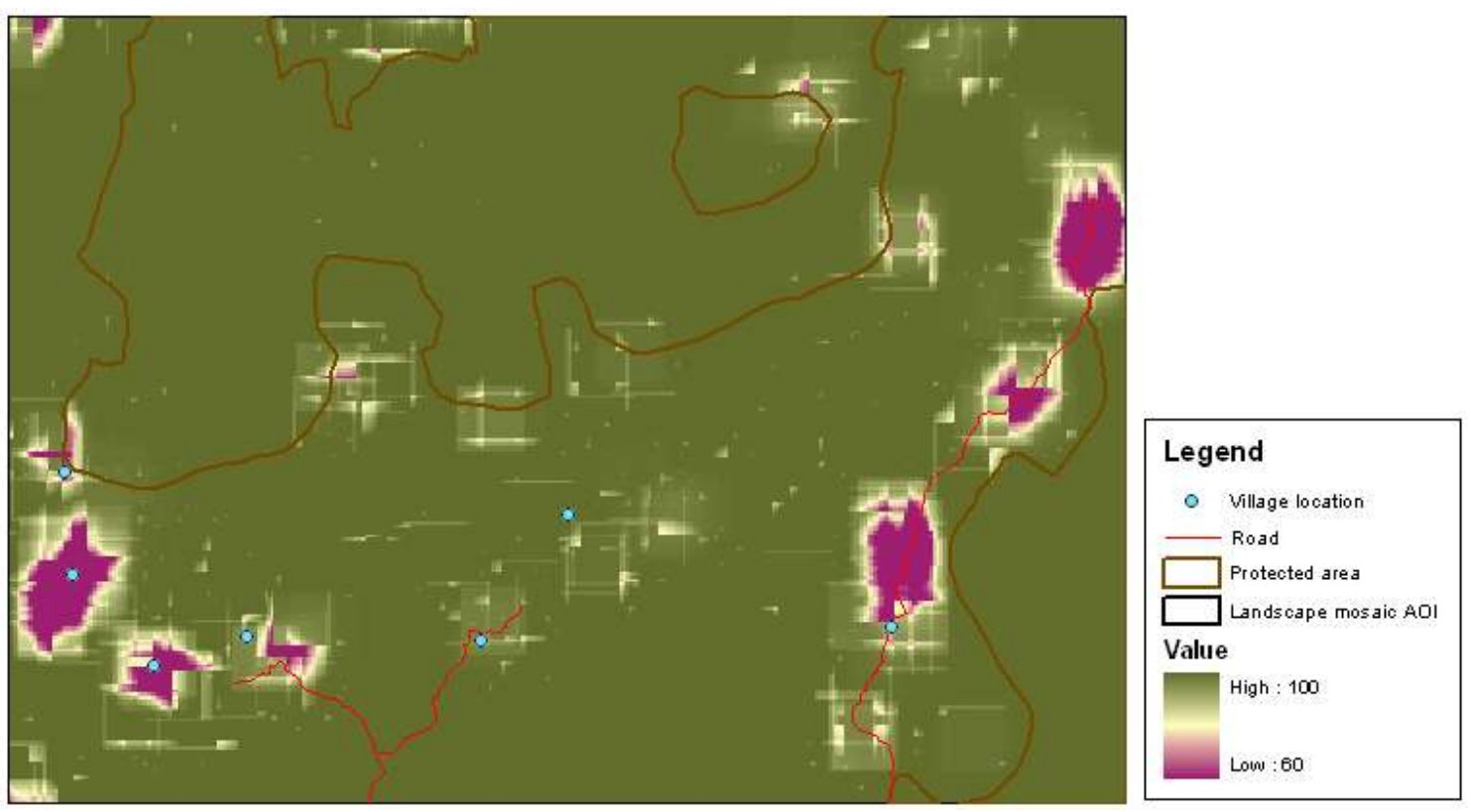

Figure 52. Current connectivity of forest (0- 100) of Takomanda Mone, Cameroon

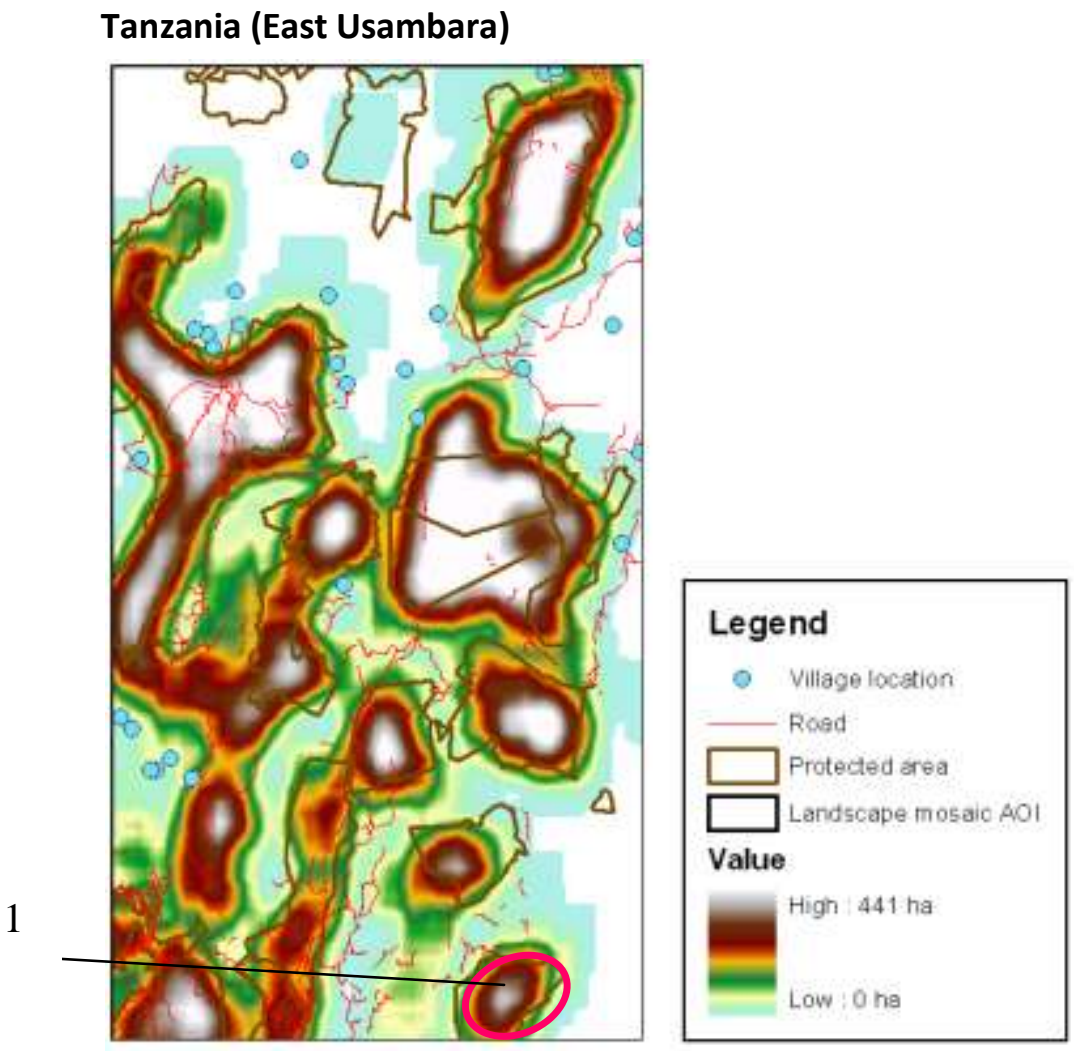

Figure 53. Current total core area of forest (0- 441 ha) of East Usambara, Tanzania 


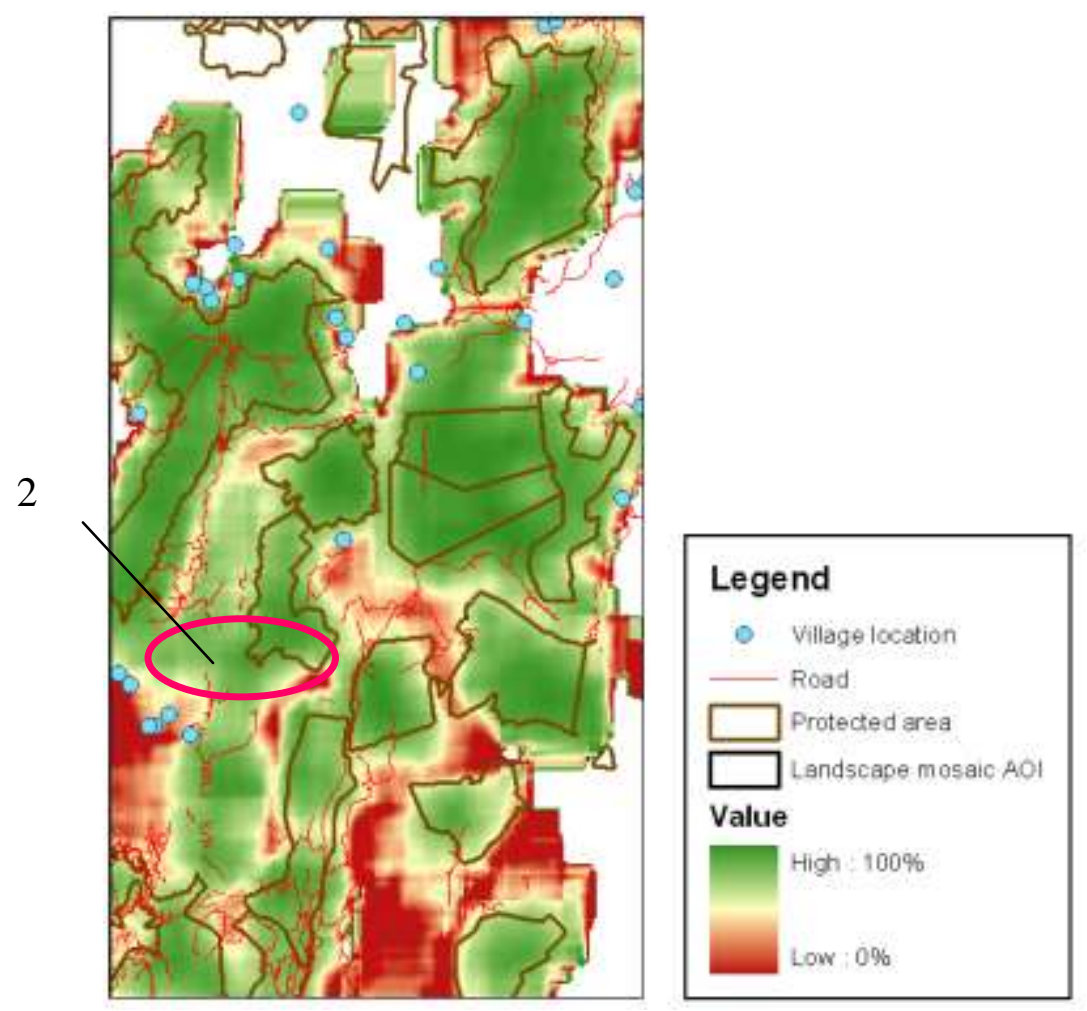

Figure 54. Current forest aggregation index (0-100\%) of East Usambara, Tanzania

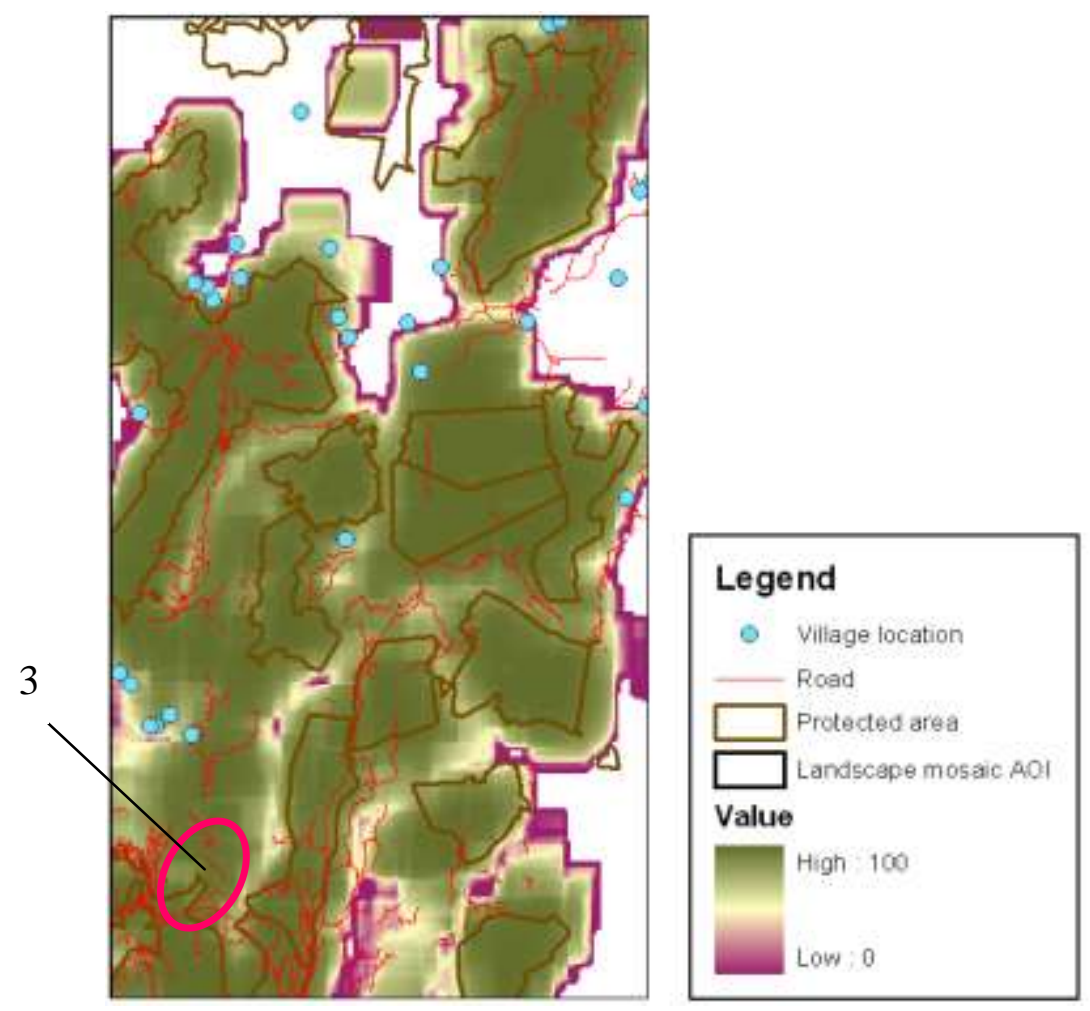

Figure 55. Current connectivity of forest (0-100) of East Usambara, Tanzania 


\section{Landscape dynamics over time and space}

In this section we will visualize changes in local (sub-landscape) configuration over time in the five sites. These analyses should be useful in projecting the future total core area, aggregation and also connectivity based on past changes. Beyond that, areas that are prone to disaggregation/fragmentation and un-connectivity/isolation can be identified.

By combining these analyses with scenarios to project the future land use/cover changes, we will able to provide an effective 'negotiation' platform with multi-stakeholders by showing the what-if situation. Showing the areas that most likely will be isolated or fragmented under particular scenarios within such and such years is a powerful way to start a discussion to land use planning.

Some guidelines, criteria and indicators to be used in the land use planning process could be derived, for instance:

- Delineating the likely loss of total forest core area based on previous pattern of deforestation, e.g., in Bungo (Figure 56), Monampana (Figure 62) and East Usambara (Figure 68) landscape cases, deforestation mainly happened as encroachment from the edge of primary forest block, while in Viengkham (Figure 59) and Takamanda-Mone (Figure 65) deforestation predominantly take places along the new road establishment and river. Apart from that settlement in the middle of primary forest blocks continues to expand in areas

- Identification of the likely loss of areas with high aggregation index surrounding large- sized primary forest blocks (Figure 57, 60, 63, 66, 69)

- Identification of the likely loss of areas with connectivity index surrounding large-sized primary forest blocks (Figure 58, 61, 64, 67, 70)

In addition to past spatial pattern of deforestation, likelihood or probability of deforestation and land use/cover changes can be derived from multi- agent modelling, empirical modelling or spatially explicit driver modelling. Further the projection or prediction can be used as a layer of information to be incorporated in identification of vulnerable areas of habitat loss, increased fragmentation and reduced connectivity. Negotiation and protection measures could be imposed in these vulnerable areas along with intervention that can be taken. Trade-offs between conservation and development should be sought, for example, identify areas of low opportunity cost (from cost-benefit analysis of land use system) with high conservation values. 


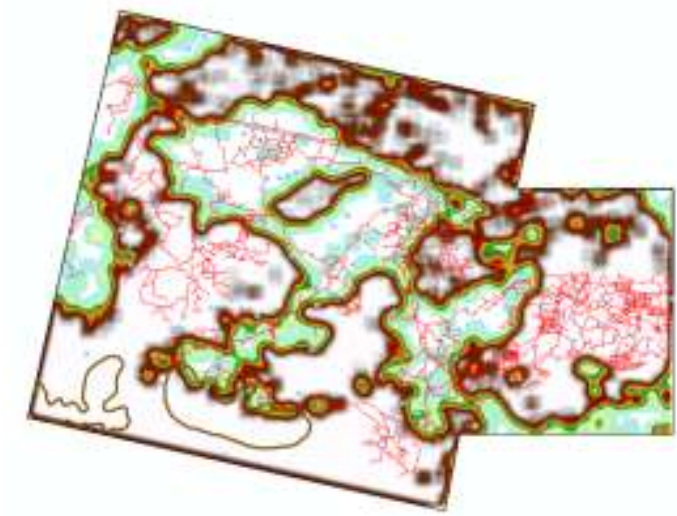

(a)

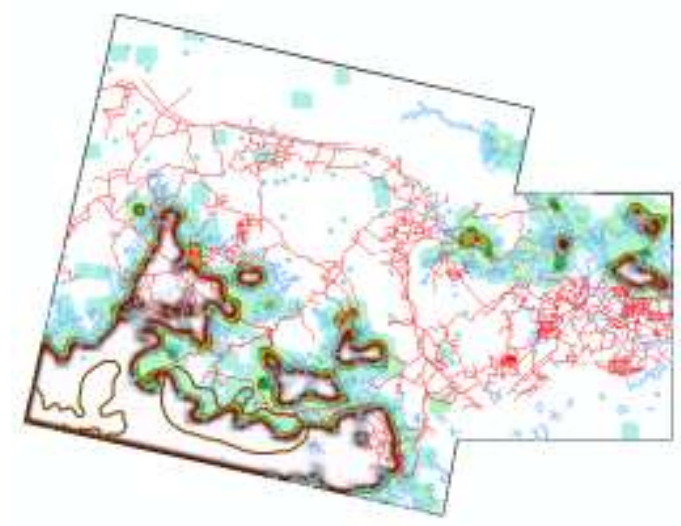

(d)

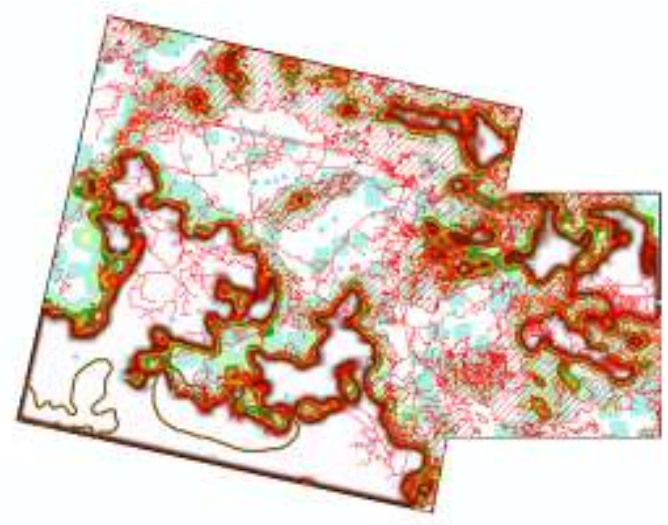

(b)

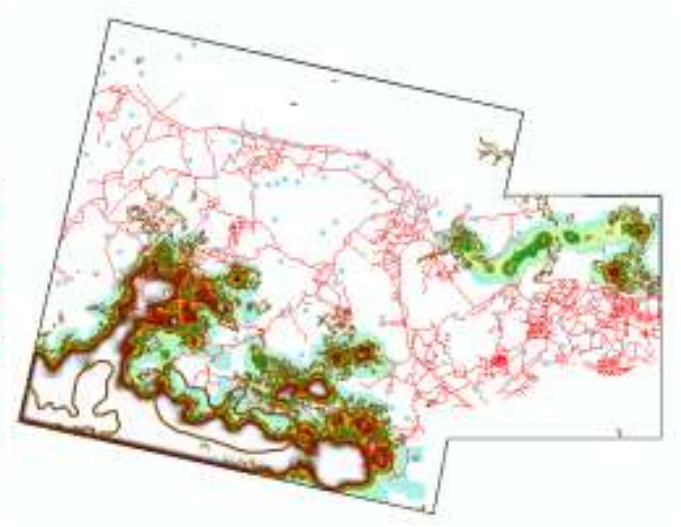

(e)

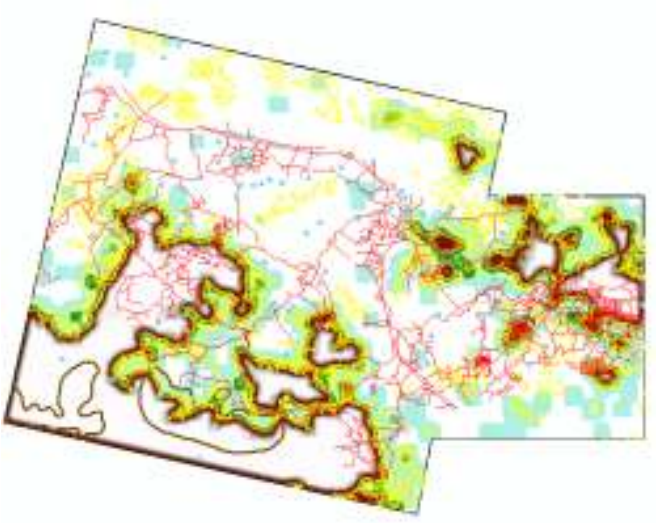

(c)

Figure 56. Time series of total core area of forest, (a) total core area in 1973 (b) total core area in 1988 with deforestation in 1973-1988 (c) total core area in 1993 with deforestation in 1988-1993 (d) total core area in 2002 with deforestation in 1993-2002 (e) total core area in 2007 with deforestation in $2002-2007$ 


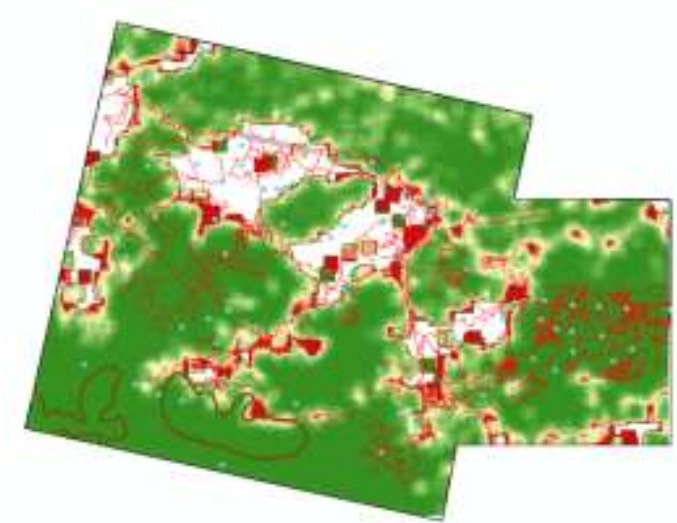

(a)

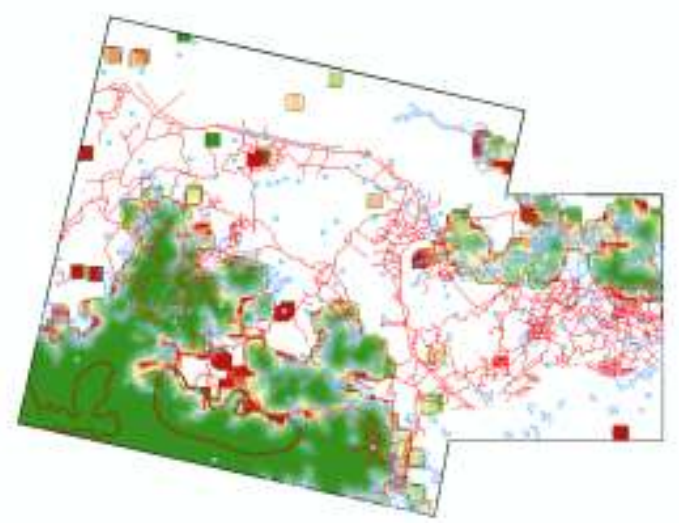

(d)

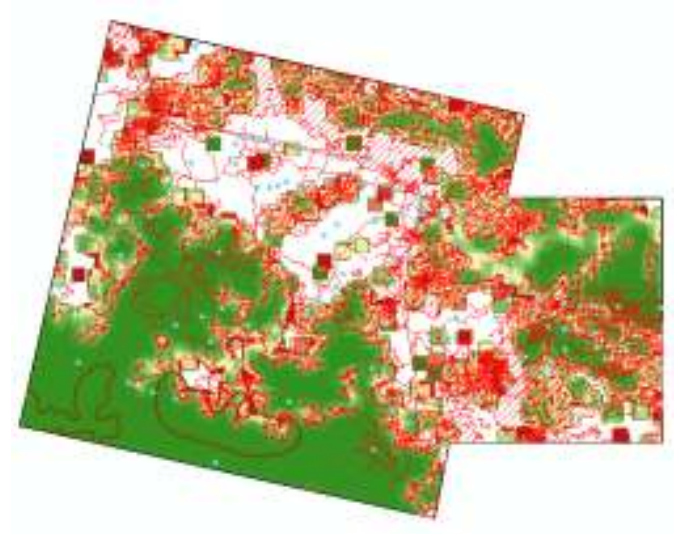

(b)

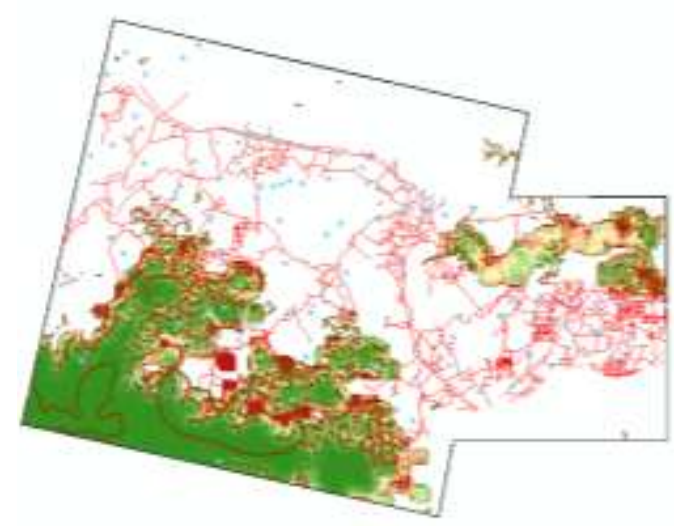

(e)

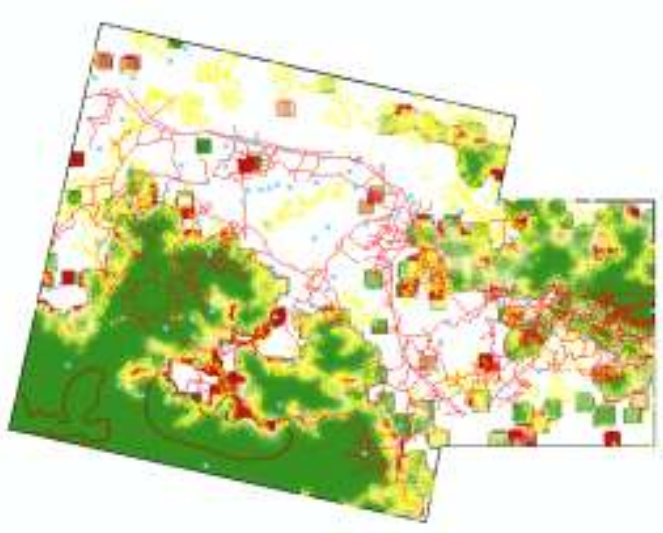

(c)

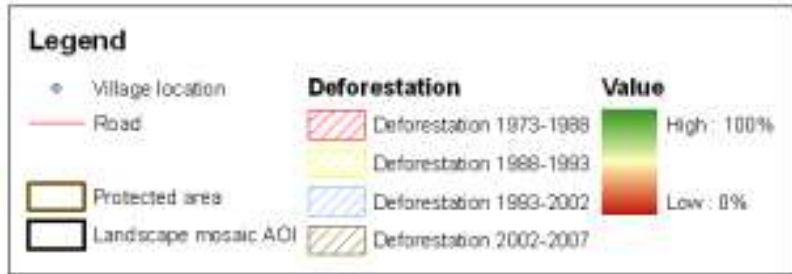

Figure 57. Time series of aggregation index of forest, (a) aggregation index in 1973 (b) aggregation index in 1988 with deforestation in $1973-1988$

(c)aggregation index in 1993 with deforestation in 1988-1993 (d) aggregation index in 2002 with deforestation in $1993-2002$ (e) aggregation index in 2007 with deforestation in 2002-2007 


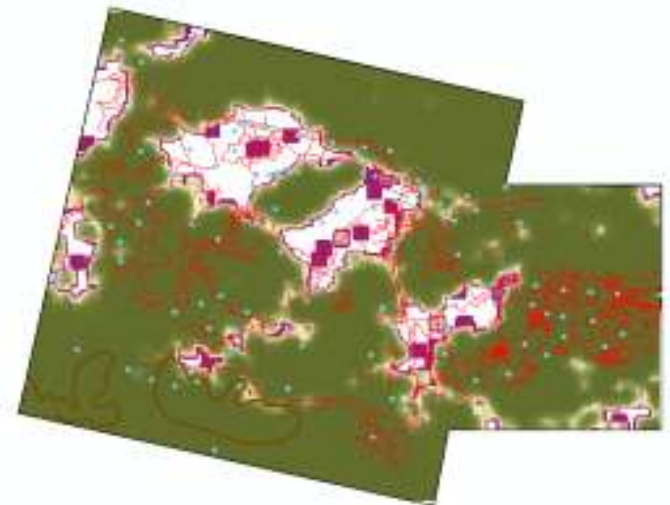

(a)

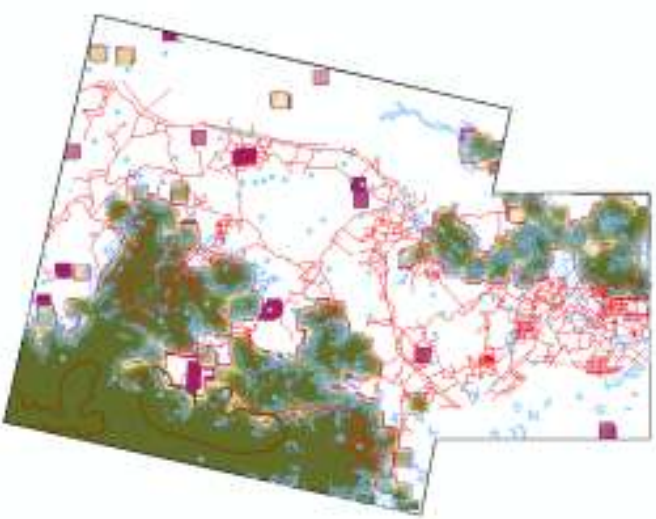

(d)

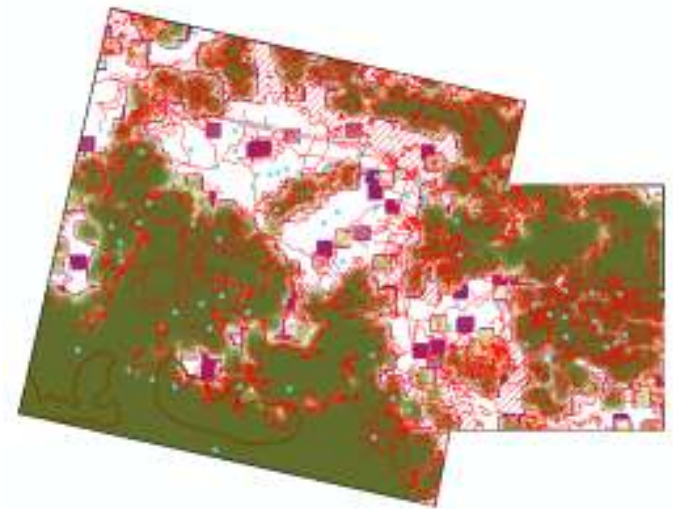

(b)

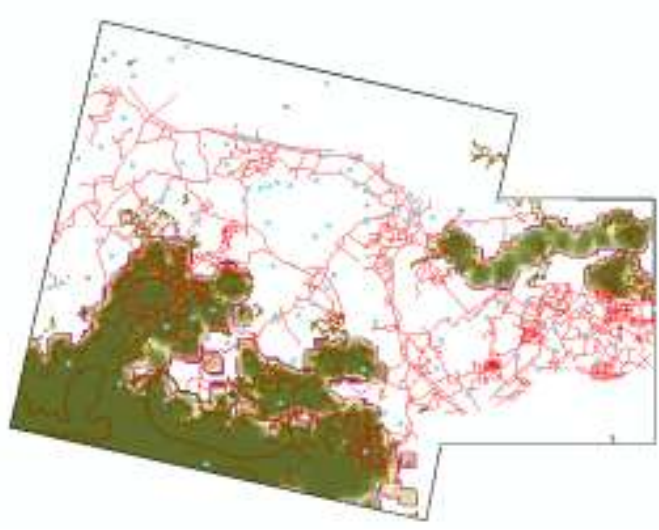

(e)

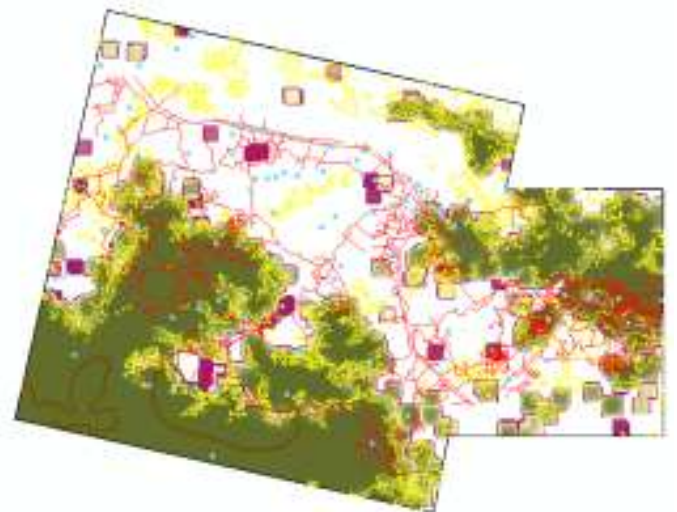

(c)

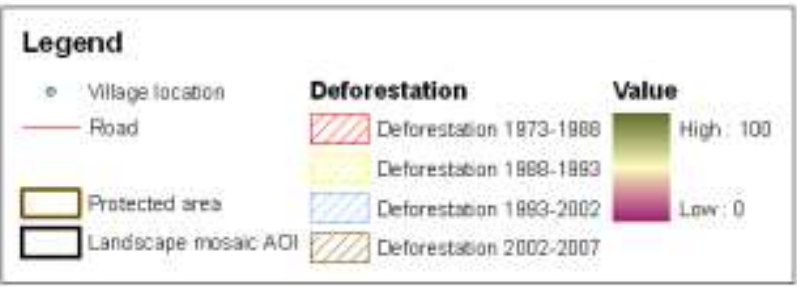

Figure 58. Time series of connectivity of forest, (a) connectivity in 1973 (b) connectivity in 1988 with deforestation in $1973-1988$ (c) connectivity in 1993 with deforestation in 1988-1993 (d) connectivity in 2002 with deforestation in 1993-2002 (e) connectivity in 2007 with deforestation in $2002-2007$ 


\section{Laos (Viengkham)}

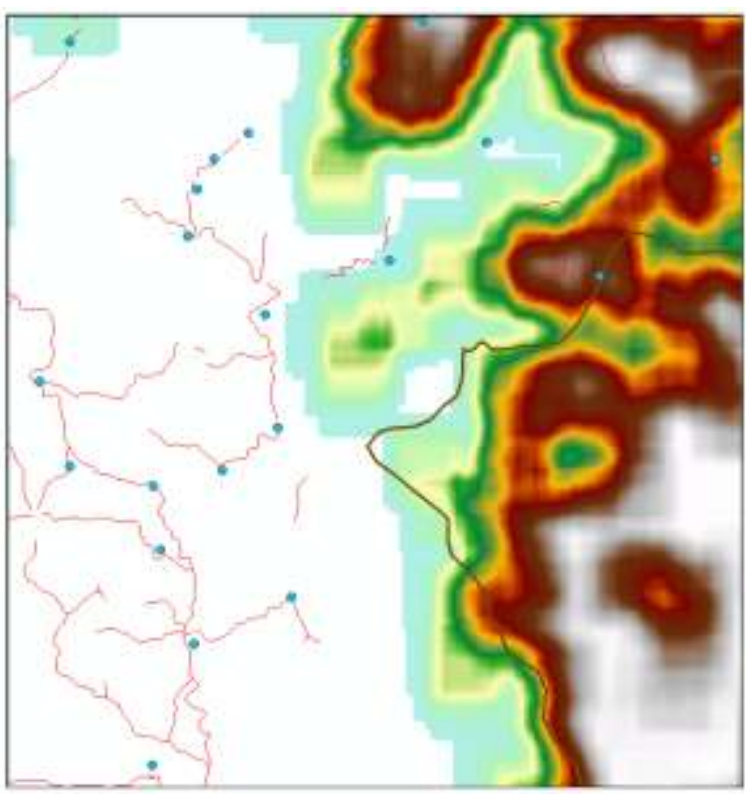

(a)

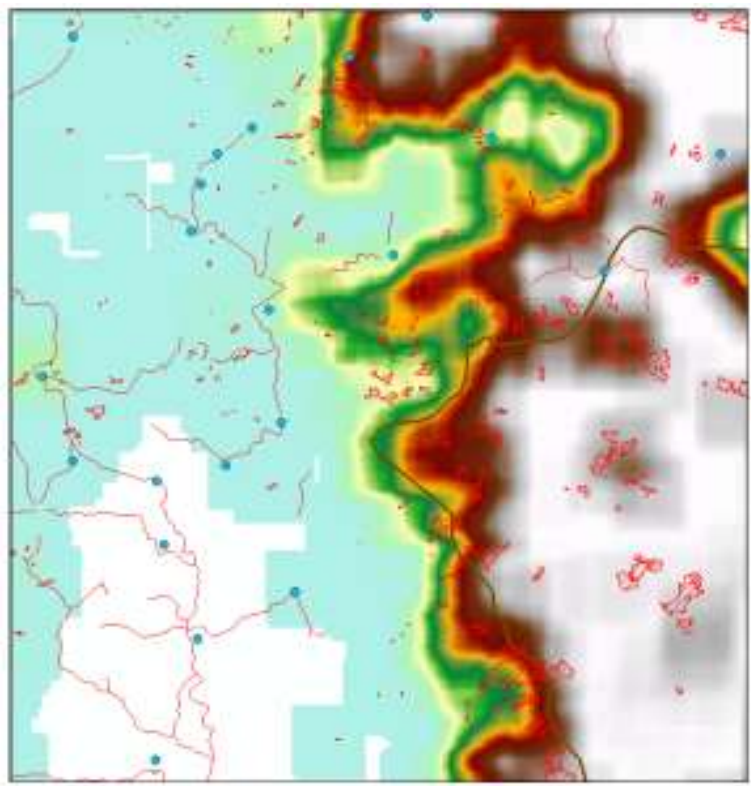

(b)

\section{Legend}

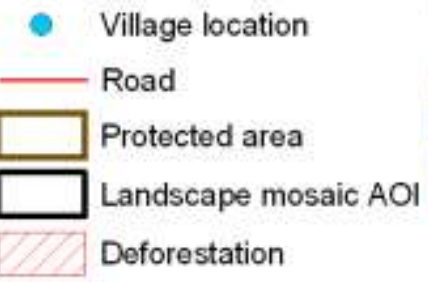

Value

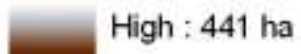

Low : 0 ha

Figure 59. Time series of total core area of forest, (a) total core area in 2002 (b) total core area in 2007 with deforestation 2002-2007 


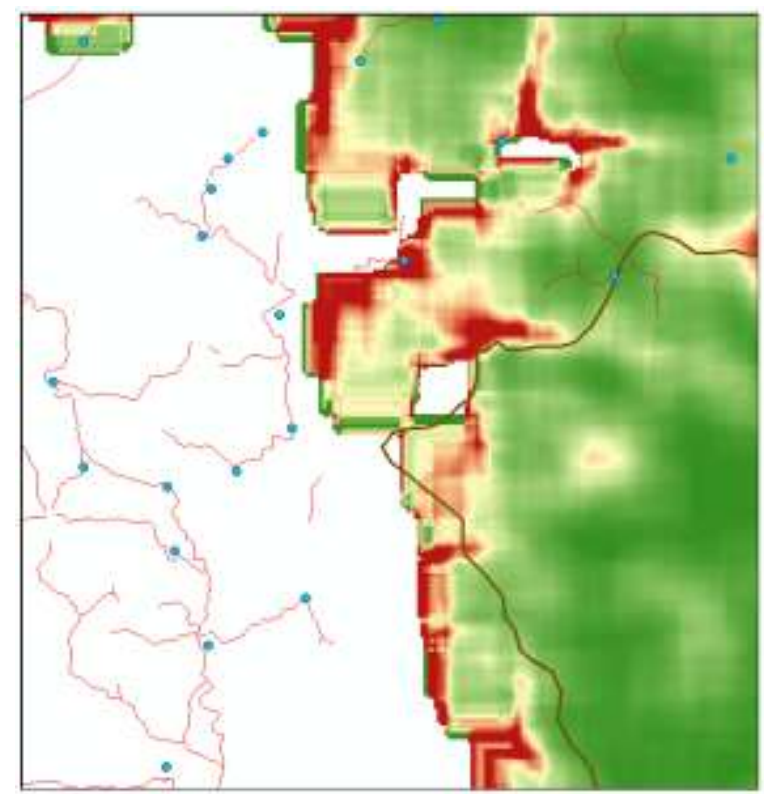

(a)

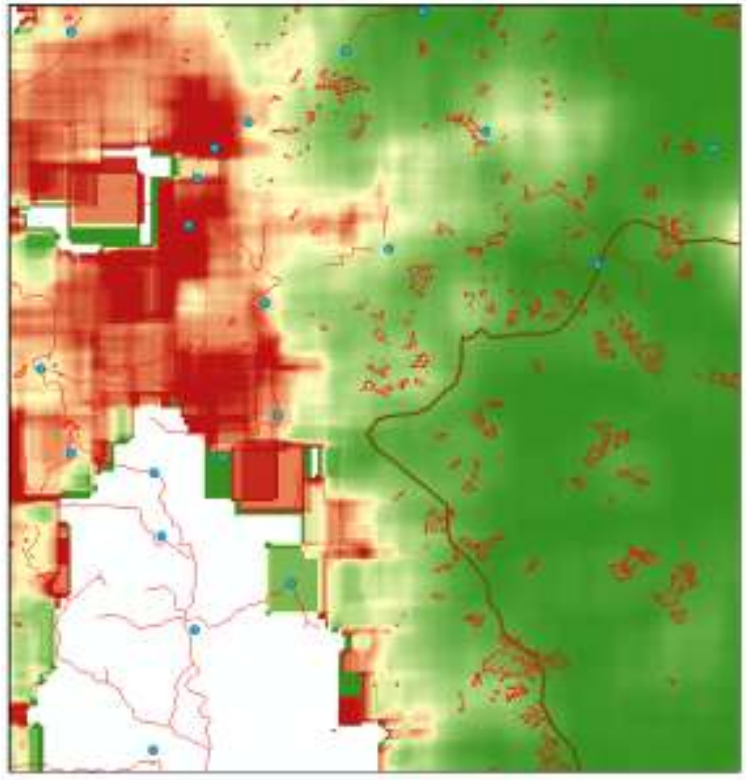

(b)

\section{Legend}

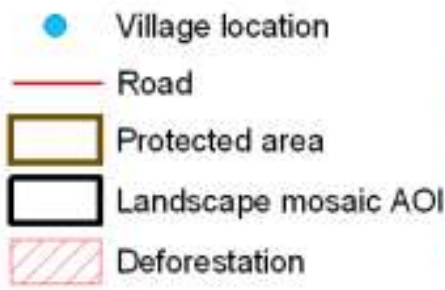

Value

High : $100 \%$

Low : $0 \%$

Figure 60. Time series of aggregation index of forest, (a) aggregation index in 2002 (b) aggregation index in 2007 with deforestation 2002-2007 


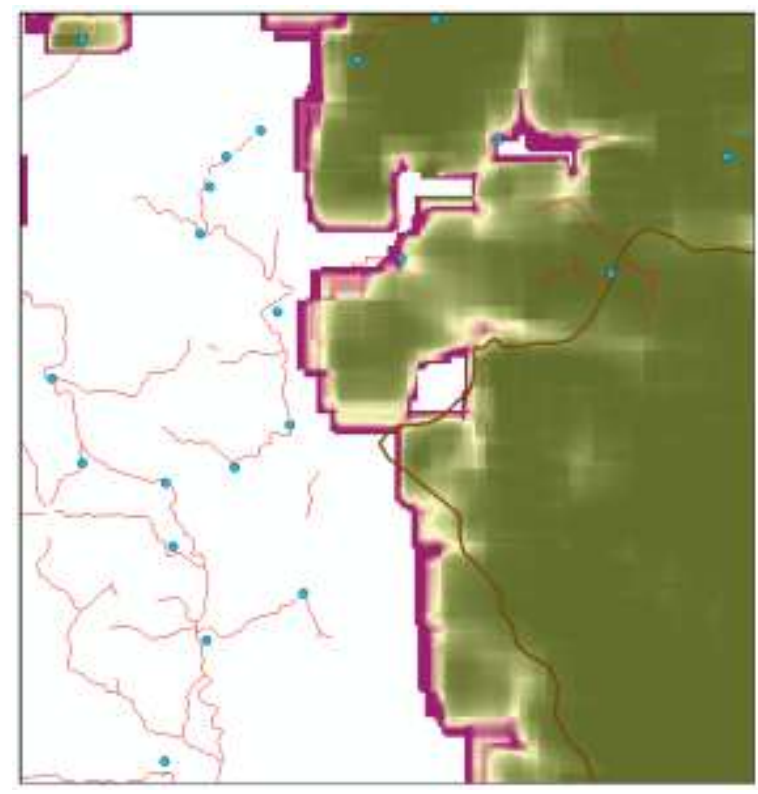

(a)

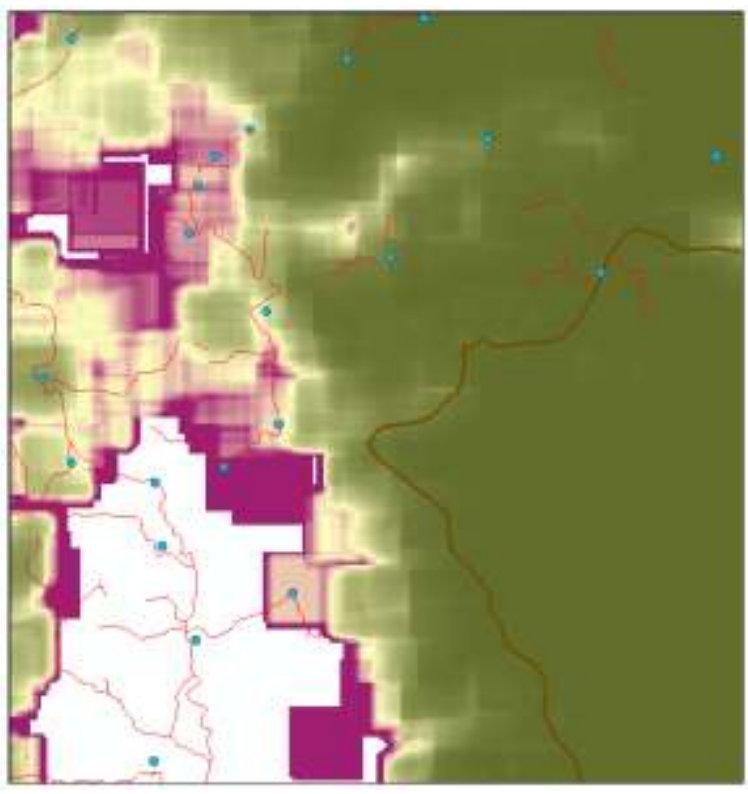

(b)

\section{Legend}

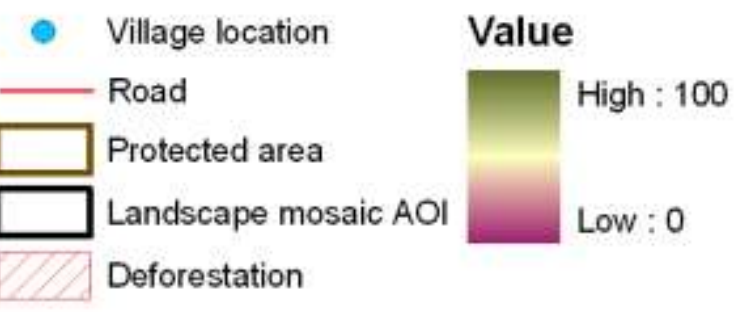

Figure 61. Time series of connectivity of forest, (a) connectivity in 2002 (b) connectivity in 2007 with deforestation 2002-2007 


\section{Madagascar (Manompana)}

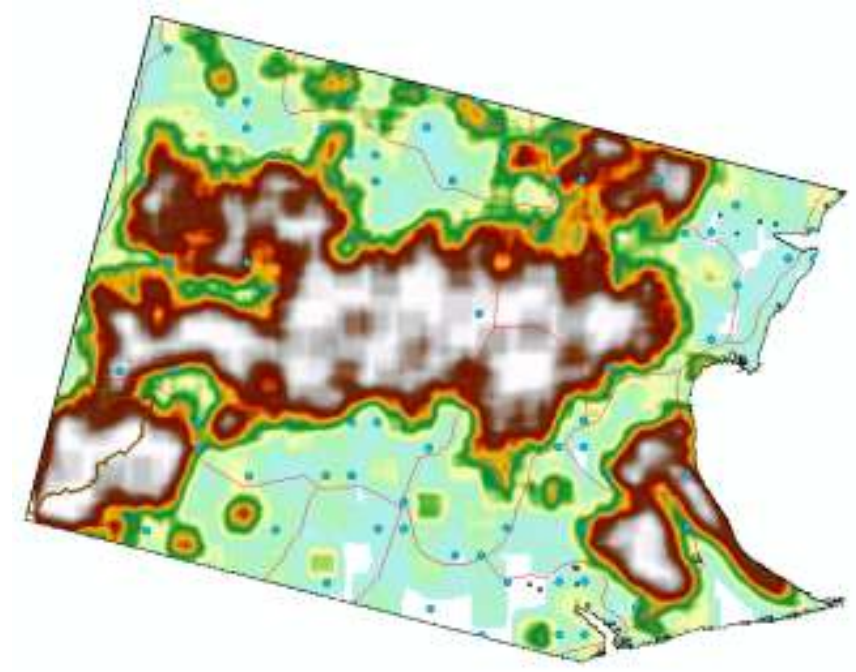

(a)

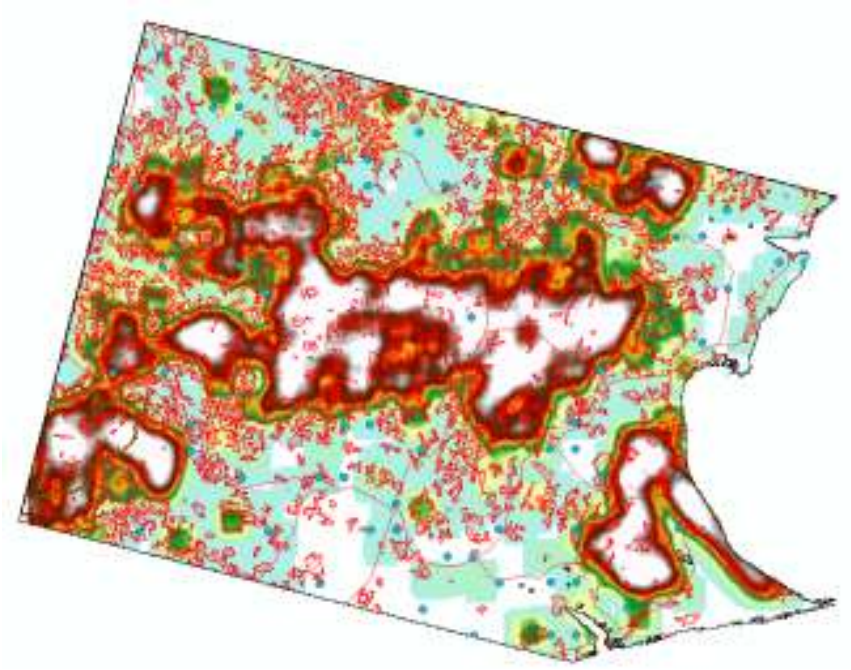

(b)

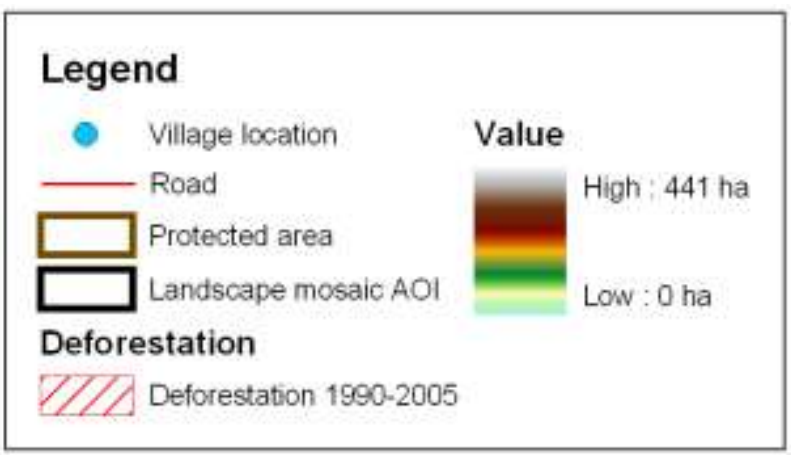

Figure 62. Time series of total core area of forest, (a) total core area in 1990 (b) total core area in 2005 with deforestation 1990-2005 


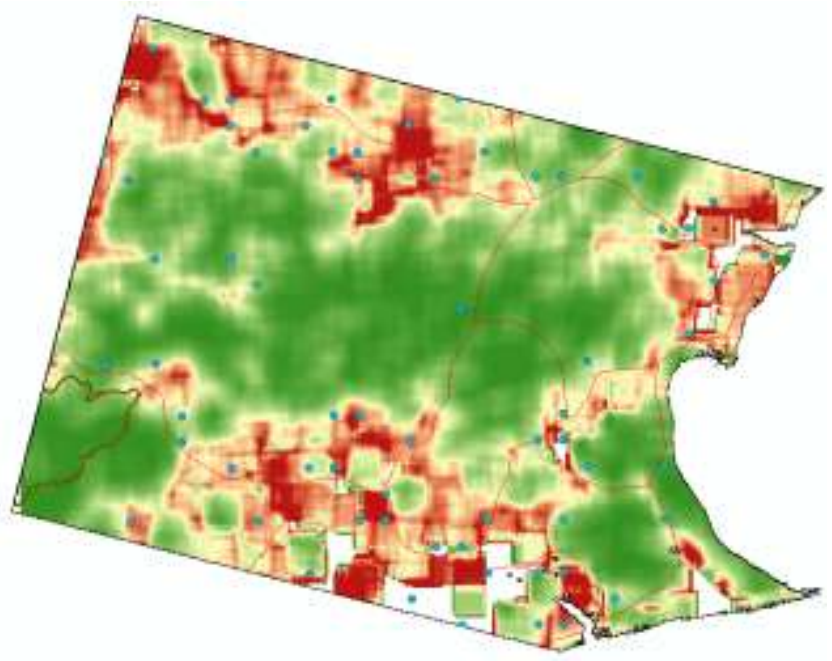

(a)

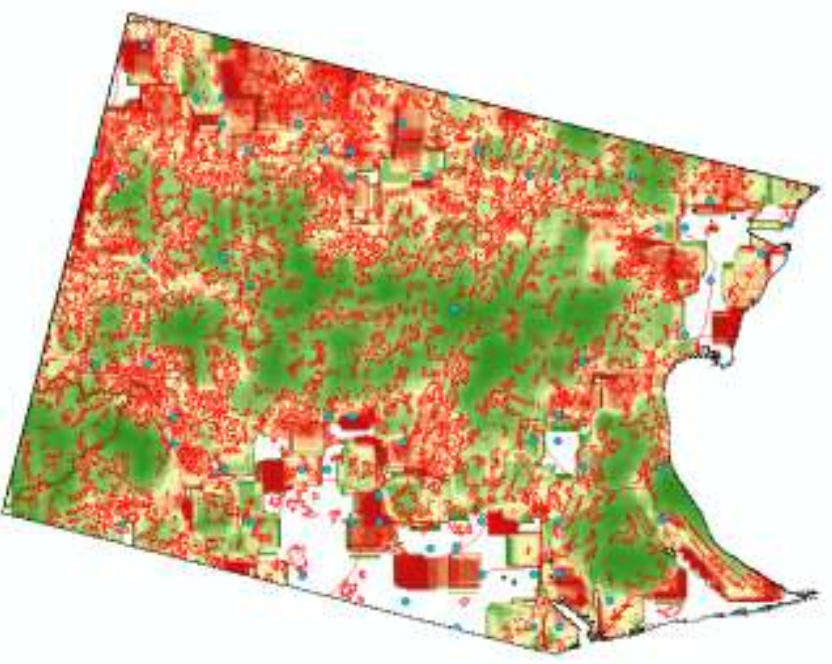

(b)

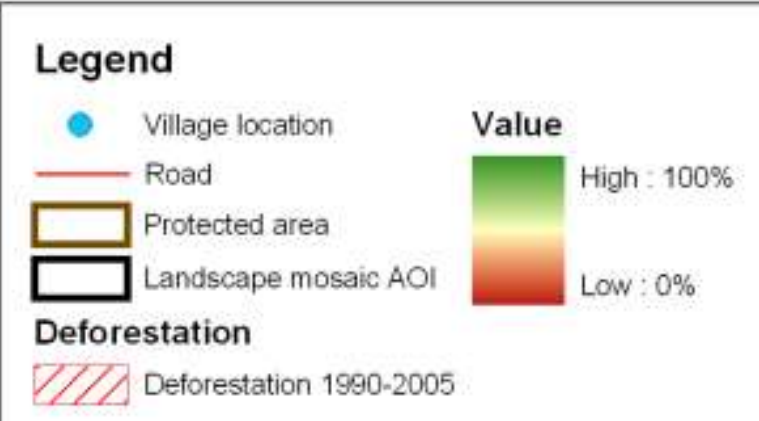

Figure 63. Time series of aggregation index forest, (a) aggregation index in 1990 (b) aggregation index in 2005 with deforestation 1990-2005 


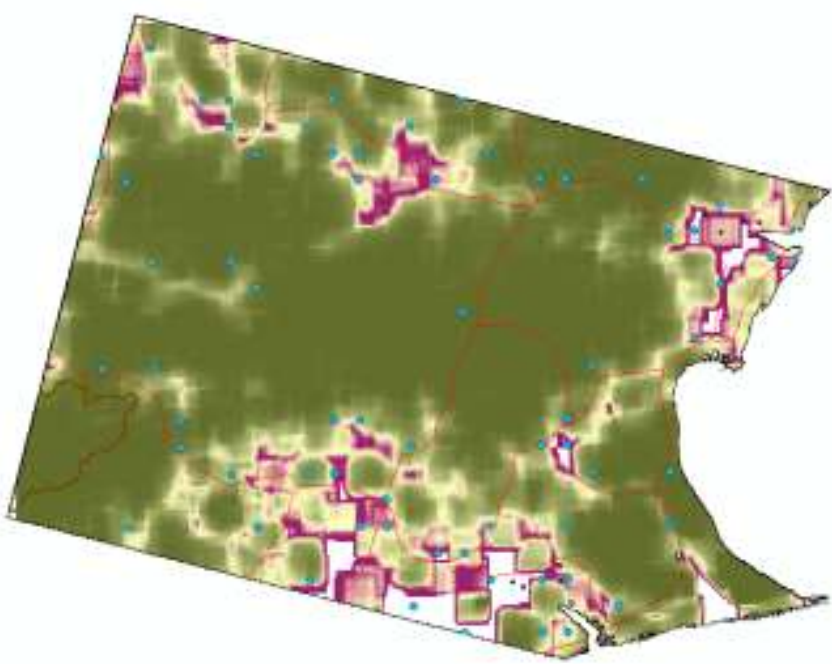

(a)

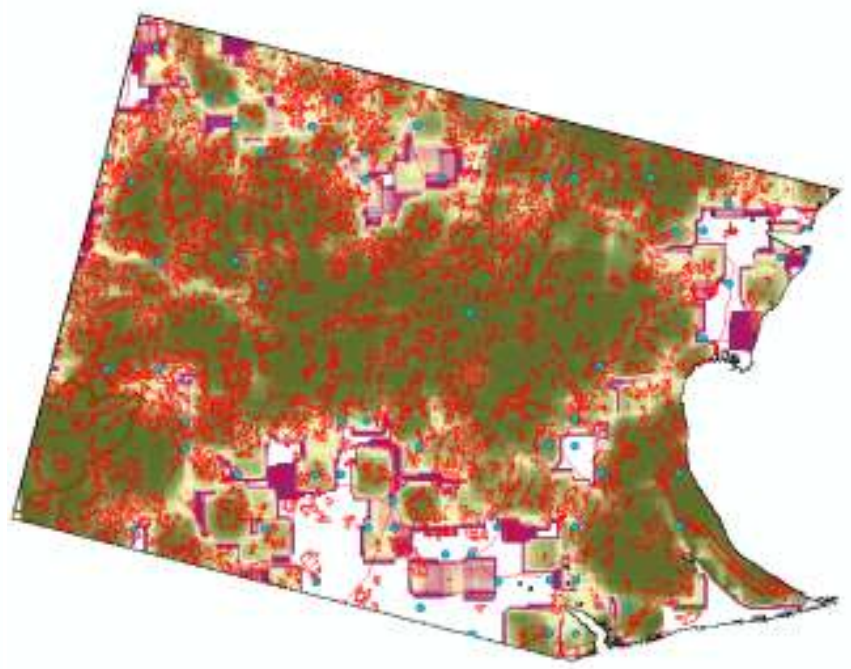

(b)

\section{Legend}

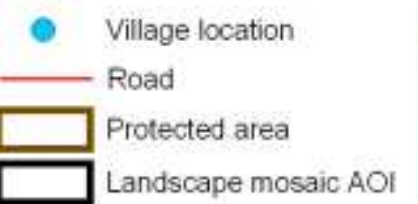

Value

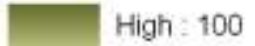

Deforestation

VI/ Deforestation 1990-2005

Figure 64. Time series of connectivity of forest, (a) connectivity in 1990 (b)connectivity in 2005 with deforestation 1990-2005 


\section{Cameroon (Takamanda Mone)}

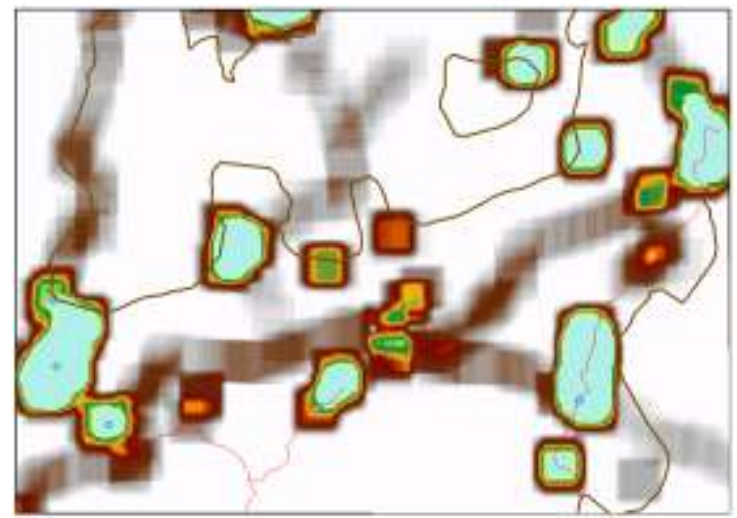

(a)

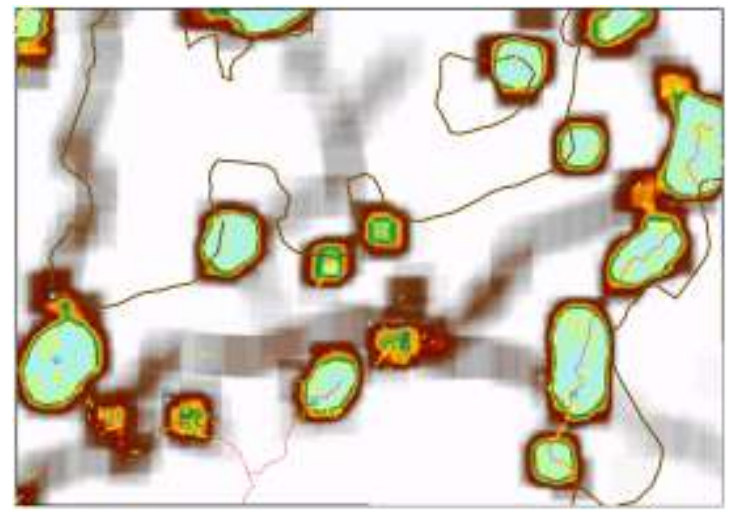

(c)

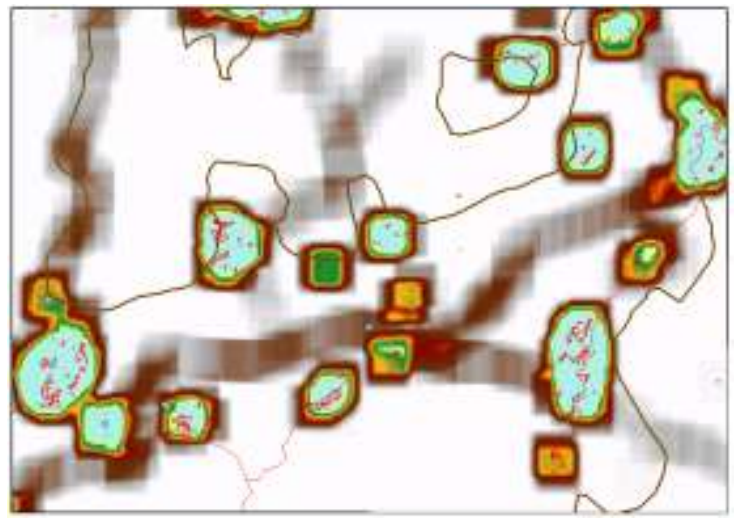

(b)

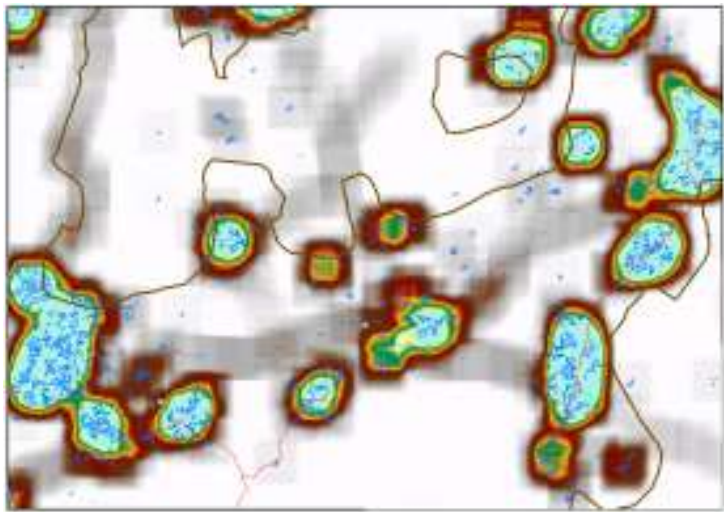

(d)

\section{Legend}

- Village location Deforestation

Value

\begin{tabular}{|c|c|c|}
\hline 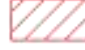 & Deforestation 1986-1990 & High : 441 ha \\
\hline & Deforestation 1990-2001 & \\
\hline & $\begin{array}{l}\text { Deforestation 2001-2005 } \\
\text { Protected area }\end{array}$ & Low : 44 ha \\
\hline
\end{tabular}

Figure 65. Time series of total core area of forest, (a) total core area in 1986 (b) total core area in 1990 with deforestation in 1986-1990 (c) total core area in 2001 with deforestation in 1990-2001 (d) total core area in 2005 with deforestation in 2001-2005 


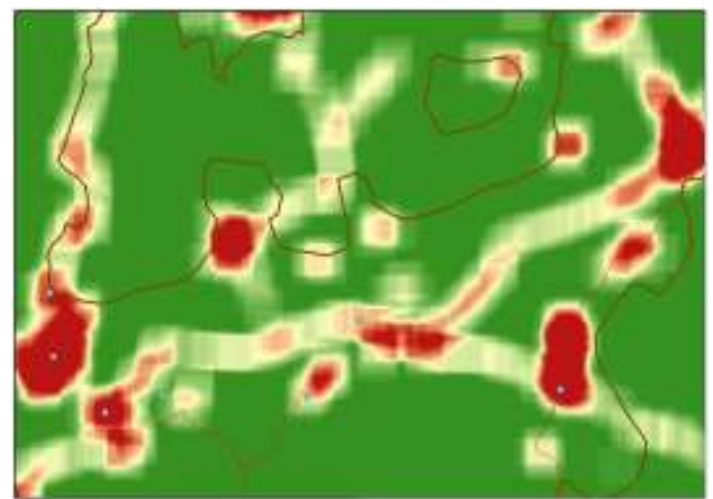

(a)

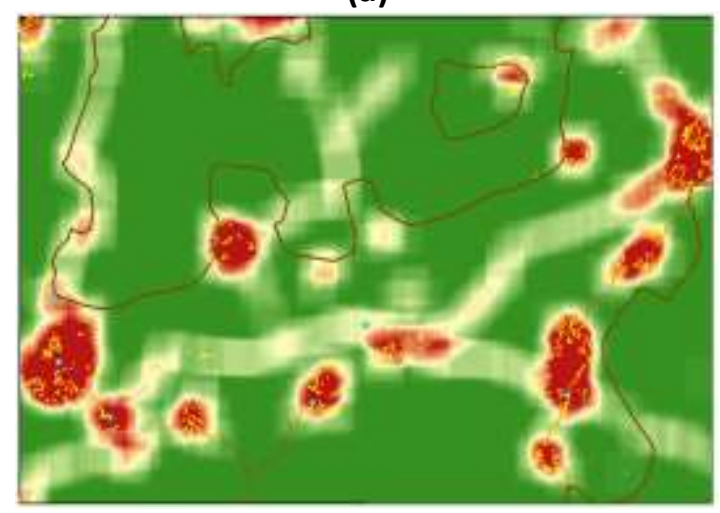

(c)

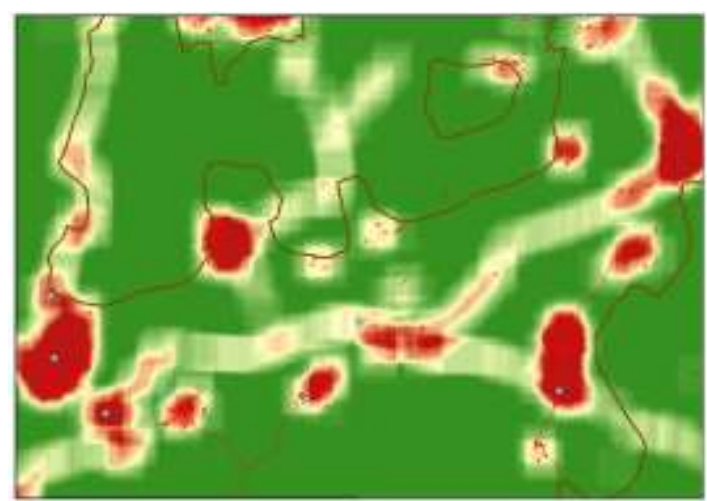

(b)

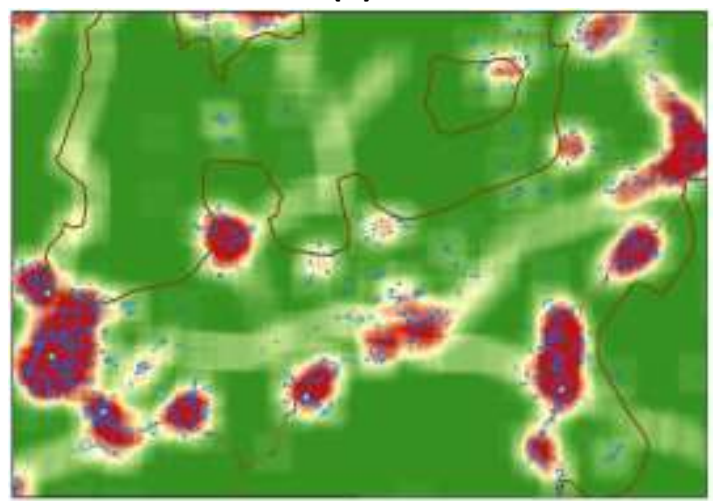

(d)

\section{Legend}

- Village location Deforestation

Value

Road

\begin{tabular}{|c|c|}
\hline Deforestation 1986-1990 & High : $100 \%$ \\
\hline Deforestation 1990-2001 & \\
\hline Deforestation 2001-2005 & Low : $41 \%$ \\
\hline Protected area & \\
\hline
\end{tabular}

Figure 66. Time series of aggregation index of forest, (a) aggregation index in 1986 (b) aggregation index in 1990 with deforestation in 1986-1990 (c) aggregation index in 2001 with deforestation in 1990-2001 (d) aggregation index in 2005 with deforestation in 2001-2005 


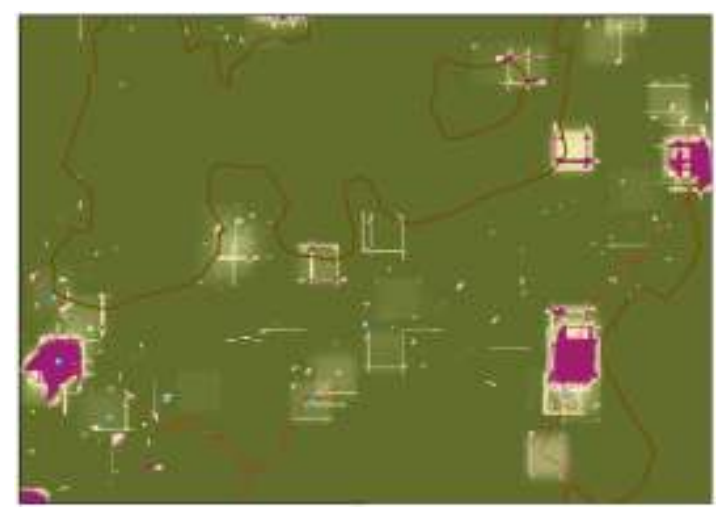

(a)

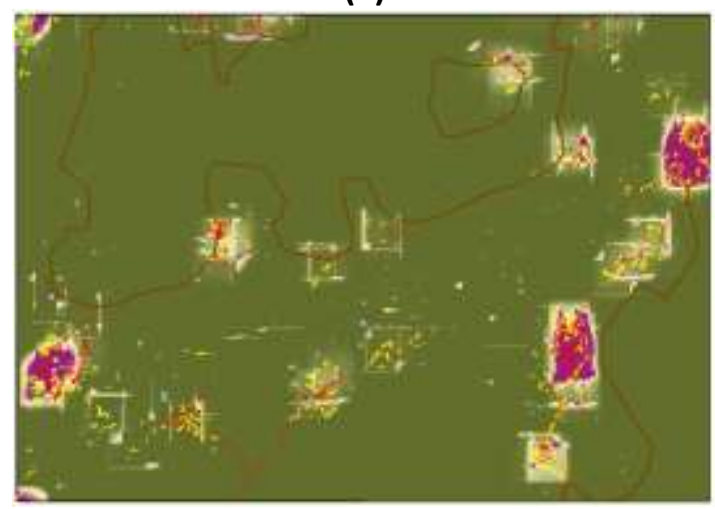

(c)

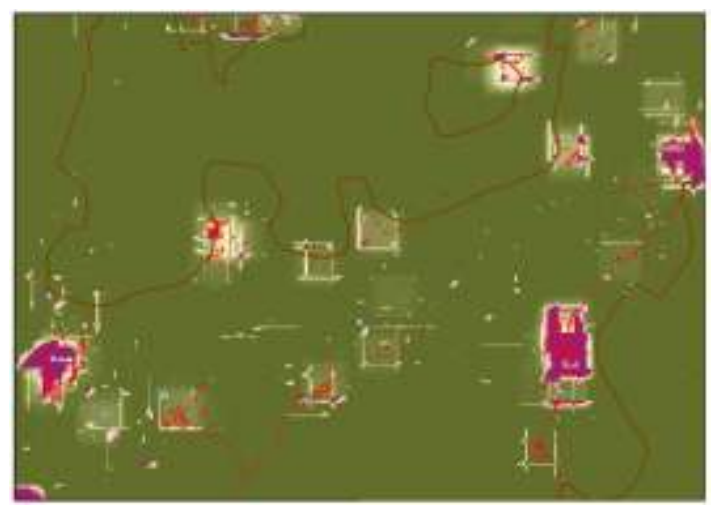

(b)

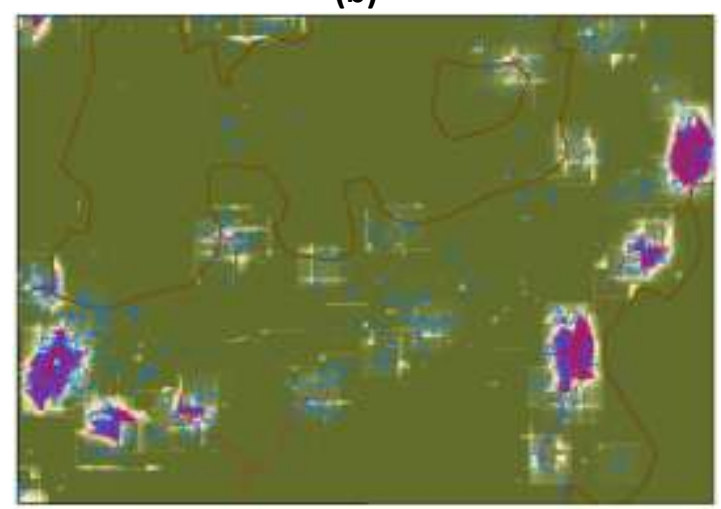

(d)

\section{Legend}

- Village location Deforestation

Value

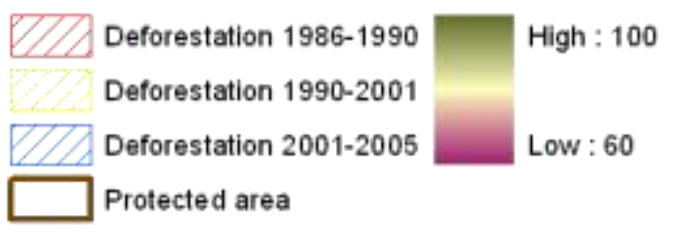

Figure 67. Time series of connectivity of forest, (a) connectivity in 1986 (b) connectivity in 1990 with deforestation in 1986-1990 (c) connectivity in 2001 with deforestation in 1990-2001 (d) connectivity in 2005 with deforestation in 2001-2005 


\section{Tanzania (East Usambara)}

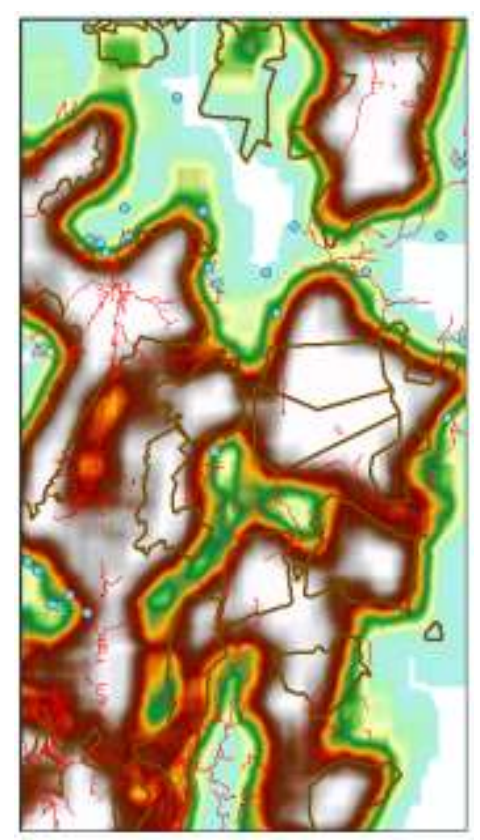

(a)

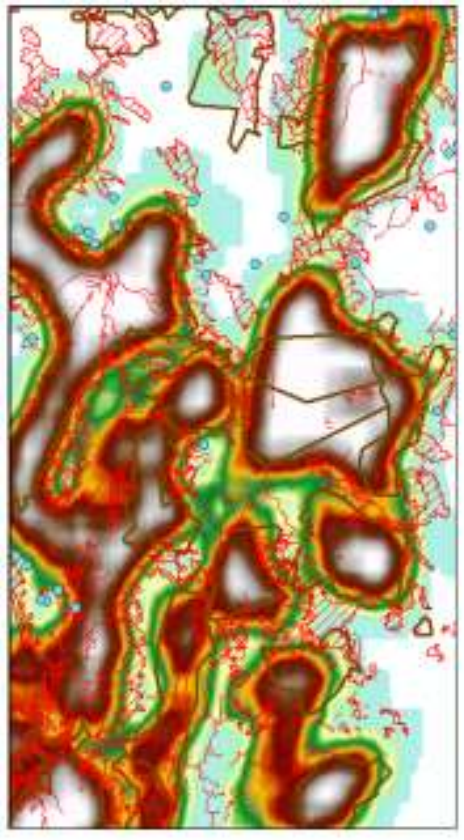

(b)

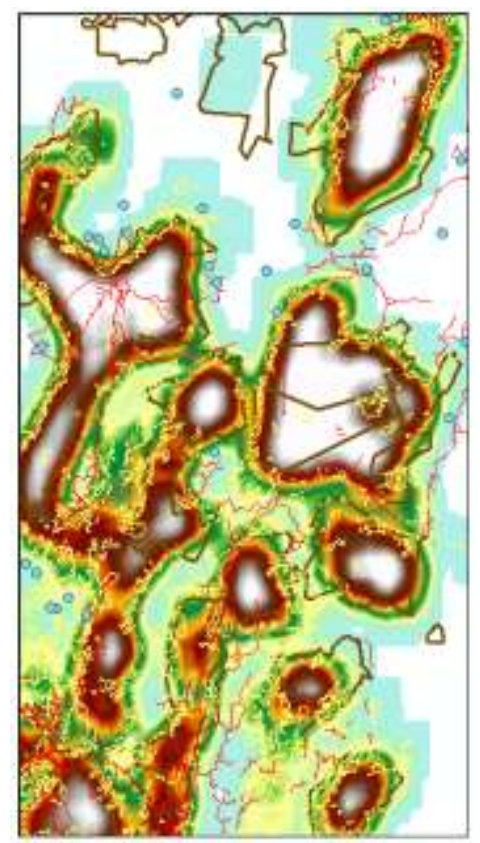

(c)

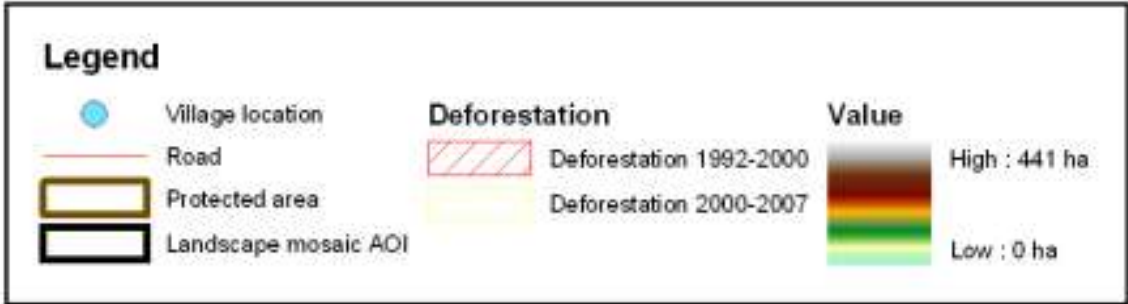

Figure 68. Time series of total core area of forest, (a) total core area in 1992 (b) total core area in 2000 with deforestation in 1992-2000 (c) total core area in 2007 with deforestation in 2000-2007 


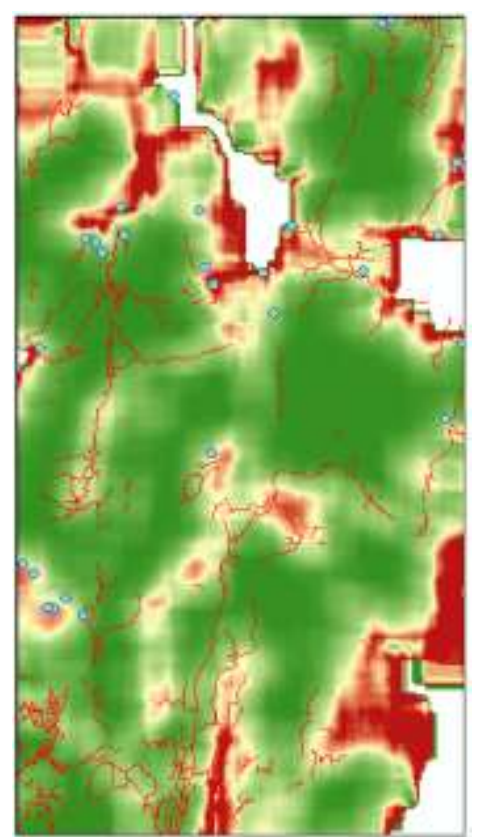

(a)

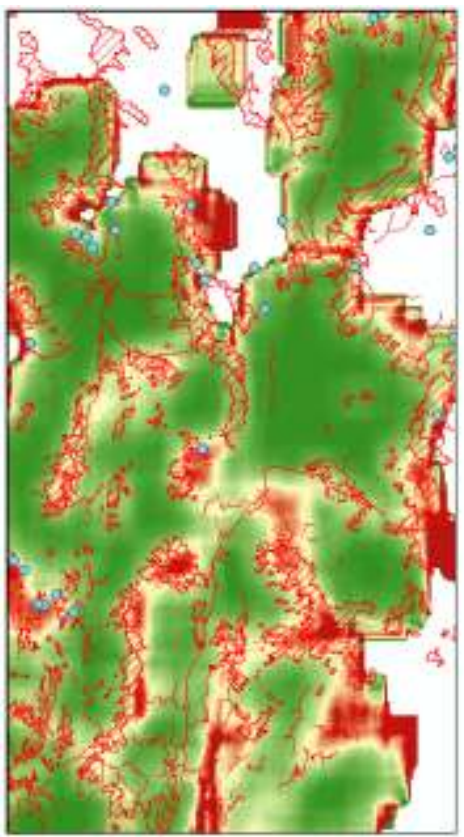

(b)

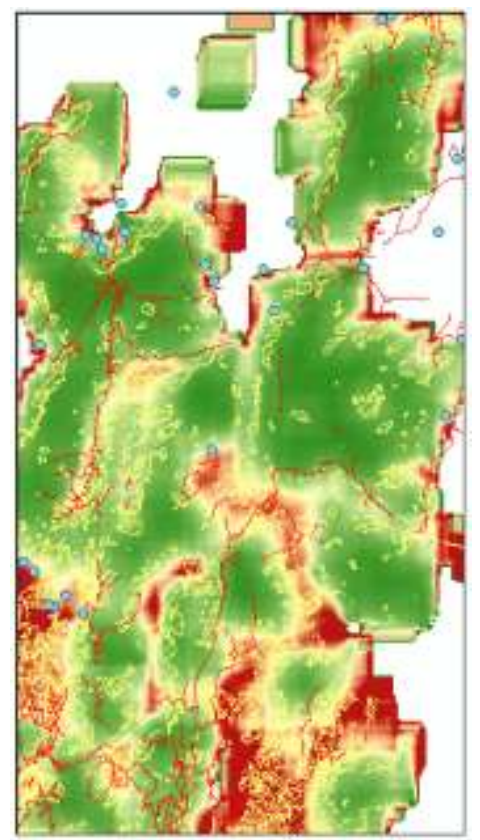

(c)

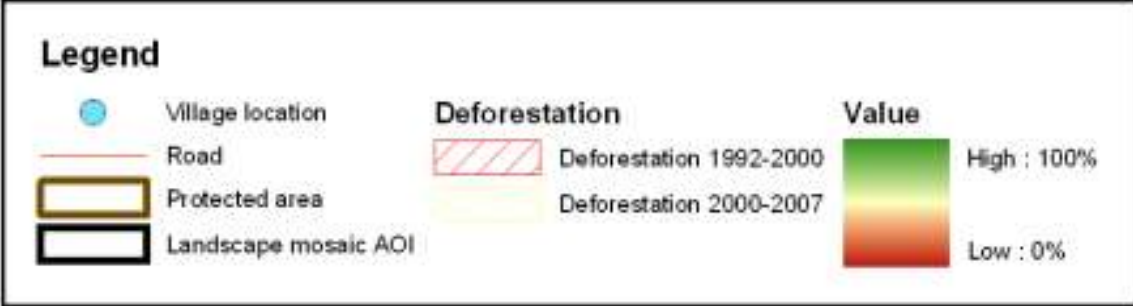

Figure 69. Time series of aggregation index of forest, (a) aggregation index in 1992 (b) aggregation index in 2000 with deforestation in 1992-2000 (c) aggregation index in 2007 with deforestation in 20002007 


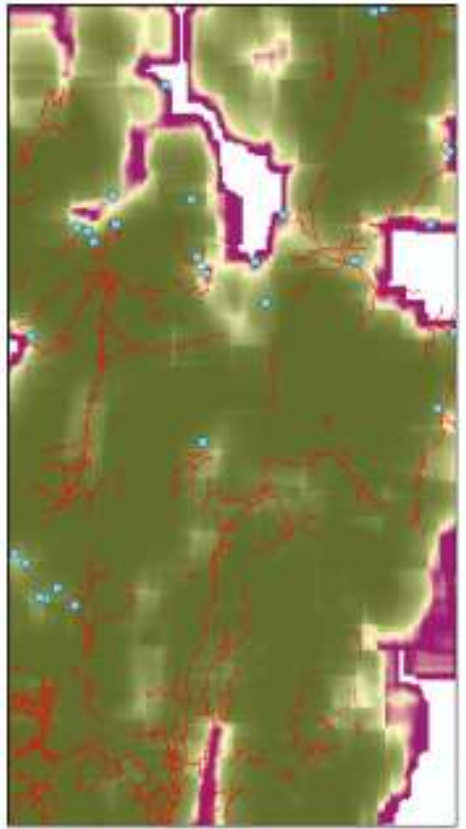

(a)

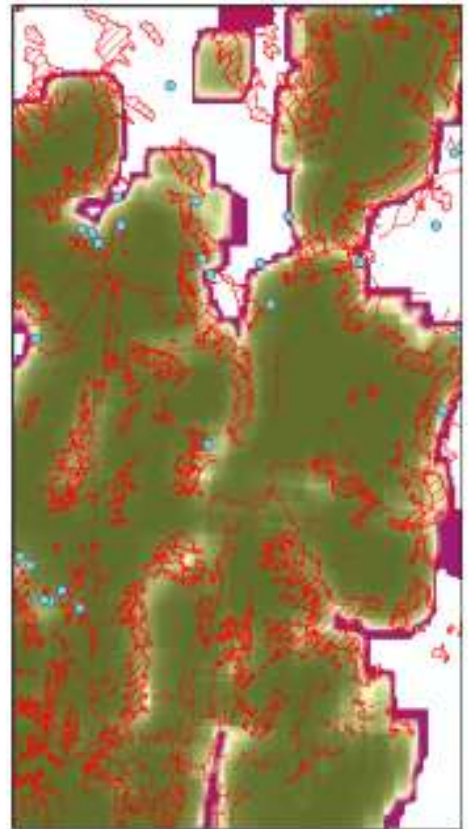

(b)

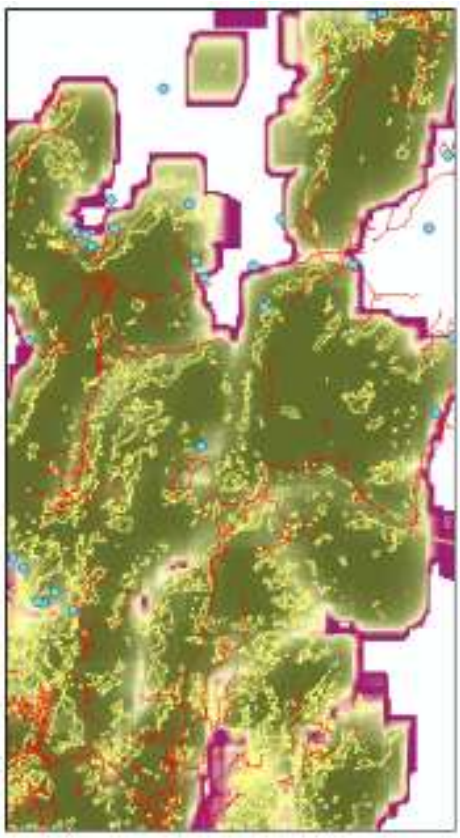

(c)

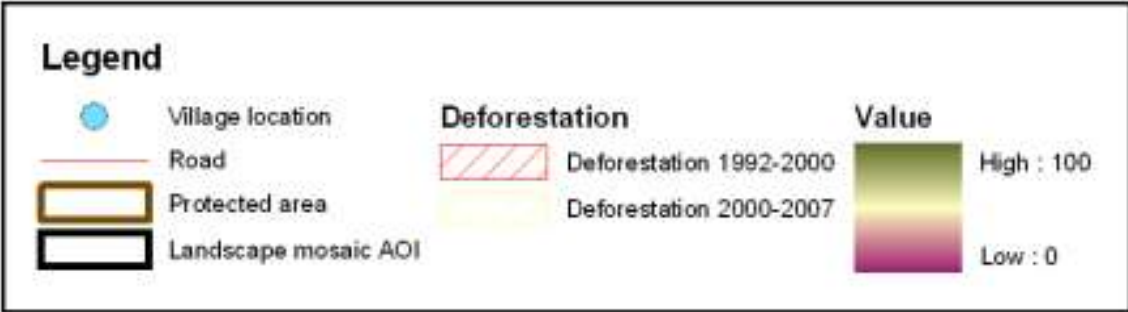

Figure 70. Time series of connectivity of forest, (a) connectivity in 1992 (b) connectivity in 2000 with deforestation in 1992-2000 (c) connectivity in 2007 with deforestation in 2000-2007 


\section{Next steps}

The results of the on-going research will further be analyzed and synthesized as well as being used for more detailed studies, including the following:

- Linking the analysis to the on-the-ground knowledge of trends and drivers and livelihoods

- Adding more data in the time series of Laos (period I and II), Cameroon and Madagascar (period II)

- Further classifying the land use/cover types by differentiating forests based on density and by differentiating tree cover based on number of dominant tree species (monoculture or mixed)

- Comparing land use and land cover changes inside and outside protected areas

- Ground-truthing for accuracy analysis

- Linking the analysis with the results of quick tree diversity survey

- Based on 'Quick Tree Diversity Survey' and analysis of dispersal, experimenting different sets of parameters to derive functional indices that reflect ecological processes and speciesspecific characteristics

- Exploring more indices that can quantify ecological properties of landscapes beyond visualization

- Scenario analysis from visioning exercise to identify opportunity and constraints for biodiversity conservation in the landscape mosaics, and therefore options and possible interventions (policies, rewards for environmental services) 


\section{Conclusion}

Changes in landscape composition and configuration over time due to land use/cover changes, including deforestation, are marked in the five landscapes of Bungo (Indonesia), Viengkham (Laos), Manompana (Madagascar), Takamanda-Mone (Cameroon) and East Usambara (Tanzania). Except for Viengkham (with only two time series such that data is very limiting), other landscapes experience decreases of forest cover over time with varying rates. Subsequent land use/cover post-deforestation also varies from fallow, mixed-tree based system such as rubber and cinnamon or monoculture trees such as oil palm and acacia, cropland and settlement. In most recent year, based on forest and tree cover fraction, the order of forest transition stages from earliest to the most advanced of the landscapes under study is Takamanda-Mone, Viengkham, Manompana, East Usambara and Bungo, with Bungo being close to reaching the reversal mode from declining forest cover to increasing tree cover. Spatial pattern of deforestation is determined by topography and transportation network (road and river) as well as the configuration of forest blocks and settlement locations/population densities. Changes in landscape level indices indicate the loss of forest core area, increased fragmentation and reduced connectivity over time, and can be used as a quick criteria to assess risks of extinction of species with particular characteristics (habitat specialized species is sensitive to rapid reduction of forest core area; species with no ability to migrate swiftly is sensitive to rapid increase of fragmentation and species which do not disperse their propagules broad enough are sensitive to rapid decrease of connectivity). The case of East Usambara is the worst among the five landscapes for such habitat specialized, sedentary and narrowly disperses species because of its high rate of habitat loss is simultaneous with rapid increase of fragmentation and decrease in connectivity.

Spatial variations of forest core area, aggregation and connectivity indices across the landscapes (indices at sub-landscape level computes across the entire landscape), which can be visualized as maps can offer valuable information and function as tools for negotiation platform within land use planning process. Past spatial pattern of deforestation can suggest where within the landscape the future deforestation will take place. In conjunction with scenario simulation based on multi-agent modelling, empirical modelling or spatially-explicit driver modelling, projection of likely areas of deforestation based on past spatial deforestation pattern can spot vulnerable area of forest core area loss, fragmentation and reduced connectivity. This will help multiple stakeholders to jointly produce guidelines, criteria and indicators of multifunctional landscapes concerning biodiversity, and further identifying options and deciding on 'optimal' landscapes where opportunity lost is lowest and conservation potential is highest. 


\section{References}

Akiefnawati, R., Villamor, G.B., Zulfikar, F., Budisetiawan, I., Mulyoutami, E., Ayat, A., van Noordwijk, M. 2010. Stewardship agreement to reduce emissions from deforestation and degradation (REDD): Lubuk Beringin's hutan desa as the first village forest in Indonesia. Working Paper 102. Bogor, Indonesia: World Agroforestry Centre (ICRAF) Southeast Asia Program.

Bhagwat, S.A., Willis, K.J., Briks, H.J.B. and Whittaker, R.J. 2008. Agroforestry: A refuge for tropical biodiversity? Trends in Ecology and Evolution, 23(5): 261-267.

Collen, B., Ram, M., Zamin, T. and McRae, L. 2008. The tropical biodiversity data gap: addressing disparity in global monitoring.Tropical Conservation Science 1 (2):75-88.

Ekadinata, A. and Vincent, G. 2008. Dinamika Tutupan Lahan Kabupaten Bungo, Jambi. In: Adnan H, Tadjudin D, Yuliani L, Komarudin H, Lopulalan D, Siagian Y, Munggoro D, eds. 2008. Belajar Dari Bungo: Mengelola Sumberdaya Alam di Era Desentralisasi. Bogor, Indonesia: Center for International Forestry Research.

Giller, K.E., Bignell, D.E., Lavelle, P., Swift, M.J., Barrios, E., Moreira, F., van Noordwijk, M., Barois, I., Karanja, N., \& Huising, J., 2005. Soil biodiversity in rapidly changing tropical landscapes: scaling down and scaling up. In Biological Diversity and Function in Soils (eds M.B. Usher, R. Bardgett \& D.W. Hopkins), pp. 295-318. Cambridge University Press, Cambridge.

Ewers, R.M., Marsh, C.J. and Wearn, O.R. 2010. Making statistics biologically relevant in fragmented landscapes. Trends in Ecology and Evolution 25: 699-704

Gardner, T.A. et al. 2009. Prospects for tropical forest biodiversity in a human-modified world. Ecology Letters 12:561-582

Koh, L.P., et al. 2009. Designer landscapes for sustainable biofuels. Trends in Ecology and Evolution 24:431 -438.

Krauss, J. et al. 2010. Habitat fragmentation causes immediate and timedelayed biodiversity loss at different trophic levels. Ecology Letters 13: 597-605.

Kuussaari, M., Bommarco, R., Heikkinen, R.K., Helm, A., Krauss, J., Lindborg, R. et al. 2009. Extinction debt: a challenge for biodiversity conservation. Trends in Ecology and Evolution 24: 564-571.

Lindenmayer, D., Hobbs, R.J., Montague-Drake, R., Alexandra, J., Benett, A., Burgman, M. et al. 2008. A checklist for ecological managment of landscapes for conservation. Ecology Letters 11: 78-91.

Martini, E., Akiefnawati, R., Joshi, L., Dewi, S., Ekadinata, A., Feintrenie, R., van Noordwijk, M. 2010. Rubber agroforests and governance: At the interface between conservation and livelihoods in Bungo district, Jambi province, Indonesia. Working Paper 10X. World Agroforestry Centre Southeast Asia Regional Office.

O'Connor, T. 2005. Birds in Coffee Agroforestry Systems of. West Lampung, Sumatra. Doctoral Thesis. University of Adelaide.

Pfund, J-L et al. 2010. Local perceptions of trees and forests in increasingly globalized tropical landscapes. Manuscript in preparation.

Mather, A.S. 1992. The forest transition. Area 24(4): 367-379.

McGarigal, K and Marks, B.J. 1995. FRAGSTATS: spatial pattern analysis program for quantifying landscape structure. 
Mc Neely, J.A. and G. Schroth. 2006. Agroforestry and biodiversity conservation: Traditional practices, present dynamics and lessons for the future. Biodiversity and Conservation 15: 549554.

Rasnovi, S. 2006. Ekologi Regenerasi Tumbuhan Berkayu pada Sistem Agroforest Karet. Doctoral Thesis. Insitut Pertanian Bogor.

Sala, O.E. et al. 2000. Global biodiversity scenarios for the year 2100. Science 287: 1770-1774.

Swallow, B., Boffa, J-M., Scherr, S.J. 2006. The potential for agroforestry to contribute to the conservation and enhancement of landscape biodiversity. In: Garrity DP, Okono A, Grayson $\mathrm{M}$ and Parrott S, (eds.). World Agroforestry into the future. Nairobi: World Agroforestry Centre (ICRAF) p. 95-101. [2006146] ICRAFP.

Tilman, D. et al. 1994. Habitat destruction and the extinction debt. Nature 371: 65-66.

Tilman D, Fargione J, Wolff B, D'Antonio C, Dobson A, Howarth R, et al. 2001. Forecasting agriculturally driven global environmental change. Science 292:281-284.

Uezu, A. 2008. Can agroforest woodlots work as stepping stones for birds in the Atlantic forest region?. Biodiversity Conservation 17:1907-1922.

van Noordwijk, M. 2006. Equipping integrated natural resource managers for healthy agroforestry landscapes. WP0074-06. World Agroforestry Centre. Southeast Asia Regional Office. 


\section{WORKING PAPERS IN THIS SERIES}

\section{5}

1. Agroforestry in the drylands of eastern Africa: a call to action

2. Biodiversity conservation through agroforestry: managing tree species diversity within a network of community-based, nongovernmental, governmental and research organizations in western Kenya.

3. Invasion of prosopis juliflora and local livelihoods: Case study from the Lake Baringo area of Kenya

4. Leadership for change in farmers organizations: Training report: Ridar Hotel, Kampala, 29th March to 2nd April 2005.

5. Domestication des espèces agroforestières au Sahel : situation actuelle et perspectives

6. Relevé des données de biodiversité ligneuse: Manuel du projet biodiversité des parcs agroforestiers au Sahel

7. Improved land management in the Lake Victoria Basin: TransVic Project's draft report.

8. Livelihood capital, strategies and outcomes in the Taita hills of Kenya

9. Les espèces ligneuses et leurs usages: Les préférences des paysans dans le Cercle de Ségou, au Mali

10. La biodiversité des espèces ligneuses: Diversité arborée et unités de gestion du terroir dans le Cercle de Ségou, au Mali

2006

11. Bird diversity and land use on the slopes of Mt. Kilimanjaro and the adjacent plains, Tanzania

12. Water, women and local social organization in the Western Kenya Highlands

13. Highlights of ongoing research of the World Agroforestry Centre in Indonesia

14. Prospects of adoption of tree-based systems in a rural landscape and its likely impacts on carbon stocks and farmers' welfare: The FALLOW Model Application in Muara Sungkai, Lampung, Sumatra, in a 'Clean Development Mechanism' context

15. Equipping integrated natural resource managers for healthy agroforestry landscapes.

16. Are they competing or compensating on farm? Status of indigenous and exotic tree species in a wide range of agro-ecological zones of Eastern and Central Kenya, surrounding Mt. Kenya.

17. Agro-biodiversity and CGIAR tree and forest science: approaches and examples from Sumatra.

18. Improving land management in eastern and southern Africa: A review of polices.

19. Farm and household economic study of Kecamatan Nanggung, Kabupaten Bogor, Indonesia: A socio-economic base line study of agroforestry innovations and livelihood enhancement.

20. Lessons from eastern Africa's unsustainable charcoal business.

21. Evolution of RELMA's approaches to land management: Lessons from two decades of research and development in eastern and southern Africa

22. Participatory watershed management: Lessons from RELMA's work with farmers in eastern Africa. 
23. Strengthening farmers' organizations: The experience of RELMA and ULAMP.

24. Promoting rainwater harvesting in eastern and southern Africa.

25. The role of livestock in integrated land management.

26. Status of carbon sequestration projects in Africa: Potential benefits and challenges to scaling up.

27. Social and Environmental Trade-Offs in Tree Species Selection: A Methodology for Identifying Niche Incompatibilities in Agroforestry [Appears as AHI Working Paper no. 9]

28. Managing tradeoffs in agroforestry: From conflict to collaboration in natural resource management. [Appears as AHI Working Paper no. 10]

29. Essai d'analyse de la prise en compte des systemes agroforestiers pa les legislations forestieres au Sahel: Cas du Burkina Faso, du Mali, du Niger et du Senegal.

30. Etat de la recherche agroforestière au Rwanda etude bibliographique, période 1987-2003

\section{7}

31. Science and technological innovations for improving soil fertility and management in Africa: A report for NEPAD's Science and Technology Forum.

32. Compensation and rewards for environmental services.

33. Latin American regional workshop report compensation.

34 Asia regional workshop on compensation ecosystem services.

35 Report of African regional workshop on compensation ecosystem services.

36 Exploring the inter-linkages among and between compensation and rewards for ecosystem services CRES and human well-being

37 Criteria and indicators for environmental service compensation and reward mechanisms: realistic, voluntary, conditional and pro-poor

38 The conditions for effective mechanisms of compensation and rewards for environmental services.

39 Organization and governance for fostering Pro-Poor Compensation for Environmental Services.

40 How important are different types of compensation and reward mechanisms shaping poverty and ecosystem services across Africa, Asia \& Latin America over the Next two decades?

41. Risk mitigation in contract farming: The case of poultry, cotton, woodfuel and cereals in East Africa.

42. The RELMA savings and credit experiences: Sowing the seed of sustainability

43. Yatich J., Policy and institutional context for NRM in Kenya: Challenges and opportunities for Landcare.

44. Nina-Nina Adoung Nasional di So! Field test of rapid land tenure assessment (RATA) in the Batang Toru Watershed, North Sumatera.

45. Is Hutan Tanaman Rakyat a new paradigm in community based tree planting in Indonesia?

46. Socio-Economic aspects of brackish water aquaculture (Tambak) production in Nanggroe Aceh Darrusalam.

47. Farmer livelihoods in the humid forest and moist savannah zones of Cameroon. 
48. Domestication, genre et vulnérabilité : Participation des femmes, des Jeunes et des catégories les plus pauvres à la domestication des arbres agroforestiers au Cameroun.

49. Land tenure and management in the districts around Mt Elgon: An assessment presented to the Mt Elgon ecosystem conservation programme.

50. The production and marketing of leaf meal from fodder shrubs in Tanga, Tanzania: A pro-poor enterprise for improving livestock productivity.

51. Buyers Perspective on Environmental Services (ES) and Commoditization as an approach to liberate ES markets in the Philippines.

52. Towards Towards community-driven conservation in southwest China: Reconciling state and local perceptions.

53. Biofuels in China: An Analysis of the Opportunities and Challenges of Jatropha curcas in Southwest China.

54. Jatropha curcas biodiesel production in Kenya: Economics and potential value chain development for smallholder farmers

55. Livelihoods and Forest Resources in Aceh and Nias for a Sustainable Forest Resource Management and Economic Progress.

56. Agroforestry on the interface of Orangutan Conservation and Sustainable Livelihoods in Batang Toru, North Sumatra.

57. Assessing Hydrological Situation of Kapuas Hulu Basin, Kapuas Hulu Regency, West Kalimantan.

58. Assessing the Hydrological Situation of Talau Watershed, Belu Regency, East Nusa Tenggara.

59. Kajian Kondisi Hidrologis DAS Talau, Kabupaten Belu, Nusa Tenggara Timur.

60. Kajian Kondisi Hidrologis DAS Kapuas Hulu, Kabupaten Kapuas Hulu, Kalimantan Barat.

61. Lessons learned from community capacity building activities to support agroforest as sustainable economic alternatives in Batang Toru orang utan habitat conservation program (Martini, Endri et al.)

62. Mainstreaming Climate Change in the Philippines.

63. A Conjoint Analysis of Farmer Preferences for Community Forestry Contracts in the Sumber Jaya Watershed, Indonesia.

64. The Highlands: A shower water tower in a changing climate and changing Asia.

65. Eco-Certification: Can It Deliver Conservation and Development in the Tropics?

66. Designing ecological and biodiversity sampling strategies. Towards mainstreaming climate change in grassland management.

67. Participatory Poverty and Livelihood Assessment Report, Kalahan, Nueva Vizcaya, the Philippines

68. An Assessment of the Potential for Carbon Finance in Rangelands

69. ECA Trade-offs Among Ecosystem Services in the Lake Victoria Basin.

70. Le business plan d'une petite entreprise rurale de production et de commercialisation des plants des arbres locaux. Cas de quatre pépinières rurales au Cameroun. 
71. Les unités de transformation des produits forestiers non ligneux alimentaires au Cameroun. Diagnostic technique et stratégie de développement Honoré Tabuna et Ingratia Kayitavu.

72. Les exportateurs camerounais de safou (Dacryodes edulis) sur le marché sous régional et international. Profil, fonctionnement et stratégies de développement.

73. Impact of the Southeast Asian Network for Agroforestry Education (SEANAFE) on agroforestry education capacity.

74. Setting landscape conservation targets and promoting them through compatible land use in the Philippines.

75. Review of methods for researching multistrata systems.

76. Study on economical viability of Jatropha curcas L. plantations in Northern Tanzania Assessing farmers' prospects via cost-benefit analysis

77. Cooperation in Agroforestry between Ministry of Forestry of Indonesia and International Center for Research in Agroforestry

78. "China's bioenergy future. an analysis through the Lens if Yunnan Province

79. Land tenure and agricultural productivity in Africa: A comparative analysis of the economics literature and recent policy strategies and reforms

80. Boundary organizations, objects and agents: linking knowledge with action in agroforestry watersheds

81. Reducing emissions from deforestation and forest degradation (REDD) in Indonesia: options and challenges for fair and efficient payment distribution mechanisms

82. Mainstreaming Climate Change into Agricultural Education: Challenges and Perspectives.

83. Challenging Conventional mindsets and disconnects in Conservation: the emerging role of eco-agriculture in Kenya's Landscape Mosaics.

84. Lesson learned RATA garut dan bengkunat: suatu upaya membedah kebijakan pelepasan kawasan hutan dan redistribusi tanah bekas kawasan hutan.

85. The emergence of forest land redistribution in Indonesia.

86. Commercial opportunities for fruit in Malawi.

87. Status of fruit production processing and marketing in Malawi.

88. Fraud in tree science.

89. Trees on farm: analysis of global extent and geographical patterns of agroforestry

90. The springs of Nyando: water, social organization and livelihoods in Western Kenya.

91. Building cpacity toward region-wide curriculum and teaching materials development in agroforestry education in Southeast Asia.

92. Overview of Biomass Energy Technology in Rural Yunnan.

93. A Pro-Growth Pathway for Reducing Net GHG Emissions in China

94. Analysis of local livelihoods from past to present in the central Kalimantan Ex-Mega Rice Project area

95. Constraints and options to enhancing production of high quality feeds in dairy production in Kenya, Uganda and Rwanda 
96. Agroforestry education in the Philippines: status report from the Southeast Asian Network for Agroforestry Education (SEANAFE)

2010

97. Economic viability of Jatropha curcas L. plantations in Northern Tanzania- assessing farmers' prospects via cost-benefit analysis.

98. Hot spot of emission and confusion: land tenure insecurity, contested policies and competing claims in the central Kalimantan Ex-Mega Rice Project area

99. Agroforestry competences and human resources needs in the Philippines

100. CES/COS/CIS paradigms for compensation and rewards to enhance environmental Services

101. Case study approach to region-wide curriculum and teaching materials development in agroforestry education in Southeast Asia

102. Stewardship agreement to reduce emissions from deforestation and degradation (REDD): Lubuk Beringin's Hutan Desa as the first village forest in Indonesia 
The World Agroforestry Centre is an autonomous, non-profit research organization whose vision is a rural transformation in the developing world where smallholder households strategically increase their use of trees in agricultural landscapes to improve their food security, nutrition, income, health, shelter, energy resources and environmental sustainability. The Centre generates science-base knowledge about the diverse role that trees play in agricultural landscapes, and uses its research to advance policies and practices that benefit the poor and the environment.

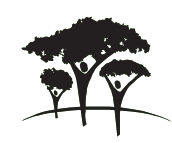

United Nations Avenue, Gigiri - PO Box 30677 - 00100 Nairobi, Kenya Tel: +254 207224000 or via USA +1 6508336645 Fax: +254207224001 or via USA +16508336646 Southeast Asia Regional Programme - Sindang Barang, Bogor 16680 PO Box161 Bogor 16001, Indonesia Tel: +62 251625415 - Fax: +62 251625416 www.worldagroforestry.org 